\title{
Design and Implementation of Model Predictive Control Strategies for Improved Power Plant Cycling
}

Xin $\mathrm{He}$

West Virginia University, xnhe@mix.wvu.edu

Follow this and additional works at: https://researchrepository.wvu.edu/etd

Part of the Process Control and Systems Commons

\section{Recommended Citation}

$\mathrm{He}$, Xin, "Design and Implementation of Model Predictive Control Strategies for Improved Power Plant Cycling" (2019). Graduate Theses, Dissertations, and Problem Reports. 3937.

https://researchrepository.wvu.edu/etd/3937

This Dissertation is protected by copyright and/or related rights. It has been brought to you by the The Research Repository @ WVU with permission from the rights-holder(s). You are free to use this Dissertation in any way that is permitted by the copyright and related rights legislation that applies to your use. For other uses you must obtain permission from the rights-holder(s) directly, unless additional rights are indicated by a Creative Commons license in the record and/ or on the work itself. This Dissertation has been accepted for inclusion in WVU Graduate Theses, Dissertations, and Problem Reports collection by an authorized administrator of The Research Repository @ WVU.

For more information, please contact researchrepository@mail.wvu.edu. 


\title{
Design and Implementation of Model Predictive Control Strategies for Improved Power Plant Cycling
}

\author{
Xin $\mathrm{He}$ \\ Dissertation submitted to the \\ Benjamin M. Statler College of Engineering and Mineral Resources \\ at West Virginia University
}

In partial fulfillment of the requirements for the degree of

\author{
Doctor of Philosophy \\ in \\ Chemical Engineering \\ Fernando V. Lima, PhD, Chair \\ Richard Turton, PhD \\ Debangsu Bhattacharyya, PhD \\ Stephen Zitney, PhD \\ Parviz Famouri, PhD \\ Rishi Amrit, PhD \\ Department of Chemical and Biomedical Engineering \\ Morgantown, West Virginia \\ 2019
}

Keywords: model predictive control, sequential quadratic programming, supercritical pulverized coal-fired power plant, power plant cycling 


\title{
Abstract
}

\section{Design and Implementation of Model Predictive Control Strategies for Improved Power Plant Cycling}

\author{
Xin $\mathrm{He}$
}

With the increasing focus on renewable energy sources, traditional power plants such as coal-fired power plants will have to cycle their load to accommodate the penetration of renewables into the power grid. Significant overshooting and oscillatory performance may occur during cycling operations if classical feedback control strategies are employed for plantwide control. To minimize the impact when power plants are operating away from their designed conditions, model-based optimal control strategies would need to be developed for improved power plant performance during cycling. In this thesis, model predictive control (MPC) strategies are designed and implemented for improved power plant cycling. The MPC strategies addressed correspond to a dynamic matrix control (DMC)-based linear MPC, a classical sequential quadratic programming (SQP)-based nonlinear MPC, a direct transcription-based nonlinear MPC and a proposed modified SQP-based nonlinear MPC. The proposed modified SQP algorithm is based on the backtracking line search framework, which employs a group of relaxed step acceptance conditions for faster convergence. The numerical results for motivating examples, which are selected from literature problem sets, served as proof of concept to verify that the proposed modified SQP has the potential for implementation on high-dimensional systems.

To illustrate the tracking performance and computational efficiency of the developed MPC strategies, three processes of different dimensionalities are addressed. The first process is an integrated gasification combined cycling power plant with a water-gas shift membrane reactor (IGCC-MR), which is represented by a first-principles and simplified systems-level nonlinear model in MATLAB. For this application, a setpoint tracking scenario simulating a step increase in power demand, a disturbance rejection scenario simulating a coal feed quality change, and a trajectory tracking scenario simulating a 
wind power penetration into the power grid are presented. The second application is an aqueous monoethanolamine (MEA)-based carbon capture process as part of a supercritical pulverized coal-fired (SCPC) power plant, whose model is built in Aspen Plus Dynamics. For this system, disturbance rejection scenarios considering a ramp decrease in the flue gas flow rate as well as wind power penetration, and a scenario considering a combination of disturbance rejection and setpoint tracking are addressed. The third process is the entire SCPC power plant with MEA-based carbon capture (SCPC-MEA), which simulation is also built in Aspen Plus Dynamics. Trajectory tracking and disturbance rejection scenarios associated with wind and solar power penetrations are presented for this process. The MPC implementations on the three processes for the different scenarios addressed are successful. The closed-loop results show that the proposed modified SQP-based nonlinear MPC enhances the tracking performance by up to $96 \%$ when compared to the DMC-based linear MPC in terms of integral squared error results. The novel approach also improves the MPC computational efficiency by $20 \%$ when compared to classical SQP-based and direct transcription-based nonlinear MPCs. 


\section{Acknowledgments}

I would like to thank many people who impacted and influenced my stay as a Ph.D. student at West Virginia University.

I would like to express my deepest gratitude to Dr. Fernando V. Lima, who served as my advisor and a great mentor during my stay in WVU. His knowledge and expertise helped me immensely with understanding model predictive control approaches and process control applications. His guidance, patience and focus set up a great role model for me. I would also like to thank my thesis committee members: Dr. Richard Turton, Dr. Debangsu Bhattacharyya, Dr. Stephen Zitney, Dr. Parviz Famouri and Dr. Rishi Amrit, for their insightful comments, support and guidance in this research work.

I would like to thank U.S.-China Clean Energy Research Center and U.S. Department of Energy for their funding support throughout my Ph.D. research work. I would like to acknowledge Drs. Lima, Turton and Bhattacharyya once again and also Qiang, Yifan, Pushpitha for the useful discussion in the project meetings and insightful comments. I would also like to express my appreciation for the research collaborators in Tsinghua University, especially Dr. Li, Dr. Liu and Jin.

I sincerely thank all the CODES research group members, Shuyun, Rebecca, Vitor, Dr. Gaurav, Dr. Juan, Jacob, for all their company in research and friendship through the years. I would also like to thank Dr. David, Dr. Bruno, Gilson, Vitor F., Brent, San, Yacine, Selorme and many others for building a friendly and interesting working environment. Thanks also to my friends Yifan, Qiang, He, Xuan, Lei, Yuan, Qiao, Xiao, Xiaogian, Xue, Xiaofei, Yu and many others for making my life at Morgantown comfortable and fun.

Finally and most importantly, my family for supporting me with love all these years. My mother, Xiaoyi He, who always ready for supporting me and helped me with important details in my life. My father, Dong He, who encouraged me and believed in me for my dreams. My gratitude to them is indescribable. 


\section{Table of Contents}

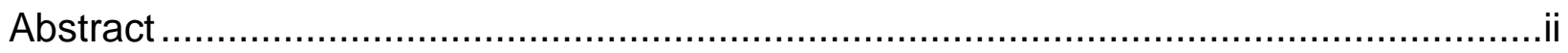

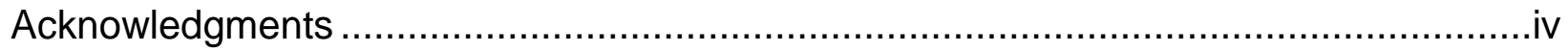

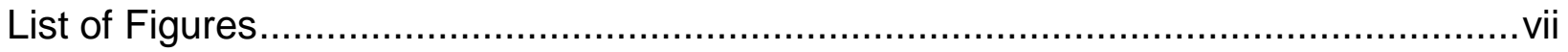

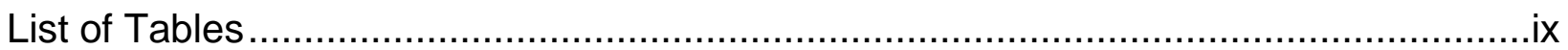

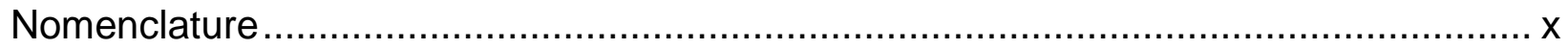

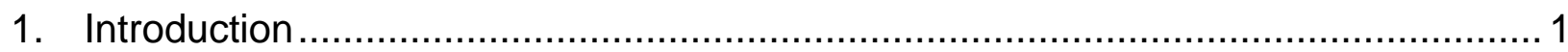

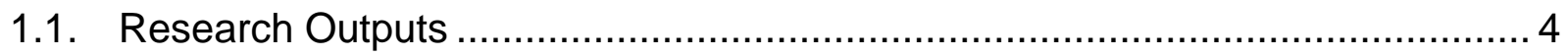

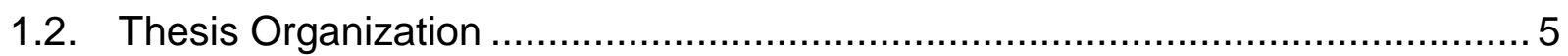

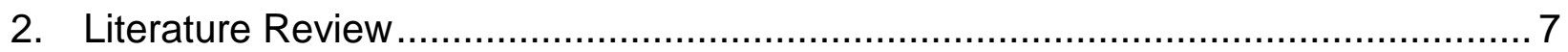

2.1. MPC Role in Hierarchical Planning and Operations ....................................... 7

2.2. Algorithms for Solving NLP for MPC Applications ........................................ 9

2.3. MPC Implementation for Coal-fired Power Plants ........................................ 10

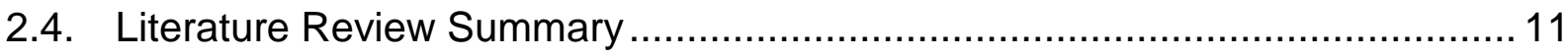

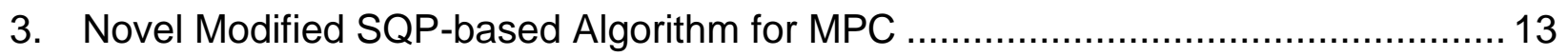

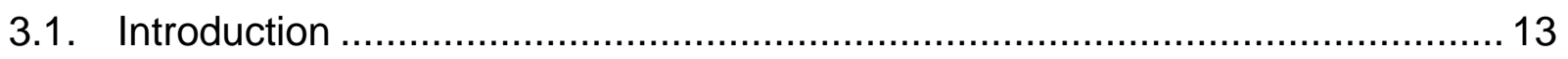

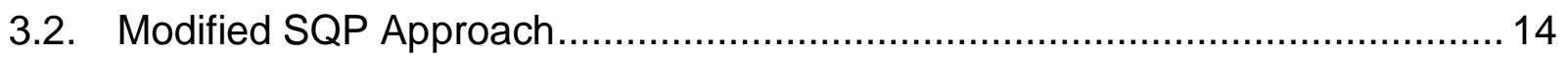

3.3. Algorithm Convergence Analysis .......................................................... 17

3.4. Numerical Results for Motivating Examples ................................................ 23

4. MPC Approaches Developed and Implementation Framework .............................26

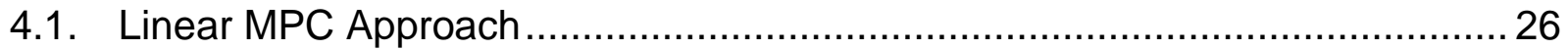

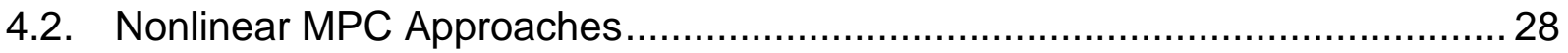

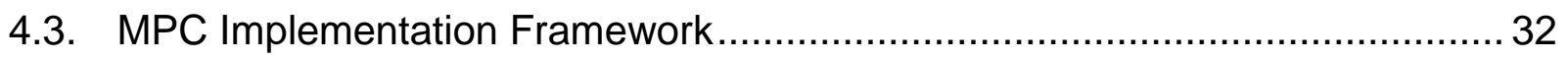

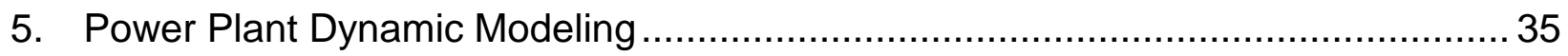

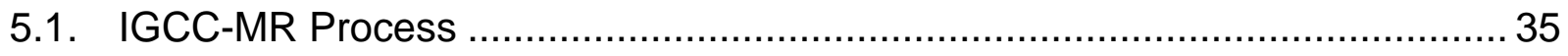


5.2. MEA-based Carbon Capture Process ............................................................ 40

5.2.1. Conventional Carbon Capture Process....................................................... 40

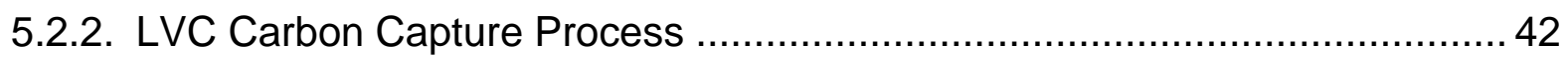

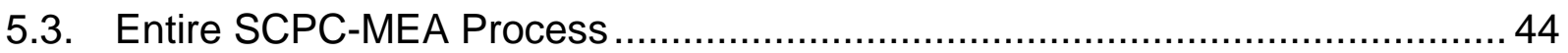

6. MPC Applications to Power Plant Cycling ….................................................. 48

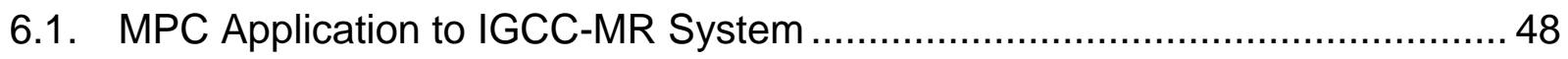

6.2. MPC Application to MEA-based Carbon Capture System...............................56

6.3. MPC Application to Entire SCPC-MEA System........................................... 70

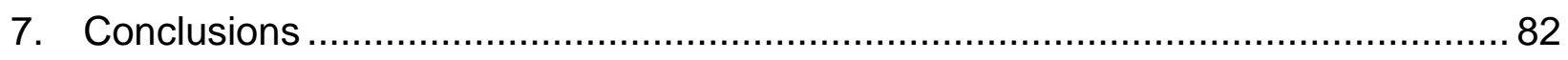

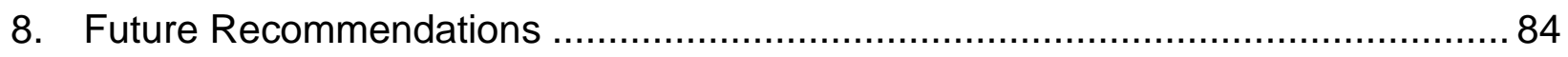

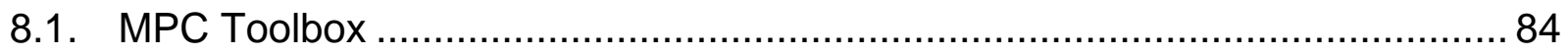

8.2. Incorporation of Optimal Profile from DRTO................................................ 84

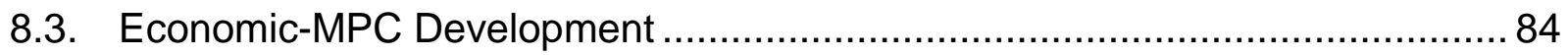

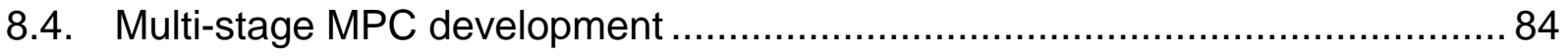

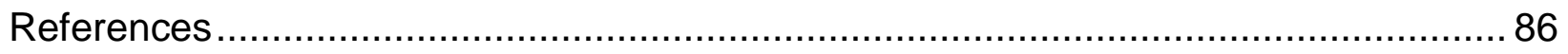




\section{List of Figures}

Figure 1.1. Load cycling profile for a dual-fired plant due to wind power generation (adapted from Bentek, 2010). 2

Figure 1.2. General concept of MPC (adapted from Seborg et al., 2010) ..................... 3

Figure 2.1. Illustration of the hierarchical planning and operations (adapted from Marlin, 1995) . .8

Figure 4.1. Schematic representation of linear step response model.........................2 27

Figure 4.2. Illustration of a single-input-single-output step response .......................... 28

Figure 4.3. Comparison between nonlinear prediction model and Aspen process model 33

Figure 4.4. MPC implementation framework with Aspen Plus Dynamics ..................... 34

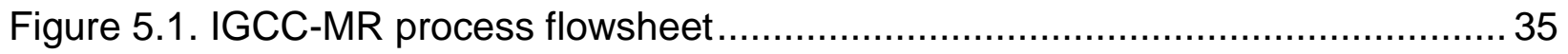

Figure 5.2. WGS-MR counter-current representation ........................................... 37

Figure 5.3. Simplified flowsheet of the conventional $\mathrm{CO}_{2}$ capture system (adapted from Zhang et al., 2016)

Figure 5.4 Simplified flowsheet of $\mathrm{LVC} \mathrm{CO}_{2}$ capture system (adapted from Karimi et al., 2012) 43

Figure 5.5. Simplified flowsheet of the SCPC-MEA process .................................... 45

Figure 6.1. IGCC-MR Case 1: closed-loop responses for power generation (CV) ........50

Figure 6.2. IGCC-MR Case 1: closed-loop responses for slurry flow (MV) …...............50

Figure 6.3. IGCC-MR Case 1: closed-loop responses for GT air feed flow (MV) .......... 51

Figure 6.4. IGCC-MR Case 2: closed-loop responses for power generation (CV) .........52

Figure 6.5. IGCC-MR Case 2: closed-loop responses for slurry flow (MV) ................... 52

Figure 6.6. IGCC-MR Case 2: closed-loop responses for steam injection flow (MV) .... 53

Figure 6.7. IGCC-MR Case 3: IGCC-MR power generation cycling trajectory ............... 54

Figure 6.8. IGCC-MR Case 3: closed-loop responses for power generation (CV) .........55

Figure 6.9. Carbon capture system Case 1: closed-loop responses for carbon capture rate (output)

Figure 6.10. Carbon capture system Case 1: closed-loop results for lean solvent flow rate (input) 59 
Figure 6.11. Carbon capture system Case 1: closed-loop results for reboiler heat steam flow rate (input) 60

Figure 6.12. Carbon capture system Case 2: closed-loop responses for carbon capture rate (output). 62

Figure 6.13. Carbon capture system Case 2: closed-loop results for lean solvent flow rate (input) 63

Figure 6.14. Carbon capture system Case 2: closed-loop results for reboiler heat steam flow rate (input) 64

Figure 6.15. Carbon capture system Case 3: SCPC-MEA power generation cycling trajectory 66

Figure 6.16. Carbon capture system Case 3: closed-loop responses for carbon capture rate $(\mathrm{CV})$ 67

Figure 6.17. Carbon capture system Case 4: closed-loop responses for carbon capture rate $(\mathrm{CV})$. 69

Figure 6.18. SCPC-MEA Case 1: closed-loop response for power generation (CV) ..... 73

Figure 6.19. SCPC-MEA Case 2: simulated solar power generation profile.................. 75

Figure 6.20. SCPC-MEA Case 2: SCPC-MEA power generation cycling trajectory ...... 76 Figure 6.21. SCPC-MEA Case 2: Closed-loop responses for power generation (CV) .. 77 Figure 6.22. SCPC-MEA Case 3: Closed-loop responses for power generation............ 79

Figure 6.23. SCPC-MEA Case 3: Closed-loop responses for carbon capture rate ....... 80 Figure 6.24. Computational times for nonlinear MPCs employing different solvers .......81 81 


\section{List of Tables}

Table 3.1. Numbers of different SQP algorithm iterations for HS problems ................. 23

Table 5.1. Initial mass fractions in the gasifier............................................................ 39

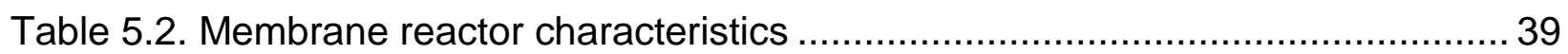

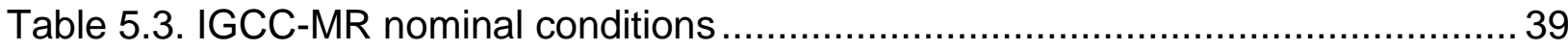

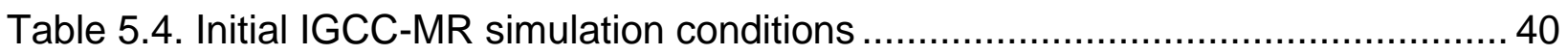

Table 5.5. Equipment duties and equivalent work for LVC (bold represents the optimal)

Table 5.6. SCPC-MEA power plant flue gas molar composition ................................ 46

Table 5.7. SCPC-MEA operating conditions at the nominal point ................................46

Table 5.8. SCPC-MEA carbon capture power losses at the nominal point.................... 46

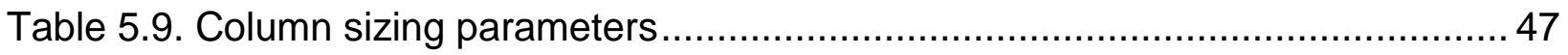

Table 5.10. Column packing parameters (IMTP 40) …........................................... 47

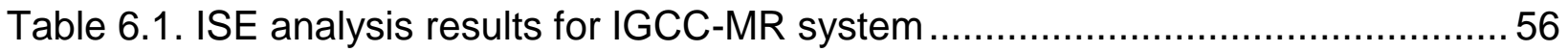

Table 6.2. ISE analysis results for the conventional configuration .............................6 60

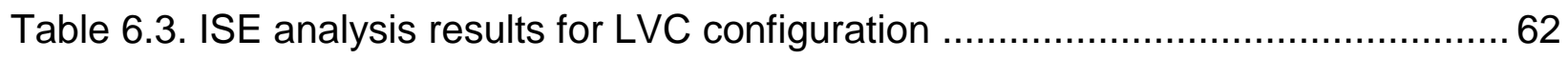

Table 6.4. Total equivalent power consumption results of two configurations ................6 65

Table 6.5. ISE analysis results for the SCPC-MEA control implementations .................69 69

Table 6.6. Nominal values of CVs and MVs for SCPC-MEA system.......................... 71

Table 6.7. SCPC-MEA Case 1: ISE analysis results for different MPC solvers.............. 72

Table 6.8. SCPC-MEA Case 1: computational time results for different MPC solvers .. 74

Table 6.9. SCPC-MEA Case 2: ISE analysis results for different MPC solvers.............. 78

Table 6.10. SCPC-MEA Case 2: computational time results for different MPC solvers 78 Table 6.11. SCPC-MEA Case 3: ISE analysis results for MPCs employing different solvers

Table 6.12. SCPC-MEA Case 3: Computational time results for MPCs employing different solvers 


\section{Nomenclature}

\section{Notation}

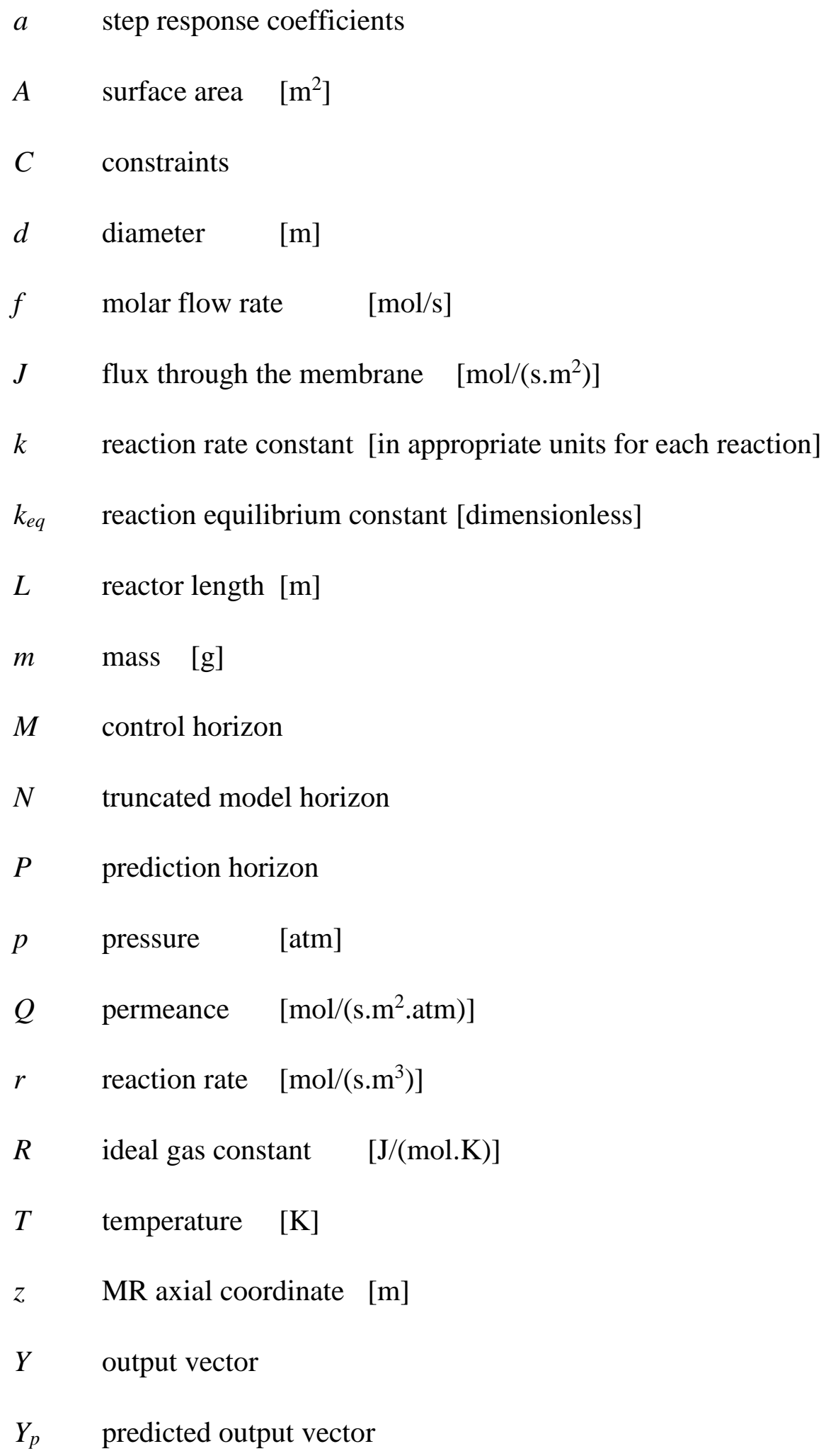


$\Delta u \quad$ control vector

\section{Acronyms}

ASU air separating unit

CPP clean power plan

DMC dynamic matrix control

DRTO dynamic real-time optimization

EPA environmental protection agency

IGCC integrated gasification combined cycle

LVC lean vapor compression

MEA monoethanolamine

MIMO multi-input-multi-output

MPC model predictive control

MR membrane reactor

NLP nonlinear programming problem

RTO real-time optimization

SCPC supercritical pulverized coal-fired

SQP sequential quadratic programming

\section{Subscripts}

c cooled

cat catalyst

comp compressor

eq equilibrium

gas gasifier 


$\begin{array}{ll}\text { inj } & \text { injection } \\ \mathrm{mt} & \text { membrane total } \\ \mathrm{lb} & \text { lower bound } \\ \mathrm{p} & \text { permeate } \\ \mathrm{Q} & \text { error weighting matrix } \\ \mathrm{r} & \text { retentate } \\ \mathrm{R} & \text { control weighting matrix } \\ \mathrm{reb} & \text { reboiler } \\ \mathrm{s} & \text { shell } \\ \mathrm{sl} & \text { slurry } \\ \mathrm{syn} & \text { syngas } \\ \mathrm{t} & \text { tube } \\ \mathrm{ub} & \text { upper bound } \\ \mathrm{wgs} & \text { water-gas shift reactor }\end{array}$




\section{Introduction}

In recent years, worldwide attention on greenhouse gas emissions and renewable energy has been heightened. In August 2015, the United States Environmental Protection Agency (EPA) finalized the Clean Power Plan (CPP) Act (EPA, 2015). The target of this plan is to cut carbon emissions from power plants by $32 \%$ of their 2005 levels within fifteen years. Driven by the CPP as well as the diversification of energy sources for incoming energy demands, renewable sources will become imperative for the energy supply in the future. However, according to a reference case calculation for power generation from years 2000 to 2040 , coal-fired power plants would still account for more than $30 \%$ in the future (EIA, 2017). With coal still likely to be one of the primary energy sources for electricity production in the foreseeable future, clean coal-fired power plants with $\mathrm{CO}_{2}$ capture technologies have attracted significant research attention.

With the increasing interest and focus on renewable energy sources, fossil-fueled power plants, which were designed to operate at the base-load point will need to cycle their load to accommodate the penetration of renewable sources into the grid. Cycling includes ramping the power generation rate up/down for load-following, shut down or start up according to load demand, and operation under variable and minimum load conditions. Figure 1.1 shows the load distribution profile from the dual-fired Cherokee Power Station (using both gas and coal) while cycling to follow the wind generation on July 2, 2008 (Bentek, 2010). It can be observed in this figure that load cycling in the coal power generation occurs to accommodate the wind generation profile (see circled portions in Figure 1.1). Operating and controlling such power plant during cycling is a challenging task. If classical feedback control strategies are employed for plantwide control, significant overshooting and oscillatory performance may occur during cycling operations. To minimize the impact when power plants are operating away from their designed conditions, model-based optimal control strategies would need to be developed for improved power plant performance during cycling. 


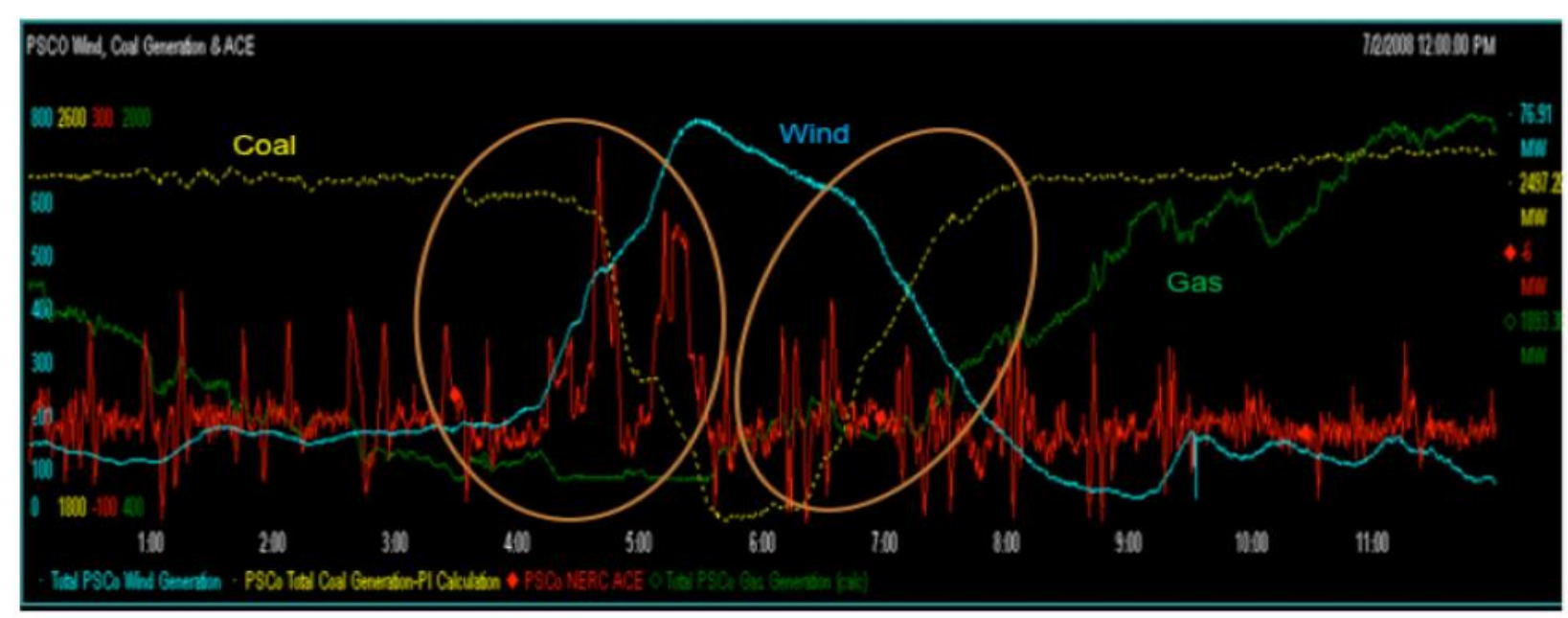

4:00 AM

8:00 AM

Figure 1.1. Load cycling profile for a dual-fired plant due to wind power generation (adapted from Bentek, 2010)

Model predictive control (MPC) is a widely used method in the process industries and it has also been a topic of research for power generation applications. Compared to chemical process applications, power generation applications need to consider not only units for reactions and separations but also larger scale heat exchanging and recovering networks coupled with turbines for electricity generation. Moreover, power generation unit (e.g., gas turbines) response times are typically much faster than traditional chemical processes (on the order of seconds instead of minutes).

The general concept of MPC is shown in Figure 1.2. At time step $k$, an optimization problem is solved. An objective function, based on output prediction errors w.r.t. the setpoint over a prediction horizon of $P$ time steps, is minimized by optimizing the manipulated variable moves over a control horizon of $M(P>M)$. Although $M$ moves are optimized, only the first control move is applied. After the control move is applied, the measured closed-loop output at the next time step is obtained and compared to the model predicted value. Using this new measurement and the new predicted error, a new optimization problem is then solved and the aforementioned procedure is repeated. Depending on the nature of the model and the solved optimization problem, MPC can be characterized either as linear MPC or nonlinear MPC. The nonlinearity and complexity of power plant systems make nonlinear MPC the preferred technique, but 
typically nonlinear MPC is more computationally expensive than linear MPC due to the need of solving a nonlinear optimization problem online.

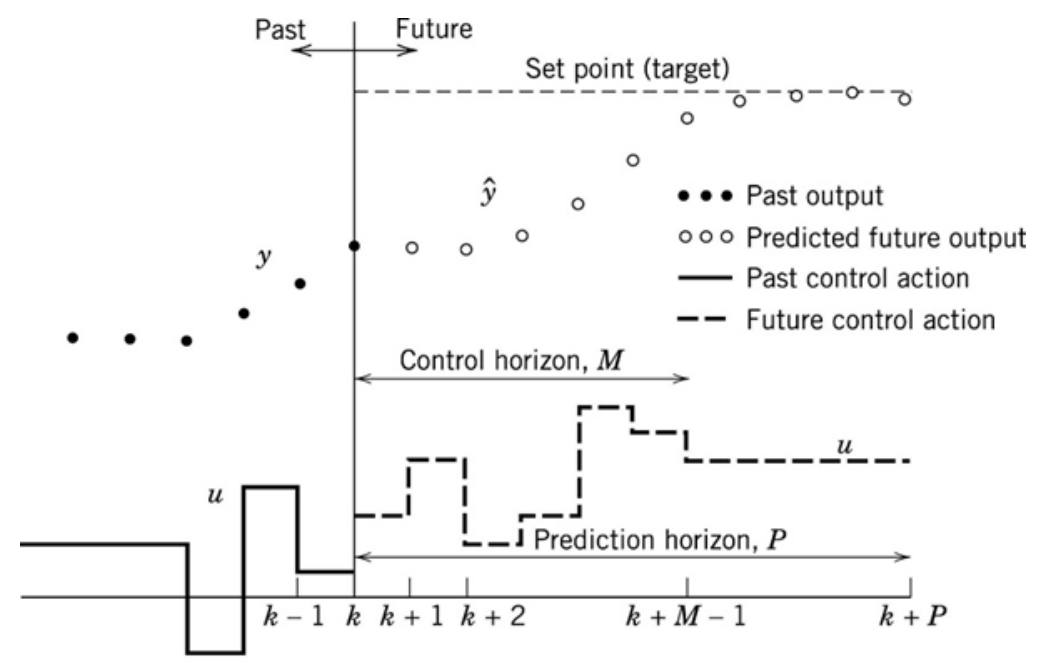

Figure 1.2. General concept of MPC (adapted from Seborg et al., 2010)

The objective in this research is to design and implement advanced control strategies for improved power plant cycling. Based on available optimal cycling trajectories, model predictive control (MPC) algorithms are developed and implemented for achieving the optimal profiles under load-following operations. The following specific aims are addressed in this research:

1) Develop MPC algorithms for subsystems of power plant cycling. Both linear and nonlinear MPC algorithms are developed for fossil fuel power plants trajectory tracking scenarios. The developed algorithms are implemented for a simplified model of an integrated gasification combined cycle (IGCC) system and a selected subsystem (carbon capture subsystem) of the supercritical pulverized coal-fired (SCPC) plant with carbon capture.

2) Design of MPC controllers for high-dimensional systems. Methods for improving the MPC computational efficiency of solving nonlinear programming problems are investigated, with focus on a sequential quadratic programming (SQP)-based method for MPC.

3) Implement MPC strategies for supercritical pulverized coal-fired power plants under cycling conditions. Plant-wide MPC controllers are developed and 
implemented according to optimal cycling strategies. The developed algorithms are also validated employing available data from power plant literature.

\subsection{Research Outputs}

The specific contributions of this dissertation are: i) develop linear and nonlinear MPC strategies with trajectory tracking-based objective functions; ii) develop a novel nonlinear programming algorithm to improve the computational efficiency of nonlinear MPC; and iii) implement the developed MPCs to high-dimensional power generation applications to tackle cycling scenarios.

The contributions of this thesis have resulted in the following products:

\section{Journal Publications}

1. Xin He and Fernando V. Lima. A modified SQP-based model predictive control algorithm: application to supercritical coal-fired power plant cycling. In preparation for publication.

2. Xin He and Fernando V. Lima. Development and implementation of advanced control strategies for power plant cycling with carbon capture. Computers \& Chemical Engineering, 121:497-509, 2019.

3. Xin He, Yifan Wang, Debangsu Bhattacharyya, Fernando V. Lima and Richard Turton. Dynamic modeling and advanced control of post-combustion $\mathrm{CO}_{2}$ capture plants. Chemical Engineering Research and Design, 131:430-439, 2018.

\section{Book Chapter}

1. Fernando V. Lima, Xin He, Rishi Amrit and Prodromos Daoutidis. Advanced control strategies for IGCC plants with membrane reactors for $\mathrm{CO}_{2}$ capture. In Process systems and materials for $\mathrm{CO}_{2}$ capture: modelling, design, control and integration, A.I. Papadopoulos and P. Seferlis (eds.), Wiley, 2017.

\section{Conference Proceedings}

1. He Jin, Xin He, Pei Liu, Fernando V. Lima, Zheng Li, Debangsu Bhattacharyya and Richard Turton. Dynamic performance of post-combustion $\mathrm{CO}_{2}$ capture plant using 
MEA. In Proceedings of the 2017 International Conference on Coal Science \& Technology and 2017 Australia-China Symposium on Energy, September 2017.

\section{$\underline{\text { Conference Presentations }}$}

1. Xin He and Fernando V. Lima. A modified SQP method for MPC of a supercritical pulverized coal-fired power plant during cycling. AIChE Annual Meeting, Pittsburgh, PA, November 2018.

2. Xin He and Fernando V. Lima. Design and implementation of model predictive control strategies for supercritical pulverized coal-fired power plant cycling with carbon capture. AIChE Annual Meeting, Minneapolis, MN, November 2017.

3. Xin He and Fernando V. Lima. Design and implementation of model predictive control strategies for IGCC power plant cycling with carbon capture. AIChE Annual Meeting, San Francisco, CA, November 2016.

4. Jacob Douglas, Xin He, Fernando V. Lima. Modeling, simulation and control of a supercritical coal-fired power plant for smart grid applications. AIChE Annual Meeting, San Francisco, CA, November 2016.

5. Xin He, Rishi Amrit, Richard Turton and Fernando V. Lima. Model predictive control of integrated gasification combined cycle power plants with membrane reactors for carbon capture. AIChE Annual Meeting, Salt Lake City, Utah, November 2015.

\subsection{Thesis Organization}

The outline for the remaining chapters of this thesis includes a generic literature review, which is presented in Chapter 2. Then, the novel modified SQP algorithm for the proposed MPC is described and motivated in Chapter 3. All the MPC strategies developed, which correspond to a dynamic matrix control (DMC)-based linear MPC, a classical SQP-based nonlinear MPC, a direct transcription-based nonlinear MPC and the proposed modified SQP-based nonlinear MPC, are summarized in Chapter 4, along with the MPC implementation framework. To illustrate the tracking performance and computational efficiency of the developed MPC strategies, three processes of different dimensionalities are addressed, which are discussed in Chapter 5: i) an integrated gasification combined cycling power plant with a water-gas shift membrane reactor for carbon capture; ii) an aqueous monoethanolamine (MEA)-based carbon capture 
process as part of an SCPC power plant; and iii) the entire SCPC plant with MEA-based carbon capture. The applications of the developed MPC strategies to power plant cycling case studies are presented in Chapter 6. Finally, the overall conclusions of the thesis are outlined in Chapter 7 and recommendations for future work are addressed in Chapter 8. 


\section{Literature Review}

This chapter presents a big picture overview of the reviewed literature to perform this research, following the main topics: i) MPC role in hierarchical planning and operations; ii) algorithms for solving nonlinear programming problems (NLP) for MPC applications; and iii) MPC implementation for coal-fired power plants.

\subsection{MPC Role in Hierarchical Planning and Operations}

Hierarchical planning and operation strategies are widely used in the operation of complex industrial processes that involve a large number of decisions. A typical hierarchical structure is shown in Figure 2.1. In this structure, the global economic optimization (or scheduling) layer focuses on economic forecasting, providing production goals, how to arrange the manufacturing sequence and when to start a certain process. The time scale of the global economic optimization layer is typically on the order of days. Business decisions from this layer are communicated to the local economic optimization layer, in which a real-time optimization (RTO) approach is considered. The RTO optimizes the profit of the plant and seeks additional profit based on real-time data reconciliation and parameter estimation. The reconciled plant data are used to compute a new set of model parameters so that the model represents the plant as accurately as possible at the current operating point. Then the plant setpoints are progressively calculated using the new model parameters to optimize an economic cost function while satisfying the process constraints.

The calculated setpoints are forwarded to the dynamic constraint control layer. Up to the 1970s, the dominating industrial practice in this layer was to use PID controllers. PID controllers are able to keep outputs at the desired setpoints and reject short-term disturbances. However, it is difficult to tune and decouple PID controllers for multi-inputmulti-output (MIMO) systems. Additionally, typical feedback control approaches are unconstrained. The current dominant practice in the process industry is to use MPC (Morari and Lee, 1999; Qin and Badgwell, 2003) as an advanced process controller. MPC can be used as a stand-alone centralized method or as a supervisory control method on top of the PIDs. It uses a dynamic model of the process to predict the future dynamic behavior over a time horizon (typically on order of minutes). Therefore, it is 
possible to compute the optimal control actions to minimize transition time and deviations of the outputs from the target setpoints. The MPC used for this purpose is defined as setpoint tracking MPC in this dissertation. The main advantages of the setpoint tracking MPC are that it can naturally handle MIMO system using model predictions and it is able to impose constraints on the associated optimization problem.

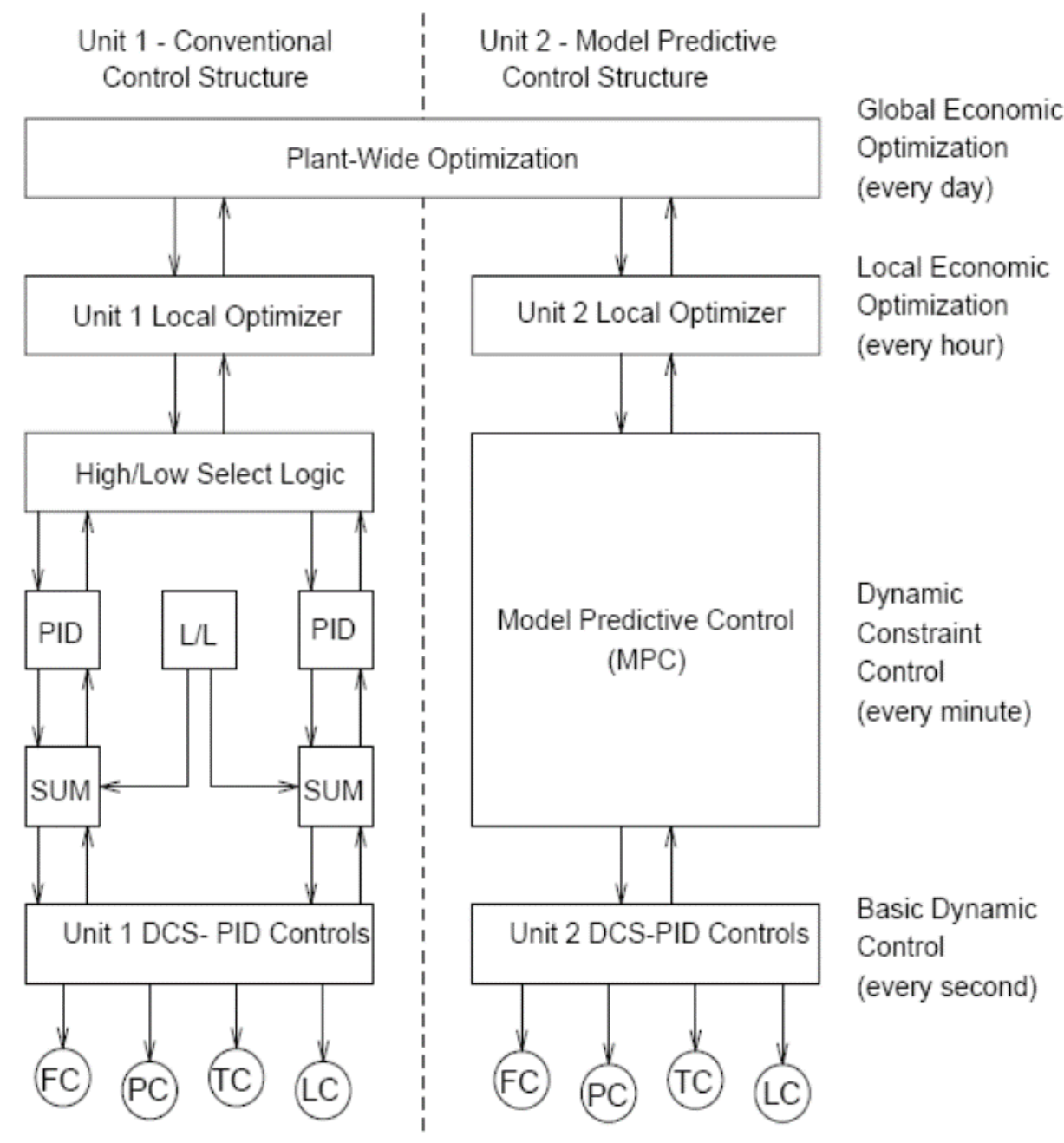

Figure 2.1. Illustration of the hierarchical planning and operations (adapted from Marlin, 1995)

Depending on the different modeling and solution strategies employed, there are many variations of MPCs. For instance, engineers at Shell Oil developed the so-called dynamic matrix control (DMC) (Cutler and Perry, 1983) that uses linear step response models and a quadratic objective function. DMC solves the optimization problem without constraints as the solution of a least-squares problem. Later on, Shell engineers 
developed QDMC (Garcia and Morshedi, 1986) by posing the DMC problem as a quadratic programming $(\mathrm{QP})$ problem in which constraints appear explicitly. More detailed review can be found in reference (Qin and Badgwell, 2003). Generally, linear MPC uses a linear data-driven model to represent the plant. Thus it has the advantage of solving a linear optimization problem, which can be done fast enough at each time step in order to be implemented in the receding horizon framework addressed in Chapter 1. On the other hand, linear MPC suffers from drawbacks such as plant-model mismatch, as the linear model is obtained around a nominal operating point.

To address the drawback of the linearized prediction model, nonlinear MPC strategies were developed to use nonlinear models for characterizing the process. Nonlinear MPC strategies have been applied widely and generated many economic benefits, especially for processes with frequent transitions (Bartusiak, 2007). However, it brings important computational challenges, due to the need for solving nonlinear programming problems online. Data-driven dynamic models can be used to manage computational challenges since they are posed in a relatively small state space, while first-principles dynamic models usually involve differential algebraic equations (DAE) with a higher level of complexity (Findeisen and Allgower, 2004). It has been shown that the computational complexity associated with online solving the DAE-constraint optimization problems may deteriorate the performance or destroy the stability of nonlinear MPC (Santos et al., 2001).

\subsection{Algorithms for Solving NLP for MPC Applications}

There are many algorithms for solving the NLP posed in MPC applications, including interior-point (Wachter et al., 2002; Waltz et al., 2006; Wachter and Biegler, 2006; Curtis et al., 2010), augmented Lagrangian (Conn et al., 1991; Birgin et al., 2005; Curtis et al., 2015) and sequential quadratic programming (SQP) methods (Boggs et al., 1995; Fletcher and Leyffer, 2002; Gould and Robinson, 2012). Each method has a variety of detailed algorithms and serves a distinct role in NLP optimizations. The interior-point method has the advantage that the main computational cost of each iteration is only a single indefinite symmetric matrix factorization. However, it is challenging for interiorpoint methods to get a warm start (i.e., start from a good initial guess). For the 
augmented Lagrangian method, a warm start is easier to be obtained and thus may be applied to large-scale problems. However, the augmented Lagrangian method has difficulties in identifying the inequality constraints satisfied as equality constraints in an optimal active set, i.e., a local solution (Gould et al., 2015). The SQP method is an iterative method based on the active set strategy that solves a sequence of optimization subproblems, which can take advantage of both warm start and optimal active-set identification.

Specifically, the SQP method contains a variety of algorithms that are distinguished by details. For example, algorithm variations include whether the global convergence is attained by a merit function, a filter or a step classification scheme. The merit function method was first introduced as a penalty that combines constraint violations with penalty parameters and the objective (Han, 1977). The penalty parameters were carefully chosen as a monotonically increasing sequence. However, the monotone strategy can lead to the Maratos effect problem (Maratos, 1978), which rejects steps that are making good progress towards the solution and dramatically slows down the SQP method. To address this problem, a filter technique was proposed and used in a trust-region SQP method (Fletcher and Leyffer, 2002). Extensions of this SQP method based on filter techniques can be found for line search methods (Wächter and Biegler, 2005), interior point approaches (Ulbrich et al., 2004) and a method without derivatives (Audet and Dennis, 2004). However, the filter mechanism has the disadvantage that a step contributing to the solution may be blocked by a filter entry, especially if there are several entries in the filter. Some other available SQP methods use neither a penalty function nor a filter technique, for example, the dynamic control of infeasibility (DCl) approach (Bielschowsky and Gomes, 2008), the trust funnel approach (Gould and Toint, 2010), the relaxed two mild condition method (Liu and Yuan, 2011), among others.

\subsection{MPC Implementation for Coal-fired Power Plants}

Several MPC applications for IGCC and SCPC plants are available in the literature. A generalized predictive control is developed and implemented on a coal-fired power plant boiler for superheater temperature control (Rossiter et al., 2002). Linear MPC was also implemented on coal mills for improving supercritical power plant dynamic responses 
(Mohamed et al., 2012) and load following capability (Mohamed et al., 2011). DMC was implemented in simulation of an ultra-supercritical coal-fired power unit for load, main steam pressure and main steam temperature control (Wang et al., 2014). An offset-free nonlinear MPC formulation with moving horizon estimator (MHE) as the state estimator was applied to a stand-alone air separating unit (ASU) that is part of IGCC plants (Huang et al., 2010). Nonlinear MPC has been implemented for heat recovery steam generator (HRSG) steam temperature control and plant efficiency improvement of combined cycle power plants that consist of a gas turbine system fed by natural gas, the HRSG and steam turbines (Aurora et al., 2005). Also for a combined cycle power plant with similar components, the optimization of the plant operation has been recast as an MPC problem that can be solved efficiently by mixed-integer linear programming (MILP) solvers (Ferrari-Trecate et al., 2004). Finally, the potential benefits of advanced process control applications to IGCC plants have been demonstrated through an MPC implementation (commercial ABB P\&C controller) in an industrial heavy residual oilbased IGCC plant in Italy, focusing on the acid gas removal, gasifier and solvent deasphalting subsections, in terms of increasing energy efficiency and reducing steam consumption (Abela et al., 2007). Nonlinear MPC was applied to a post-combustion carbon capture process, and the tradeoff between MPC fast tracking performance and robustness was discussed (Zhang et al., 2018). Furthermore, economic model predictive control (EMPC) was studied to enable IGCC plant dispatch capabilities (Omell and Chmielewski, 2013). The performance of EMPC was compared to a setpoint tracking MPC for a post-combustion carbon capture application (Decardi-Nelson et al., 2018).

\subsection{Literature Review Summary}

On the basis of the performed literature review, computational time is an important challenge for nonlinear MPC plantwide control applications. The development of an advanced algorithm for solving NLP online can improve the computational efficiency of nonlinear MPC, especially when applied to high-dimensional processes. Also, the implementation of nonlinear plant-wide MPC studies for coal-fired power plants, especially with carbon capture, under conditions that consider renewable penetration 
and power plant cycling are scarce. Thus, there is a gap with respect to MPC implementations on carbon capture processes and cycling power generation units. The implementation of the developed nonlinear MPCs for power plant cycling scenarios will fill this gap in order to enable the smooth penetration of renewables into the grid. 


\section{Novel Modified SQP-based Algorithm for MPC}

In this chapter, the proposed modified SQP algorithm is described, and the global convergence of the algorithm is proved. Also, motivating examples, which are selected from literature problem sets, are tackled to verify that the proposed modified SQP has the potential for better acceptance of long steps and faster convergence than classical SQP solvers.

\subsection{Introduction}

The SQP method, which is widely used for NLP solvers, is an iterative method based on the active set strategy that solves a sequence of optimization subproblems. Typically, to promote SQP global convergence, a merit function is introduced as a penalty that combines constraint violations with penalty parameters and the objective (Han, 1977). In this approach, the next iteration step is obtained by a backtracking line search approach with sufficient merit function decrease. If the penalty parameters in the merit function are too low, an infeasible point might be obtained. If the parameters are too large, the weight of the objective in the penalty function would decrease. In this case, steps that have good contributions to objective reduction but move towards the feasible region would be blocked, which would result in very slow convergence. Typically, the penalty parameters are carefully chosen as a monotonically increasing sequence. To avoid the difficulty between balancing the reduction of the objective and infeasibilities, a filter technique is proposed and used in a trust-region SQP method (Fletcher and Leyffer, 2002). However, the filter mechanism has the disadvantage that a step contributing to the solution may be blocked by a filter entry, especially if there are several entries in the filter.

The proposed modified SQP method, which has potential for higher computational efficiency, is based on a backtracking line search framework. Differently from the classical SQP methods that employ a single merit function or filter techniques, a relaxed group of conditions is designed for better acceptance of long steps and faster convergence. 


\subsection{Modified SQP Approach}

A general NLP, which the MPC controller needs to solve online at each time step, is considered as follows:

$$
\begin{array}{ll}
\min & f(x) \\
\text { s.t. } & c(x) \leq 0
\end{array}
$$

in which the objective function $f: \mathbb{R}^{n} \rightarrow \mathbb{R}$ and the constraint function $c: \mathbb{R}^{n} \rightarrow \mathbb{R}^{m}$ are twice continuously differentiable, $n$ is the number of state variables and $m$ is the number of constraints, the state variables are $x \in \mathbb{R}^{n}$.

The quadratic programming problem (QP) solved in each SQP iteration $k$ is given by:

$$
\begin{array}{ll}
\min & \nabla f\left(x_{k}\right)^{T} d_{k}+\frac{1}{2} d_{k}{ }^{T} B_{k} d_{k} \\
\text { s.t. } & c_{i}\left(x_{k}\right)+\nabla c_{i}\left(x_{k}\right)^{T} d_{k} \leq 0, \quad i=1,2, \ldots, m
\end{array}
$$

in which the subscript $k$ represents the $k$-th iteration, the subscript $i$ represents the $i$-th constraint, $d_{k}$ is the search direction of the QP subproblem and $B_{k}$ is the BroydenFletcher-Goldfarb-Shanno (BFGS) approximation to the current Hessian of the Lagrangian. The Lagrangian of the objective function is defined as:

$$
L(x, \lambda)=f(x)+\lambda^{T} c(x)
$$

in which $\lambda \in \mathbb{R}^{m}$ is the vector of Lagrange multipliers.

The first-order Karush-Kuhn-Tucker (KKT) optimal conditions for the QP subproblem are:

$$
\begin{aligned}
& \nabla f\left(x_{k}\right)+B_{k} d_{k}+\sum_{i=1}^{m} \nabla c_{i}\left(x_{k}\right) \lambda_{i}=0 \\
& c_{i}\left(x_{k}\right)+\nabla c_{i}\left(x_{k}\right)^{T} d_{k} \leq 0 \\
& \lambda_{i}\left(c_{i}\left(x_{k}\right)+\nabla c_{i}\left(x_{k}\right)^{T} d_{k}\right)=0, \quad i=1,2, \ldots, m
\end{aligned}
$$

After a search direction $d_{k}$ has been computed, an appropriate step size $\alpha$ will need to be determined in order to obtain the next iteration: 


$$
x_{k+1}=x_{k}+\alpha d_{k}
$$

A trial step is accepted if the trial point can provide a sufficient reduction of the exact penalty function (Han, 1977) given by:

$$
P\left(d_{k}, \rho_{k}\right)=f\left(x_{k}\right)+\nabla f\left(x_{k}\right)^{T} d_{k}+\frac{1}{2} d_{k}^{T} B_{k} d_{k}+\rho_{k} \theta\left(x_{k}\right)
$$

in which $\rho_{k}$ is the penalty parameter and the infeasibility measure $\theta\left(x_{k}\right)$ is defined as:

$$
\theta\left(x_{k}\right)=\sum_{i=1}^{m}\left\|\max \left(0, c_{i}\left(x_{k}\right)+\nabla c_{i}\left(x_{k}\right)^{T} d_{k}\right)\right\|
$$

Three different penalty parameters are used in the proposed algorithm. Given the parameter $\rho_{k}{ }^{1}$ an initial value $\rho_{0}{ }^{1}$ with $\rho_{0}{ }^{1}>0$, the second parameter $\rho_{k}{ }^{2}$ must satisfy $\rho_{k}^{2}=\max \left(\xi_{k}, \rho_{k}^{1}\right)$, in which

$$
\xi_{k}:=\left\{\begin{array}{cc}
\gamma \frac{\nabla f\left(x_{k}\right)^{T} d_{k}+\frac{1}{2} d_{k}{ }^{T} B_{k} d_{k}}{\theta\left(x_{k}\right)} & , \text { if } \theta\left(x_{k}\right) \geq \vartheta \\
\left\|\lambda^{(k)}\right\|_{\infty} & \text {, if } \theta\left(x_{k}\right)<\vartheta
\end{array}\right.
$$

where $\vartheta \in(0,1)$ and $\gamma \in(1,+\infty)$ are constants.

Given the third parameter $\rho_{k}{ }^{3}$ an initial value $\rho_{0}{ }^{3}$ with $\rho_{0}{ }^{3}>\rho_{0}{ }^{1}$, the third parameter must satisfy $\rho_{k}^{3}>\xi_{k}$.

The parameter $\rho_{k}{ }^{1}$ will then be updated as:

$$
\rho_{k+1}{ }^{1}=\min \left(\rho_{k}{ }^{3}, \rho_{k}{ }^{1}+\varepsilon\right)
$$

in which $\varepsilon \in(0,+\infty)$ is a constant, typically small (e.g., $\left.10^{-6}\right)$.

The proposed step acceptance conditions are stated next. The first condition is adapted from the Armijo condition: 


$$
\begin{aligned}
& \phi(x, \rho):=f(x)+\rho \theta(x) \\
& \phi\left(x_{k}+\alpha d_{k}, \rho_{k}^{1}\right) \leq \phi\left(x_{k}, \rho_{k}^{1}\right)-\beta^{1} \alpha\left[P\left(0, \rho_{k}^{2}\right)-P\left(d_{k}, \rho_{k}^{2}\right)\right]
\end{aligned}
$$

in which $\beta^{1} \in(0,1)$ is a constant and $\phi\left(\cdot, \rho_{k}{ }^{1}\right)$ is a common merit function. If the first condition is satisfied, the objective is then decreased sufficiently. If the first condition failed, a second switch condition is considered:

$$
\alpha<\frac{\beta^{2} \theta\left(x_{k}\right)}{-\nabla f\left(x_{k}\right)^{T} d_{k}}
$$

in which $\beta^{2} \in(0,1)$ is a constant. If this switch condition holds, the direction is of sufficient decrease. For such case, the following expressions are applied:

$$
f\left(x_{k}+\alpha d_{k}\right) \leq f\left(x_{k}\right)-\beta^{3} \alpha\left[-\nabla f\left(x_{k}\right)^{T} d_{k}\right]
$$

and

$$
\theta\left(x_{k}+\alpha d_{k}\right) \leq\left(1+\frac{1}{(k+1)^{\eta}}\right) \theta\left(x_{k}\right)
$$

in which $\beta^{3} \in(0,1)$ and $\eta \in(1,+\infty)$ are constants. In this case, there is a sufficient decrease in the objective with an acceptable infeasibility. If the second switch condition does not hold, then the third condition is considered for feasibility reduction:

$$
\phi\left(x_{k}+\alpha d_{k}, \rho_{k}^{3}\right) \leq \phi\left(x_{k}, \rho_{k}{ }^{3}\right)-\beta^{1} \alpha\left[P\left(0, \rho_{k}{ }^{3}\right)-P\left(d_{k}, \rho_{k}{ }^{3}\right)\right]
$$

Note that the Equations (3.14) and (3.10) use different penalty parameters. If the third condition does not hold, the current trial step size $\alpha$ is not acceptable. Based on the backtracking line search framework, a new trial step size $s \alpha$ is considered, in which $s \in(0,1)$ is a constant.

The steps of the overall proposed SQP algorithm can now be outlined:

Step 0. Initialization: Given the initial point $x_{0}$, initial matrix $B_{0}$, set parameters $\vartheta, \beta^{1}, \beta^{2}, \beta^{3}, s \in(0,1), \gamma, \eta \in(1,+\infty), \varepsilon \in(0,+\infty)$, initial penalty parameters $\rho_{k}{ }^{1}$ and $\rho_{k}^{3}$, and iteration index $k=0$. 
Step 1. Computation of search directions: Solve Equation (3.4) for a step direction $d_{k}$ and the Lagrange multiplier vector $\lambda$.

Step 2. Proposed backtracking line search:

Set the trial step $\bar{x}_{k}=x_{k}+\alpha d_{k}$ with $\alpha=1$.

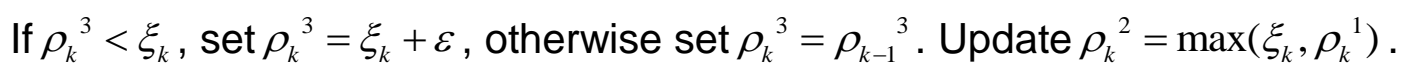

Find the largest value in the sequence $\left\{1, s, s^{2}, \ldots\right\}$ to be the appropriate step length, such that one of the following three scenarios is satisfied:

i. Equation (3.10) holds

ii. Equation (3.10) fails but (3.11), (3.12) and (3.13) hold

iii. Equation (3.10) fails and one of (3.11), (3.12) and (3.13) fails, but (3.14) holds.

Step 3. Next iteration: Define the next iteration as $x_{k+1}=x_{k}+\alpha d_{k}$.

If the third condition holds, update the penalty parameter $\rho_{k}{ }^{1}$ by $\rho_{k}{ }^{1}=\min \left(\rho_{k}{ }^{3}, \rho_{k}{ }^{1}+\varepsilon\right)$. Update the matrix $B_{k+1}$ by the BFGS method.

Step 4. Set $k=k+1$ and go back to Step 1.

\subsection{Algorithm Convergence Analysis}

Here, the global convergence of the proposed modified SQP algorithm is proved. Note that the global convergence means that the algorithm can converge for an arbitrary initial approximation. The global convergence proof is based on the following assumptions:

- The sequences $\left\{x_{k}\right\},\left\{x_{k}+d_{k}\right\}$ remain in a compact and convex set $X$;

- The objective $f$ and the constraint function $c$ are twice continuously differentiable on the open set containing $X$;

- The matrices $B_{k}$ are uniformly bounded and uniformly positive definite; 
- The vector of Lagrange multipliers is uniformly bounded;

- The QP subproblems are feasible for all iterations.

With these assumptions, there exist positive constants $\mu, G, G_{c}, G_{f}, G_{d}, G_{\lambda}$ independent of $k$, such that: $\mu\|d\|^{2} \leq d^{T} B_{k} d \leq G\|d\|^{2},\left\|\nabla_{x x}^{2} c_{i}(x)\right\| \leq G_{c},\|\nabla f(x)\| \leq G_{f},\left\|\nabla_{x x}^{2} f(x)\right\| \leq G_{f}$ and $\left\|d_{k}\right\| \leq G_{d},\left\|\lambda^{(k)}\right\|_{\infty} \leq G_{\lambda}$ for all $d \in \mathbb{R}^{n}, x \in X, i$, and $k$.

\section{Lemma 1}

For any iteration index $k$, if $d_{k}=0$, then the algorithm terminates at a KKT point for the problem. Otherwise, the backtracking line search will terminate finitely.

\section{Proof}

If $d_{k}=0$, then Equation (3.5) shows that the KKT condition will be satisfied at $\left(x_{k}, \lambda^{(k)}\right)$. Otherwise, if $\theta\left(x_{k}\right) \leq \vartheta$, then

$$
\begin{aligned}
& P\left(d_{k}-\rho_{k}{ }^{3}\right)-P\left(0-\rho_{k}{ }^{3}\right) \\
& =\nabla f\left(x_{k}\right)^{T} d_{k}+\frac{1}{2} d_{k}^{T} B_{k} d_{k}-\rho_{k}{ }^{3} \theta\left(x_{k}\right) \\
& =-d_{k}{ }^{T} B_{k} d_{k}-\sum_{i=1}^{m} \lambda_{i}^{(k)} \nabla c_{i}\left(x_{k}\right)^{T} d_{k}+\frac{1}{2} d_{k}^{T} B_{k} d_{k}-\rho_{k}{ }^{3} \theta\left(x_{k}\right) \\
& \leq-\frac{1}{2} d_{k}{ }^{T} B_{k} d_{k}-\sum_{i \in\left\{i \mid c_{i}\left(x_{k}\right)>0\right\}}\left(\rho_{k}{ }^{3}-\lambda_{i}^{(k)}\right) c_{i}\left(x_{k}\right) \leq-\frac{1}{2} d_{k}{ }^{T} B_{k} d_{k}
\end{aligned}
$$

if $\theta\left(x_{k}\right) \geq \vartheta$, then

$$
\begin{aligned}
& P\left(d_{k}-\rho_{k}{ }^{3}\right)-P\left(0-\rho_{k}{ }^{3}\right) \\
& =\nabla f\left(x_{k}\right)^{T} d_{k}+\frac{1}{2} d_{k}{ }^{T} B_{k} d_{k}-\rho_{k}^{3} \theta\left(x_{k}\right) \\
& \leq-\frac{\gamma-1}{\gamma} \rho_{k}^{3} \theta\left(x_{k}\right) \leq-\frac{\gamma-1}{\gamma} \rho_{0}^{3} \vartheta
\end{aligned}
$$

From Equations (3.15) and (3.16), it is possible to obtain $P\left(0-\rho_{k}{ }^{3}\right)-P\left(d_{k}-\rho_{k}{ }^{3}\right)>0$. Then from Taylor's series expansions: 


$$
\begin{aligned}
\phi & \left(x_{k}+\alpha d_{k}, \rho_{k}^{3}\right)-\phi\left(x_{k}, \rho_{k}^{3}\right) \\
= & f\left(x_{k}+\alpha d_{k}\right)-f\left(x_{k}\right)+\rho_{k}^{3}\left(\theta\left(x_{k}+\alpha d_{k}\right)-\theta\left(x_{k}\right)\right) \\
= & \alpha \nabla f\left(x_{k}\right)^{T} d_{k}+\frac{1}{2} \alpha^{2} \nabla_{x x}^{2} f(\underline{x}) d_{k}-\rho_{k}^{3} \theta\left(x_{k}\right) \\
& +\rho_{k}^{3} \theta\left(x_{k}+\alpha d_{k}\right) \\
\leq & \alpha \nabla f\left(x_{k}\right)^{T} d_{k}+\frac{1}{2} \alpha^{2} G_{f}\left\|d_{k}\right\|^{2}-\rho_{k}^{3} \theta\left(x_{k}\right) \\
& +\rho_{k}^{3}(1-\alpha) \sum_{i=1}^{m} \max \left(0, c_{i}\left(x_{k}+\alpha d_{k}\right)\right) \\
\leq & \alpha \nabla f\left(x_{k}\right)^{T} d_{k}-\rho_{k}^{3} \theta\left(x_{k}\right)+\frac{1}{2} \alpha^{2} G_{f}\left\|d_{k}\right\|^{2} \\
& +\rho_{k}^{3}(1-\alpha)+\frac{1}{2} \rho_{k}^{3} \alpha^{2} m G_{c}\left\|d_{k}\right\|^{2} \\
\leq & \alpha\left(P\left(d_{k}-\rho_{k}^{3}\right)-P\left(0-\rho_{k}^{3}\right)\right)+\frac{1}{2} \alpha^{2}\left(G_{f}+\rho_{k}^{3} m G_{c}\right)\left\|d_{k}\right\|^{2}
\end{aligned}
$$

in which $\underline{x}$ is an interpolation between $x_{k}$ and $x_{k}+d_{k}$.

Thus, if the step length satisfies

$$
\alpha \leq \frac{2\left(1-\beta^{1}\right)\left(P\left(0-\rho_{k}{ }^{3}\right)-P\left(d_{k}-\rho_{k}{ }^{3}\right)\right)}{\left(G_{f}+\rho_{k}{ }^{3} m G_{c}\right)\left\|d_{k}\right\|^{2}}
$$

Then, the third condition by Equation (3.14) will be satisfied for the current iteration and the line search will be terminated.

\section{Lemma 2}

There exist indices $k_{1}, k_{2}$ and $k_{3}$ such that $\rho_{k}{ }^{1}=\rho_{k_{1}}{ }^{1}=\underline{\rho}^{1}$ for all $k>k_{1}, \rho_{k}{ }^{2}=\rho_{k_{2}}{ }^{2}=\underline{\rho}^{2}$ for all $k>k_{2}$, and $\rho_{k}{ }^{3}=\rho_{k_{3}}{ }^{3}=\underline{\rho}^{3}$ for all $k>k_{3}$.

\section{Proof}

Based on Equation (3.8), there will be a constant that bounds $\xi_{k}$ :

$$
G_{\xi}=\max \left(\gamma \frac{G_{f} G_{d}+\frac{1}{2} G_{d}^{2} G}{\vartheta}, G_{\lambda}\right)
$$


Then by following step 2 of the algorithm, $\rho_{k}{ }^{3}$ will only be able to be updated finite times. Once $\rho_{k}{ }^{3}$ becomes a constant for a sufficiently large $k$ and based on Equation (3.9), $\rho_{k}{ }^{1}$ will also only be able to be updated finite times. Since $\rho_{k}{ }^{2}=\max \left(\xi_{k}, \rho_{k}{ }^{1}\right)$, then $\rho_{k}{ }^{2}$ will become a constant within finite updates as well.

\section{Lemma 3}

If there are finite iterations based on scenarios (i) and (iii), then $d_{k} \rightarrow 0$.

\section{Proof}

For all sufficiently large $k: f\left(x_{k}+\alpha d_{k}\right) \leq f\left(x_{k}\right)+\beta^{3} \alpha_{k} \nabla f\left(x_{k}\right)^{T} d_{k} \leq f\left(x_{k}\right)-\beta^{3} \beta^{2} \theta\left(x_{k}\right)$ or $\beta^{3} \beta^{2} \theta\left(x_{k}\right) \leq f\left(x_{k}\right)-f\left(x_{k}+\alpha d_{k}\right)$, and $f\left(x_{k}\right)$ is bounded when $\theta\left(x_{k}\right) \rightarrow 0$.

If $\left\|d_{k_{i}}\right\| \geq \sigma$ for some sequence $\left\{x_{k i}\right\}$ with a constant $\sigma>0$, then based on Equation (3.12) we have:

$$
f\left(x_{k+1}\right)-f\left(x_{k}\right) \leq \beta^{3} \alpha_{k_{i}} \nabla f\left(x_{k_{i}}\right)^{T} d_{k_{i}} \leq \beta^{3} \alpha_{k_{i}}\left(G_{\lambda} \theta\left(x_{k_{i}}\right)-\mu\left\|d_{k_{i}}\right\|^{2}\right)
$$

which is a contradiction with $f\left(x_{k}\right)$ being bounded, and thus $d_{k} \rightarrow 0$.

\section{Lemma 4}

If there are finite iterations based only on the scenario (ii), then $d_{k} \rightarrow 0$.

\section{Proof}

Suppose by contradiction that there exists a sequence $\left\{k_{i}\right\}$ such that $\left\|d_{k_{i}}\right\| \geq \sigma$ with a constant $\sigma>0$.

From Equations (3.15) and (3.16), the predicted reduction will satisfy:

$$
\begin{aligned}
& P\left(0-\rho_{k_{i}}{ }^{2}\right)-P\left(d_{k_{i}}-\rho_{k_{i}}{ }^{2}\right) \geq \min \left(\frac{1}{2} \mu \sigma^{2}, \frac{\gamma-1}{\gamma} \vartheta \rho_{0}{ }^{2}\right) \\
& P\left(0-\rho_{k_{i}}{ }^{3}\right)-P\left(d_{k_{i}}-\rho_{k_{i}}{ }^{3}\right) \geq \min \left(\frac{1}{2} \mu \sigma^{2}, \frac{\gamma-1}{\gamma} \vartheta \rho_{0}{ }^{3}\right)
\end{aligned}
$$


Then from Lemma 3, Equation (3.21) will be satisfied for all sufficiently large $k$.

If there are infinite iterations based on the scenario (iii), then for all $i$ sufficiently large:

$$
\begin{aligned}
& \phi\left(x_{k_{i}+1}, \underline{\rho}^{1}\right)=\phi\left(x_{k_{i}+1}, \underline{\rho}^{3}\right) \\
& \leq \phi\left(x_{k_{i}}, \underline{\rho}^{3}\right)-\beta^{1} \underline{\alpha}\left(P\left(0-\rho_{k_{i}}^{3}\right)-P\left(d_{k_{i}}-\rho_{k_{i}}^{3}\right)\right) \\
& \quad=\phi\left(x_{k_{i}}, \underline{\rho}^{1}\right)-\beta^{1} \underline{\alpha}\left(P\left(0-\rho_{k_{i}}^{3}\right)-P\left(d_{k_{i}}-\rho_{k_{i}}^{2}\right)\right)
\end{aligned}
$$

in which

$$
\underline{\alpha}=\min \left(1, \frac{\left(1-\beta^{1}\right) s \mu}{G_{f}+\rho_{k}{ }^{3} m G_{c}}, \frac{2\left(1-\beta^{1}\right)(\gamma-1) \vartheta \rho_{0}{ }^{3}}{\gamma\left(G_{f}+\rho_{k}{ }^{3} m G_{c}\right) G_{d}{ }^{2}}\right)
$$

Similarly, if there are infinite iterations based on the scenario (i), Equation (3.22) is also satisfied for a sufficiently large $i$.

Then based on Equation (3.21) and Lemma 1, $\phi\left(x_{k_{i}+1}, \underline{\rho}^{1}\right) \rightarrow-\infty$, which is a contradiction with $\phi\left(x_{k_{i}+1}, \underline{\rho}^{1}\right)$ being bounded. Hence, we can conclude that $d_{k} \rightarrow 0$.

\section{Theorem 1}

There exists a sequence $\left\{x_{k i}\right\}$ such that $\lim _{i \rightarrow \infty} d_{k_{i}}=0$ and a KKT point of the problem will be an accumulation point.

\section{Proof}

Assume the iterations based on scenarios (i) and (ii) are infinite, but the iteration based on the scenario (iii) is finite. Define the subsequences $\left\{k_{i}{ }^{1}\right\}$ and $\left\{k_{i}{ }^{2}\right\}$ such that $k_{i}{ }^{1}<k_{i}^{2}<$ $k_{i+1}{ }^{1}$, in which $k_{i}^{1}$ and $k_{i}^{2}-1$ are based on scenario (i), $k_{i}^{1}-1$ and $k_{i}^{2}$ are based on scenario (ii).

Based on Equation (3.10):

$$
\begin{aligned}
& \phi\left(x_{k_{i}^{1}}, \underline{\rho}^{1}\right) \geq \phi\left(x_{k_{i}^{2}-1}, \underline{\rho}^{1}\right) \\
& \quad \geq \phi\left(x_{k_{i}^{2}}, \underline{\rho}^{1}\right)+\beta^{1} \alpha_{k_{i}^{2}-1}\left(P\left(0-\underline{\rho}^{2}\right)-P\left(d_{k_{i}^{2}-1}-\underline{\rho}^{2}\right)\right)
\end{aligned}
$$




$$
\begin{gathered}
f\left(x_{k_{i}^{2}}\right) \geq f\left(x_{k_{i}^{1}+1}\right)-\sum_{j=k_{i}^{2}}^{k_{i+1}{ }^{1}-1} \beta^{3} \alpha_{j} \nabla f\left(x_{j}\right)^{T} d_{j} \\
\geq f\left(x_{k_{i}^{1}+1}\right)-\beta^{3} \alpha_{k_{i}^{2}} \nabla f\left(x_{k_{i}^{2}}\right)^{T} d_{k_{i}^{2}}
\end{gathered}
$$

and

$$
\theta\left(x_{k_{i}^{2}}\right)=\theta\left(x_{k_{i}^{1}+1}\right)+\sum_{j=k_{i}^{2}}^{k_{i+1} 1^{1}-1}\left(\theta\left(x_{j}\right)-\theta\left(x_{j+1}\right)\right)
$$

Then with Equation (3.11):

$$
f\left(x_{k_{i}^{2}}\right) \geq f\left(x_{k_{i}^{1}+1}\right)+\min \left(\frac{\beta^{3} \underline{\alpha} \mu G_{d}{ }^{2}}{2}, \frac{\beta^{3} \beta^{2} \mu G_{d}{ }^{2}}{2 G_{\lambda}}\right)
$$

Since $\theta\left(x_{k_{i}^{2}+1}\right)-\theta\left(x_{k_{i}^{2}}\right) \leq \frac{1}{(k+1)^{\eta}} \theta\left(x_{k_{i}^{2}}\right)$ with $\eta \in(1,+\infty)$, then for all sufficiently large $i$ :

$$
\sum_{j=k_{i}^{2}}^{k_{i+1}{ }^{1}-1}\left(\theta\left(x_{j}\right)-\theta\left(x_{j+1}\right)\right) \geq-\min \left(\frac{\beta^{3} \underline{\alpha} \mu G_{d}^{2}}{2 \underline{\rho^{1}}}, \frac{\beta^{3} \beta^{2} \mu G_{d}{ }^{2}}{2 \underline{\rho^{1} G_{\lambda}}}\right)
$$

Therefore

$$
\begin{aligned}
& \phi\left(x_{k_{i}^{1}}, \underline{\rho}^{1}\right)-\phi\left(x_{k_{i}^{1}+1}, \underline{\rho}^{1}\right) \geq \phi\left(x_{k_{i}^{1}}, \underline{\rho}^{1}\right)-\phi\left(x_{k_{i}^{2}}, \underline{\rho}^{1}\right) \\
& \geq \min \left(\frac{1}{2} \beta^{1} \underline{\alpha} \mu \sigma^{2}, \frac{\gamma-1}{\gamma} \beta^{1} \underline{\alpha} \vartheta \rho_{0}{ }^{2}\right)
\end{aligned}
$$

If $\left\|d_{k}\right\| \geq \sigma$ with a constant $\sigma>0$, and for all sufficiently large $k$, then $\phi\left(x, \underline{\rho}^{1}\right)$ will be unbounded. Therefore, there must exist a subsequence of $\left\{x_{k i}\right\}$ such that $d_{k} \rightarrow 0$. Similarly, if the iterations based on scenarios (ii) and (iii) are infinite, there must exist a subsequence of $\left\{x_{k i}\right\}$ such that $d_{k} \rightarrow 0$.

Based on Lemma 3 and Lemma 4, if there are finite iterations based on scenarios (i) and (iii), or if there are finite iterations based only on the scenario (ii), then $d_{k} \rightarrow 0$. Therefore, a sequence $\left\{x_{k i}\right\}$ must exist such that $\lim _{i \rightarrow \infty} d_{k_{i}}=0$ and a KKT point of the problem will be an accumulation point. 


\subsection{Numerical Results for Motivating Examples}

To verify that the proposed modified SQP has the potential for better acceptance of long steps and faster convergence than the classical SQP algorithm, a group of motivating examples are tackled. The 60 motivating examples are selected from the Hock and Schittkowski (HS) problem set in the literature (Hock and Schittkowski, 1981). The numbers of the proposed modified SQP and a classical SQP from the literature (Martinsen et al., 2002) iterations to reach the optimal solution are presented in Table 3.1 , including the problem names from the set and their dimensions ( $n$ is the number of states and $m$ is the number of constraints).

Table 3.1. Numbers of different SQP algorithm iterations for HS problems

\begin{tabular}{|c|c|c|c|c|c|c|c|c|c|}
\hline Problem & $\mathbf{n}$ & $\mathbf{m}$ & $\begin{array}{c}\text { Modified } \\
\text { SQP }\end{array}$ & $\begin{array}{c}\text { Classical } \\
\text { SQP }\end{array}$ & Problem & $\mathbf{n}$ & $\mathbf{m}$ & $\begin{array}{c}\text { Modified } \\
\text { SQP }\end{array}$ & $\begin{array}{c}\text { Classical } \\
\text { SQP }\end{array}$ \\
\hline HS1 & 2 & 0 & 26 & 71 & HS40 & 4 & 3 & 7 & 6 \\
\hline HS2 & 2 & 0 & 7 & 18 & HS41 & 4 & 1 & 5 & 8 \\
\hline HS3 & 2 & 0 & 9 & 10 & HS42 & 4 & 2 & 9 & 14 \\
\hline HS4 & 2 & 0 & 1 & 2 & HS43 & 4 & 3 & 13 & 14 \\
\hline HS5 & 2 & 0 & 9 & 8 & HS44 & 4 & 6 & 5 & 12 \\
\hline HS6 & 2 & 1 & 10 & 10 & HS45 & 5 & 0 & 7 & 2 \\
\hline HS7 & 2 & 1 & 11 & 13 & HS46 & 5 & 2 & 11 & 12 \\
\hline HS8 & 2 & 2 & 5 & 9 & HS47 & 5 & 3 & 14 & 21 \\
\hline HS9 & 2 & 1 & 6 & 8 & HS48 & 5 & 2 & 7 & 8 \\
\hline HS10 & 2 & 1 & 11 & 20 & HS49 & 5 & 2 & 5 & 6 \\
\hline HS11 & 2 & 1 & 7 & 11 & HS90 & 4 & 1 & 59 & 81 \\
\hline HS12 & 2 & 1 & 8 & 12 & HS91 & 5 & 1 & 47 & 62 \\
\hline
\end{tabular}


Table 3.1 (Continued). Numbers of different SQP algorithm iterations for HS problems

\begin{tabular}{|c|c|c|c|c|c|c|c|c|c|}
\hline Problem & $\mathbf{n}$ & $\mathbf{m}$ & $\begin{array}{c}\text { Modified } \\
\text { SQP }\end{array}$ & $\begin{array}{c}\text { Classical } \\
\text { SQP }\end{array}$ & Problem & $\mathbf{n}$ & $\mathbf{m}$ & $\begin{array}{c}\text { Modified } \\
\text { SQP }\end{array}$ & $\begin{array}{c}\text { Classical } \\
\text { SQP }\end{array}$ \\
\hline HS13 & 2 & 1 & 24 & 42 & HS92 & 6 & 1 & 50 & 94 \\
\hline HS14 & 2 & 2 & 6 & 7 & HS93 & 6 & 2 & 14 & 41 \\
\hline HS15 & 2 & 2 & 4 & 5 & HS94 & 6 & 4 & 2 & 3 \\
\hline HS16 & 2 & 2 & 6 & 12 & HS95 & 6 & 4 & 1 & 2 \\
\hline HS17 & 2 & 2 & 13 & 20 & HS96 & 6 & 4 & 1 & 1 \\
\hline HS18 & 2 & 2 & 9 & 8 & HS97 & 6 & 4 & 4 & 7 \\
\hline HS19 & 2 & 2 & 5 & 7 & HS98 & 6 & 4 & 6 & 13 \\
\hline HS20 & 2 & 3 & 4 & 5 & HS99 & 7 & 2 & 92 & 249 \\
\hline HS30 & 3 & 1 & 19 & 18 & HS100 & 7 & 4 & 29 & 32 \\
\hline HS31 & 3 & 1 & 8 & 12 & HS101 & 7 & 6 & 70 & 61 \\
\hline HS32 & 3 & 2 & 3 & 5 & HS102 & 7 & 6 & 52 & 91 \\
\hline HS33 & 3 & 2 & 4 & 5 & HS103 & 7 & 6 & 46 & 36 \\
\hline HS34 & 3 & 2 & 7 & 8 & HS104 & 8 & 1 & 16 & 15 \\
\hline HS35 & 3 & 1 & 5 & 7 & HS105 & 8 & 6 & 53 & 68 \\
\hline HS36 & 3 & 1 & 5 & 10 & HS106 & 8 & 6 & 357 & 594 \\
\hline HS37 & 3 & 2 & 10 & 12 & HS107 & 9 & 6 & 7 & 23 \\
\hline HS38 & 4 & 0 & 39 & 115 & HS108 & 9 & 13 & 16 & 37 \\
\hline HS39 & 4 & 2 & 11 & 14 & HS109 & 9 & 10 & 56 & 72 \\
\hline
\end{tabular}

For the 60 problems tested, the proposed SQP algorithm requires less number of iterations for 54 problems (90\%) when compared to the classical SQP algorithm. This result verified that the proposed modified SQP has the potential for better acceptance of 
long steps and faster convergence. The 6 problems for which the proposed algorithm requires more number of iterations, for example HS45, are result of a longer first trial step that reached a region with constraint violations and thus the following search directions are less efficient in terms of reducing the objective reduction. The constraint violation acceptance region can be reduced by increasing the tuning parameter $\eta$ in Equation (3.13) 


\section{MPC Approaches Developed and Implementation}

\section{Framework}

In this chapter, the four MPC approaches developed are presented. One is based on the DMC method, which is a linear MPC approach. The other three are nonlinear MPC approaches: the proposed modified SQP-based MPC, a classical SQP-based MPC and a direct transcription-based MPC. The MPC implementation framework is also addressed in this chapter.

\subsection{Linear MPC Approach}

As one of the most commonly used linear MPC strategies, DMC is addressed in this work to represent a linear MPC approach. The key features of the DMC method include:

- Linear step response model of the plant

- Minimization of a quadratic performance objective over a finite prediction horizon

- Future plant output behavior specified by tracking the setpoint as closely as possible

- Optimal inputs calculated as the solution of a least-squares problem

The original multiple-input-multiple-output DMC formulation (Cutler and Perry, 1980) is adapted here for the implementations. DMC employs the rolling optimal objective function as follows:

$$
\min _{u} J=\left\|Y(k)-Y_{p}(k)\right\|_{Q}^{2}+\|\Delta u(k)\|_{R}^{2}
$$

in which $Y$ is the target value vector for the outputs, $Y_{p}$ is the predicted value vector, $Q$ is the error weighting matrix, $\Delta u$ is the control vector and $R$ is the control weighting matrix. The $Q$ and $R$ matrices are both selected as identity matrices for the DMC implementations in this thesis. By minimizing the least-square errors between predicted and target values for the desired outputs at each sample time, optimal input values can be obtained by optimization. Also, by implementing the feedback error correction by 
changing the inputs at each time step, $k$, the closed-loop control results can be obtained and the calculations repeated for the next time step.

The linear step response model used by the DMC relates changes in a process output according to a weighted sum of past input changes, referred to as input moves (see schematic in Figure 4.1).

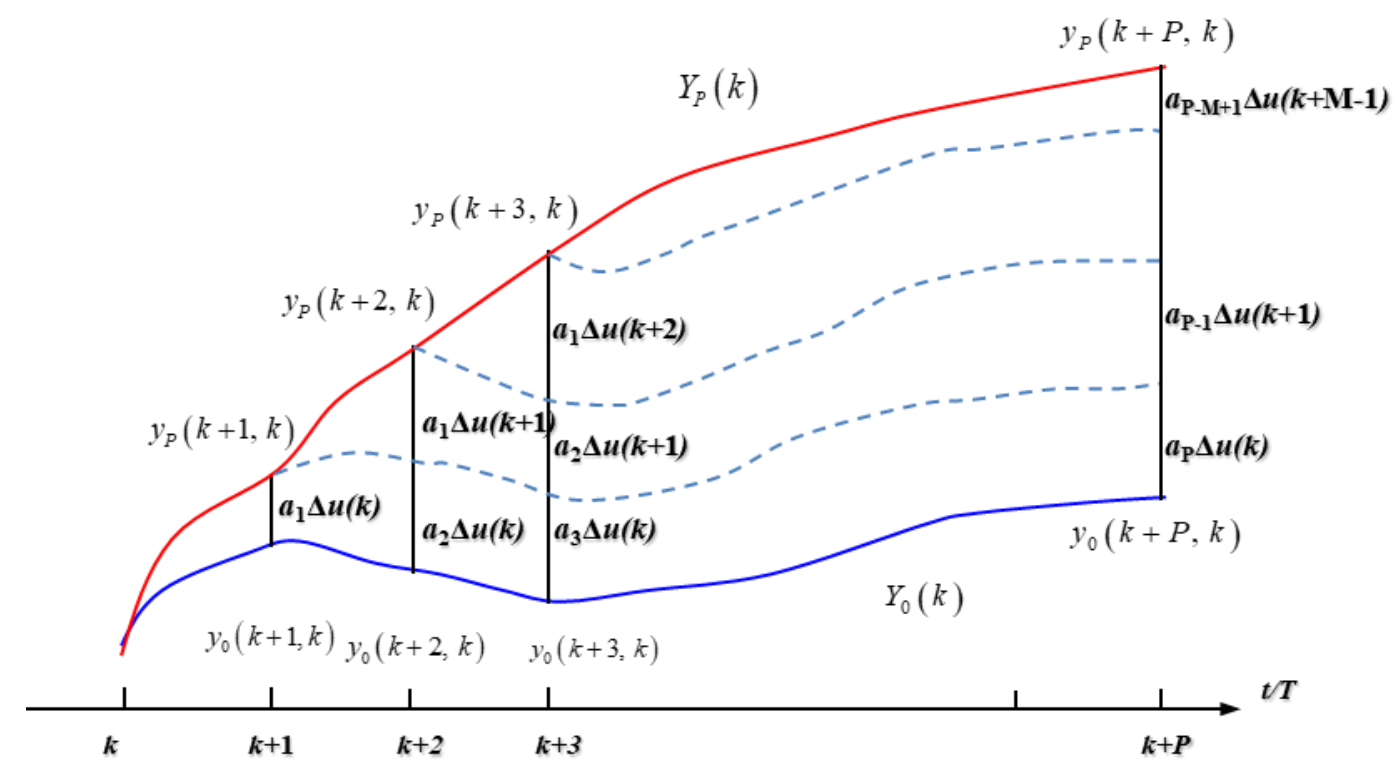

Figure 4.1. Schematic representation of linear step response model

To obtain the linear step response model for the MPC application of interest, each input variable needs to be moved as a step and the step response for each output needs to be captured. For example, for the IGCC application studied in this thesis, carbon capture rate is considered as a controlled variable and water for syngas cooling is considered as an input variable (see Figure 4.2). In this case, the water is moved in a step change while the other input variables remain the same and the carbon capture rate response data is collected. The combination of all the single-input-single-output step response data gives the linear prediction model for DMC. 


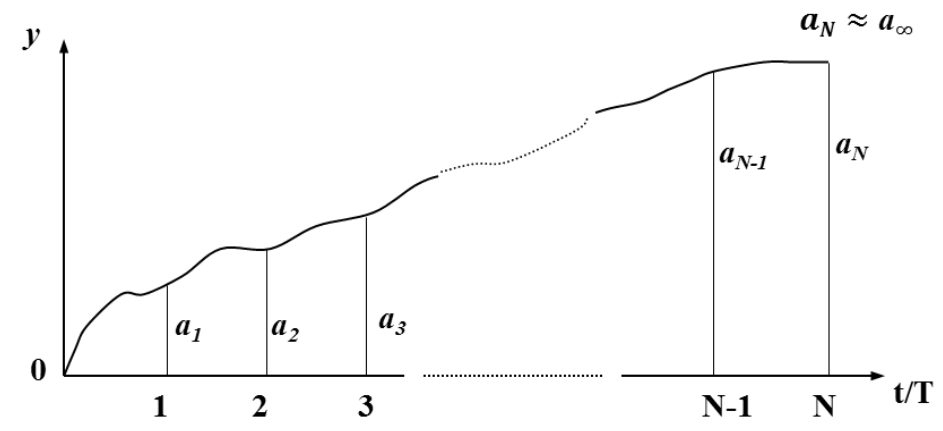

Figure 4.2. Illustration of a single-input-single-output step response

By using the step response model, the predicted future outputs can be written as a linear combination of the calculated future input moves. The predicted output is given by:

$$
y(k+j, k)=\sum_{i=1}^{j} a_{i} \Delta u(k-i+j)+\sum_{i=1+1}^{N-1} a_{i} \Delta u(k-i+j)+a_{N} u(k-N+j)+d(k+j)
$$

in which $y(k+j, k)$ is the predicted value of the output $y$ at time $k+j$ based on information available at time $k ; a_{1}, a_{2}, \ldots a_{N}$ are the model step response matrix coefficients obtained from step tests (see Figure 4.2); $u$ is the manipulated input; $d$ is the predicted value of the additive disturbances affecting the process output; and $N$ is the truncated model horizon (i.e., $a_{N}=a_{\infty}$ ). The output prediction in Equation (4.2) involves four terms on the right hand side. The first term includes the present and future moves of the manipulated variables (MVs) to be determined by solving Equation (4.1). The second and third terms include past values of the MVs and are completely known at time $k$. The fourth term is the predicted disturbance, which is assumed constant for all future times $(j \geq 0)$. At time $k$, this term is estimated as the difference between the predicted output and the measured output (output bias model).

\subsection{Nonlinear MPC Approaches}

In nonlinear MPC algorithms, fully nonlinear models are used instead of linear step response models to predict the future output responses at a certain time point. Similarly to the DMC, the nonlinear MPC dynamic problem is solved by minimizing a setpoint 
tracking control objective. The nonlinear MPC objective can be formulated in the following fashion:

$$
\begin{aligned}
\min _{u} \quad J & =\sum_{j=0}^{M-1}\left\|y(k)-y_{s p}\right\|_{Q}^{2}+\|\Delta u(k)\|_{R}^{2} \\
\text { s.t. } \frac{d x}{d t} & =f(x(t), u(t)) \\
0 & =g(x(t), u(t)) \\
y(t) & =h(x(t), u(t)) \\
c_{l b} & \leq C(y(t), u(t)) \leq c_{u b}
\end{aligned}
$$

in which $y$ in this case represents the controlled variables (CVs), $y_{s p}$ denotes the CV set point vector, $x$ are state variables, $u$ are manipulated variables (MVs), $\Delta u$ are control moves and $M$ is the control horizon. The functions $f, g, h$ represent the differential and algebraic equations that characterize the system model and the equations to calculate the outputs, respectively. The imposed lower $\left(c_{l b}\right)$ and upper $\left(c_{u b}\right)$ bounds on the CVs and MVs are generalized as the nonlinear constraints $C(y(t), u(t))$. Similarly to the DMC, the $Q$ matrix here is also considered as an identity matrix. Due to the smooth profiles obtained for inputs in the case studies performed, the penalty term for the inputs ( $R$ matrix in the objective function) in the nonlinear MPC formulation is set to a zero matrix.

In this thesis, two nonlinear MPC approaches employing the SQP-based method are developed for solving the NLP given by Equation (4.3). The first approach, the proposed modified SQP-based MPC, employs the algorithm detailed in Chapter 3. The second approach developed, a classical SQP-based MPC, employs an algorithm reproduced from the literature (Martinsen et al., 2002). Similarly to the modified SQP algorithm, the classical SQP algorithm solves a sequence of optimization sub-problems, in which each sub-problem optimizes a quadratic objective subject to a linearization of the constraints. This formulation results in a quadratic programming problem to be solved at each iteration of the SQP algorithm. At each step, the classical SQP algorithm searches for a new iterate that provides a reduction in a merit function. The merit function is needed to ensure convergence to a point satisfying the strong second-order assumptions from any 
starting point under certain additional assumptions. To improve the NLP solver performance, an open-source automatic differentiation package, ADOL-C (Walther and Griewank, 2012), is employed for both SQP-based approaches.

Since the proposed modified SQP-based and the classical SQP-based MPC approaches are based on a sequential method, a direct transcription-based MPC approach is selected as benchmark to represent the simultaneous approaches. Suitable choices between feasible and infeasible path methods, sequential and simultaneous methods, as well as reduced and full space methods have been discussed in the literature (Martinsen et al., 2002).

In the direct transcription-based MPC approach (Amrit et al., 2013; Lima et al., 2013; Lima et al., 2017; He et al., 2018), the state and differential profiles of the system are approximated by a family of polynomials on finite elements. In such approximation, Radau collocation points are used for allowing constraints to be set at the end of each element and stabilizing the system more efficiently in case of high index differential algebraic equation (DAE) systems. The following monomial basis representation is used for the differential profiles:

$$
x(t)=x(k-1)+l(k) \sum_{j=1}^{K} \Omega_{j}\left(\frac{t-t(k)}{l(k)}\right) \frac{d x}{d t_{k, j}}
$$

Here $k$ is the number of finite elements, $l(k)$ is the length of element $k, d x / d t_{k, j}$ is the firstorder derivative of collocation point $j$ in the element $k$, and $\Omega_{j}$ is a $K$ th-degree polynomial satisfying:

$$
\begin{aligned}
& \Omega_{j}(0)=0 \\
& \Omega^{\prime}{ }_{j}\left(\rho_{r}\right)=\delta_{j, r}
\end{aligned}
$$

in which $\rho_{r}$ represents the $r$ th collocation point within the element and $\delta$ is the Dirac delta function.

The algebraic and the manipulated variables are allowed to be discontinuous, while continuity is enforced on the state and differential profiles at each time step as follows: 


$$
x(t)=x(k-1)+l(k) \sum_{j=1}^{K} \Omega_{j}(1) \frac{d x}{d t_{k, j}}
$$

The CV and MV profiles are approximated based on a Lagrange representation:

$$
\begin{aligned}
& y(t)=\sum_{j=1}^{K} \Psi_{j}\left(\frac{t-t(k-1)}{l(k)}\right) y_{k, j} \\
& u(t)=\sum_{j=1}^{K} \Psi_{j}\left(\frac{t-t(k-1)}{l(k)}\right) u_{k, j}
\end{aligned}
$$

in which $y_{k, j}$ and $u_{k, j}$ represent the values of CVs and MVs, respectively, in element $k$ at collocation point $j . \Psi_{j}$ is a $K$ th-degree Lagrange polynomial satisfying $\Psi_{j}(r)=\delta_{j, r}$. The original system in Equation (4.3) is now converted to the following discrete time large-scale nonlinear programming (NLP) problem:

$$
\begin{aligned}
\min \quad J & =\sum_{j=0}^{M-1}\left\|y(k)-y_{s p}\right\|_{Q}^{2}+\|\Delta u(k)\|_{R}^{2} \\
\text { s.t. } \frac{d x}{d t_{k, j}} & =f\left(x_{k, j}, u_{k, j}\right) \\
x_{k, j} & =x(k-1)+l(k) \sum_{j=1}^{K} \Omega_{j^{\prime}}\left(\rho_{j}\right) \frac{d x}{d t_{k, j}} \\
x(k) & =x(k-1)+l(k) \sum_{j=1}^{K} \Omega_{j}(1) \frac{d x}{d t_{k, j}} \\
0 & =g\left(x_{k, j}, u_{k, j}\right) \\
y_{k, j} & =h\left(x_{k, j}, u_{k, j}\right) \\
c_{l b} & \leq C\left(x_{k, j}, u_{k, j}\right) \leq c_{u b}
\end{aligned}
$$

This formulation leads to a standard NLP of the form:

$$
\min _{w} f(w) \quad \text { s.t. } c(w)=0, w_{l b} \leq w \leq w_{u b}
$$

in which $w=\left(x(k), x_{k, j}, d x / d t_{k, j}, y_{k, j}, u_{k, j}\right)$.

The NLP problem is then solved using IPOPT: an efficient interior point-based largescale nonlinear optimization algorithm (Wächter and Biegler, 2006). Specifically, the 
IPOPT algorithm is a primal-dual interior-point algorithm with a filter line-search method that takes advantage of sparse matrix memory management capabilities to implement the NLP solution efficiently. The first and second-order derivative information is critical for the IPOPT performance. The ADOL-C is employed to improve the NLP solver performance. The numerical values of the derivative vectors are obtained free of truncation errors at a small multiple of the runtime and random access memory is required by the given function evaluation program. This strategy allows the computation of the sparsity patterns of the Jacobian and the Hessian before starting the optimization algorithm, which requests only the nonzero values of the exact first and second-order derivatives, instead of the whole matrix. In particular, IPOPT is initialized with a small barrier parameter value $\left(10^{-4}\right)$ at each execution cycle to prevent that the initialization is perturbed from the previous solution, which provides the NLP problem a warm start.

\subsection{MPC Implementation Framework}

The developed MPC approaches are coded in MATLAB and implemented on process models built in MATLAB and Aspen Plus Dynamics (detailed process dynamic modeling is addressed in Chapter 5). The nonlinear models in MATLAB employed here are characterized by first-principles models. For the processes corresponding to Aspen Plus Dynamics models, the nonlinear process models for control purposes are identified using an autoregressive-moving average model with exogenous variables (ARMAX). The outputs of the nonlinear model for control purposes are then calculated based on nonlinear first-principles equations applied to the ARMAX identified states. The ARMAX model is different from the typical autoregressive with exogenous inputs (ARX) identification technique as the structure of an ARMAX model includes a term to account for the stochastic dynamic performance. The following equation shows the form of the ARMAX model:

$$
A(z) y(z)=B(z) u(k-n)+C(z) e(k)
$$

where $y(z)$ are the system outputs, $u(k)$ are the system inputs, and $n$ is the number of input samples that occur before the inputs affect the outputs. Also, $e(k)$ are the system disturbances and, $A(z), B(z)$, and $C(z)$ are polynomials in the backward shift operator $z$ 
(defined by $x_{n-1}=z^{-1} x_{n}$ ). By providing the time-domain process simulation data of states to MATLAB and using the armax function, a discrete-time polynomial model with identifiable parameters is returned as the output. Based on this polynomial model, the output states of ARMAX model are then employed to calculate the CVs of the controllers using nonlinear functions. For example, the armax model provides the flowrates $(F)$ and concentrations $(C)$ of $\mathrm{CO}_{2}$ in the flue gas and clean gas streams. The system output carbon capture rate is then calculated by a nonlinear function as follows:

$$
\text { Carbon Capture Rate }=\frac{C_{\mathrm{CO}_{2}, \text { flue gas }} \cdot F_{\mathrm{CO}_{2}, \text { flue gas }}-C_{\mathrm{CO}_{2} \text {, clean gas }} \cdot F_{\mathrm{CO}_{2}, \text { clean gas }}}{C_{\mathrm{CO}_{2} \text {, flue gas }} \cdot F_{\mathrm{CO}_{2} \text {, flue gas }}}
$$

Figure 4.3 shows the differences between the Aspen process model and the nonlinear prediction model obtained for control purposes.

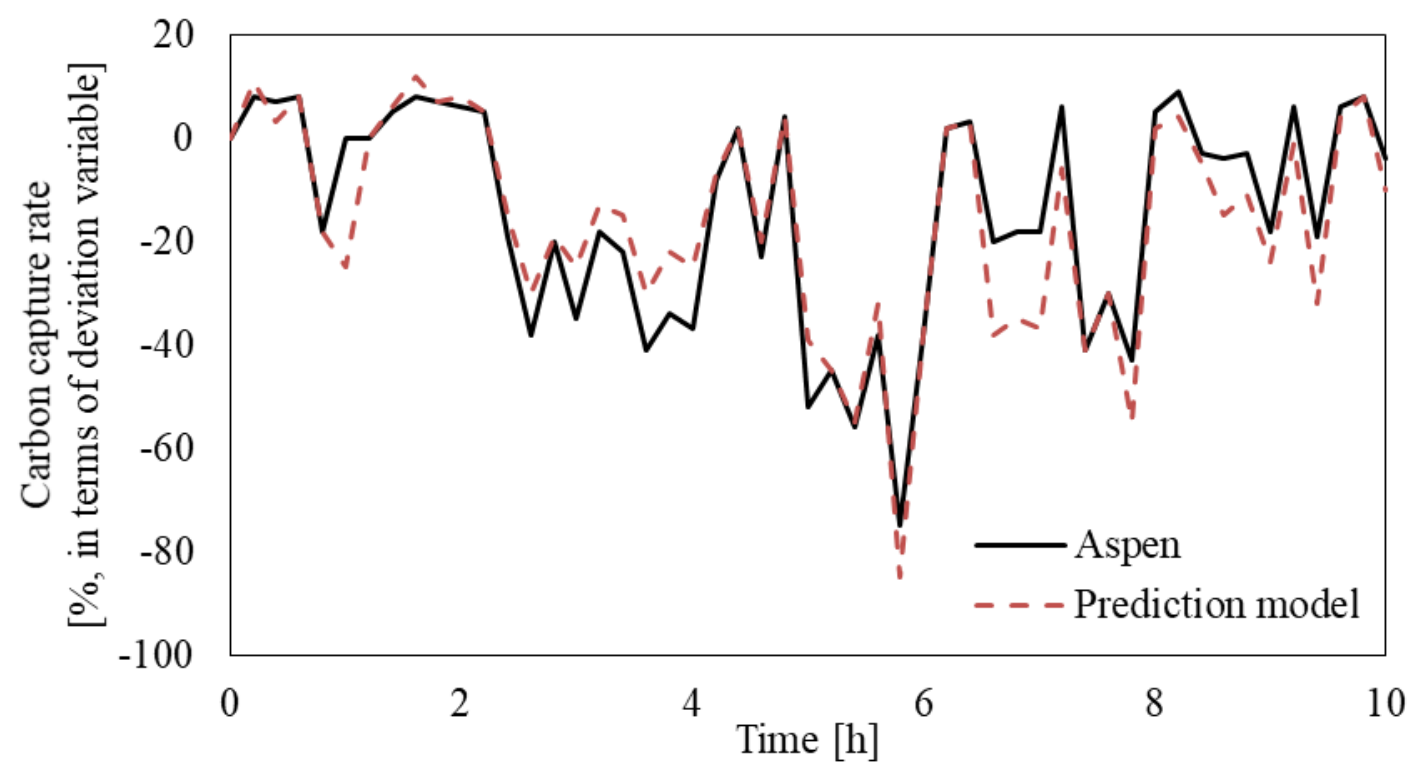

Figure 4.3. Comparison between nonlinear prediction model and Aspen process model Figure 4.4 shows the implementation framework with Aspen Plus Dynamics and MATLAB components. In such framework, MATLAB Simulink is used for interfacing the MPC codes programmed in MATLAB and the plant model in Aspen Plus Dynamics. The input changes calculated by the MPC controllers are sent from MATLAB Simulink to Aspen Plus Dynamics, where the variables are directly changed in the Aspen process model. 


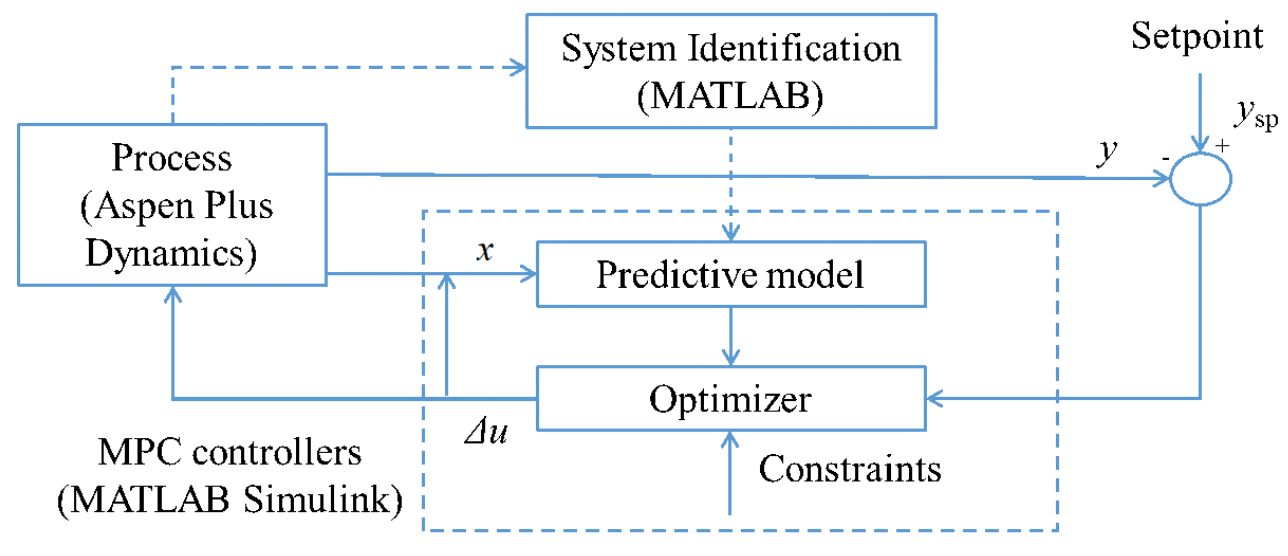

Figure 4.4. MPC implementation framework with Aspen Plus Dynamics 


\section{Power Plant Dynamic Modeling}

To illustrate the tracking performance and computational efficiency of the developed MPC strategies, three processes of different dimensionalities are addressed. The first process is an integrated gasification combined cycle power plant with a water-gas shift membrane reactor (IGCC-MR), which corresponds to a first-principles and simplified systems-level nonlinear model in MATLAB. The second process is an aqueous monoethanolamine (MEA)-based carbon capture process as part of a supercritical pulverized coal-fired (SCPC) power plant, which is built in Aspen Plus Dynamics. The third process is the entire SCPC power plant with MEA-based carbon capture (SCPCMEA), which is also built in Aspen Plus Dynamics.

\subsection{IGCC-MR Process}

The simplified IGCC-MR process flowsheet addressed in this thesis is shown in Figure 5.1 .

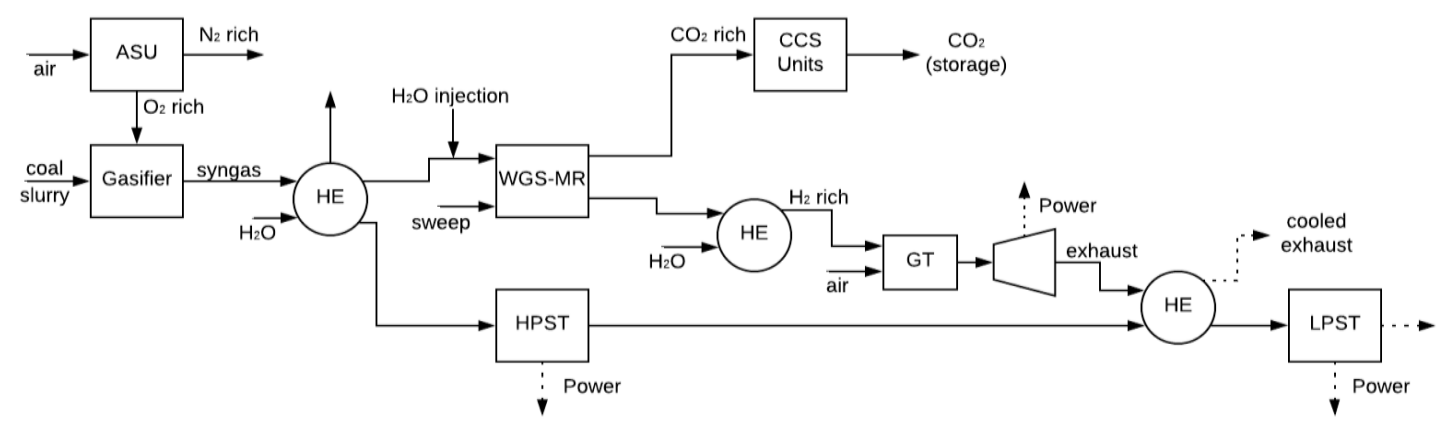

Figure 5.1. IGCC-MR process flowsheet

In particular, the ASU model assumes an isothermally operated one-stage flash with a relative volatility that allows enriched $\mathrm{O}_{2}$ stream production for the gasifier. The gasifier model considers a horizontal zone for combustion and a vertical zone for gasification. Both zones are assumed to be well mixed. There are two inlet streams into the gasifier: slurry, consisting of coal and water, which feeds both zones, and the $\mathrm{O}_{2}$ enriched air stream from the ASU that only enters the combustion zone. The output of the gasifier unit consists of the syngas from the gasification zone. The following reactions take place in the gasifier (Jillson et al., 2009; Lima et al., 2017): 


$$
\begin{gathered}
\mathrm{C}+\mathrm{O}_{2} \stackrel{k_{1}}{\longrightarrow} \mathrm{CO}_{2} \\
2 \mathrm{C}+\mathrm{O}_{2} \stackrel{k_{2}}{\longrightarrow} 2 \mathrm{CO} \\
\mathrm{C}+\mathrm{CO}_{2} \stackrel{k_{3}}{\longrightarrow} 2 \mathrm{CO} \\
\mathrm{C}+\mathrm{H}_{2} \mathrm{O} \stackrel{k_{4}}{\longrightarrow} \mathrm{CO}+\mathrm{H}_{2} \\
\mathrm{CO}+\mathrm{H}_{2} \mathrm{O} \stackrel{k_{5}}{\longrightarrow} \mathrm{CO}_{2}+\mathrm{H}_{2} \\
\mathrm{CH}_{4}+2 \mathrm{O}_{2} \stackrel{k_{6}}{\longrightarrow} \mathrm{CO}_{2}+2 \mathrm{H}_{2} \mathrm{O} \\
2 \mathrm{CO}_{+} \mathrm{O}_{2} \stackrel{k_{7}}{\longrightarrow} 2 \mathrm{CO}_{2} \\
\mathrm{CH}_{4}+\mathrm{H}_{2} \mathrm{O} \stackrel{k_{8}}{\longrightarrow} \mathrm{CO}_{+} 3 \mathrm{H}_{2} \\
2 \mathrm{H}_{2}+\mathrm{O}_{2} \stackrel{k_{9}}{\longrightarrow} 2 \mathrm{H}_{2} \mathrm{O} \\
\mathrm{C}+2 \mathrm{O}_{2} \stackrel{k_{10}}{\longrightarrow} \mathrm{CH}_{4}
\end{gathered}
$$

The IGCC-MR process has three heat exchanger (HE) networks. The first network uses water to cool the syngas from the gasifier and generate steam for the high-pressure steam turbine. The second network is employed to reheat the steam for the lowpressure turbine employing the gas turbine (GT) exhaust as the heating fluid. The third network provides necessary cooling for the resulting permeate stream $\left(\mathrm{H}_{2}\right.$ rich) from the MR to satisfy the GT inlet temperature constraint. The cooling water stream used is heated to produce additional steam for power generation by the low pressure steam turbine (LPST). The retentate ( $\mathrm{CO}_{2}$ rich) outlet stream proceeds to the carbon capture and sequestration (CCS) units.

The water gas shift membrane reactor (WGS-MR) is integrated downstream of the gasifier, as shown in Figure 5.2. The original WGS-MR model derived in Lima et al., (2012) assumes a one-dimensional shell and tube reactor in lab scale. In particular, a $\mathrm{Cu} / \mathrm{Zn}$-based catalyst is packed in the tube side where the WGS reaction takes place to convert the syngas feed. Also, a thin zeolite-based $\mathrm{H}_{2}$-selective membrane layer is placed on the tube wall surface and the sweep gas flows in the shell side. The reactor is scaled up here by using a membrane area large enough to process the syngas flow after cooling and additional steam injection, but still keeping an equivalent performance 
of the laboratory-scale reactor. For such a performance, the sweep gas flow is also increased accordingly.

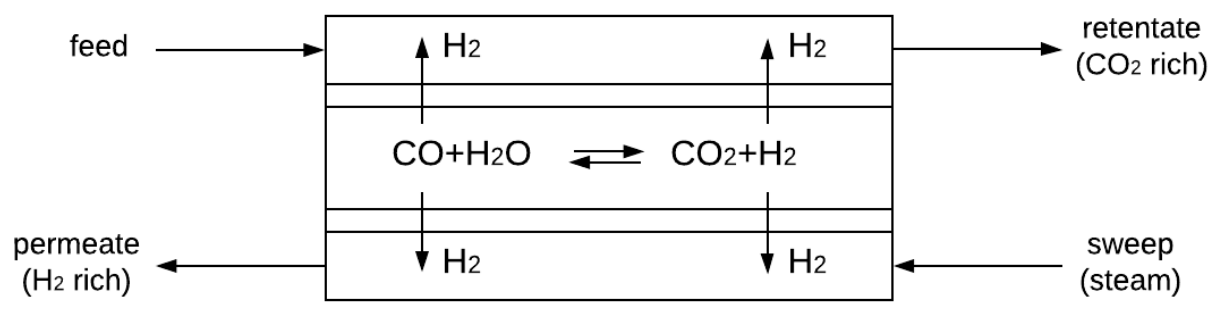

Figure 5.2. WGS-MR counter-current representation

The following mole balances for the tube and shell sides are considered to represent the WGS-MR (Lima et al., 2012):

- Tube mole balance

$$
\begin{gathered}
\frac{d f_{t, C O}}{d z}=r_{w g s, C O} A_{t}-J_{C O} \pi d_{t} \\
\frac{d f_{t, H_{2} O}}{d z}=r_{w g s, C O} A_{t}-J_{H_{2} O} \pi d_{t} \\
\frac{d f_{t, C O_{2}}}{d z}=-r_{w g s, C O} A_{t}-J_{C O_{2}} \pi d_{t} \\
\frac{d f_{t, H_{2}}}{d z}=-r_{w g s, C O} A_{t}-J_{H_{2}} \pi d_{t} \\
\frac{d f_{t, i}}{d z}=-J_{i} \pi d_{t}
\end{gathered}
$$

in which $i$ in the last equation represents all species other than $\mathrm{CO}, \mathrm{H}_{2} \mathrm{O}, \mathrm{H}_{2}$ and $\mathrm{CO}_{2}$ (see notation section for definition of model variables and subscripts).

- Shell mole balance

$$
-\frac{d f_{s, i}}{d z}=J_{i} \pi d_{t}
$$

in which $i$ represents all species and the negative sign is associated with the countercurrent flow configuration employed here. Moreover, the flux $J_{i}$ through the membrane 
is assumed to be proportional to the $i$ component partial pressure difference across the membrane:

$$
J_{i}=Q_{i} \Delta P_{i}
$$

The reaction rate, $r_{w g s, C O}$, for the WGS reaction is given by:

$$
r_{w g s, C O}=k_{w g s}\left(P_{C O} P_{H_{2} O}-\frac{P_{\mathrm{CO}_{2}} P_{\mathrm{H}_{2} \mathrm{O}}}{k_{e q}}\right) \frac{m_{c a t}}{A_{t} L}
$$

in which

$$
\begin{aligned}
& k_{w g s}=82.2 \exp \left(-\frac{47400}{R T}\right) \\
& k_{e q}=\exp \left(\frac{4577.8}{T}-4.33\right)
\end{aligned}
$$

The obtained retentate and permeate streams proceed to the CCS and power generation units, respectively. More details on the WGS-MR portion model can be found in reference (Lima et al., 2012). A dynamic version of this model described by partial differential equations (PDEs) can be found in reference (Georgis et al., 2014). For the MR integration into the IGCC plant detailed below, we assume that the MR dynamics are negligible when compared to the dynamics of the rest of the IGCC plant for such integration.

Due to the presence of the WGS-MR unit, the GT can be fired with air instead of the enriched $\mathrm{O}_{2}$ stream in typical IGCC applications. The GT model is based on a lumped parameter model that considers a combustion zone followed by a turbine portion. The turbine is assumed to have constant isentropic efficiency and outlet temperature. The $\mathrm{O}_{2}$ enriched stream from the ASU and the cooled syngas are fed into the combustion zone. The resulting outlet stream enters the turbine portion to generate electric power. The HPST and LPST are modeled similarly to the GT turbine portion and are assumed to have constant efficiencies and outlet temperatures. Additional details and equations for these unit models can be found in references (Jillson et al., 2009; Lima et al., 2012; Lima et al.,2017). The resulting plant model is represented by a system of differential algebraic equations that are integrated using the appropriate subroutines in MATLAB. 
For the nominal operating point considered for control studies, the initial mass fractions in the combustion and gasification zones of the gasifier unit are shown in Table 5.1. The temperatures of the combustion zone and gasification zone are set to $2300 \mathrm{~K}$ and 1800 $\mathrm{K}$, respectively. The counter-current membrane reactor characteristics are presented in Table 5.2. The operating conditions for the IGCC-MR at the nominal point are shown in Table 5.3. The initial input flow rates and temperatures for the IGCC-MR simulation are given in Table 5.4 (Lima et al., 2016).

Table 5.1. Initial mass fractions in the gasifier

\begin{tabular}{|l|l|l|l|l|l|l|}
\hline & $\mathrm{CO}$ & $\mathrm{CO}_{2}$ & $\mathrm{H}_{2}$ & $\mathrm{H}_{2} \mathrm{O}$ & $\mathrm{CH}_{4}$ & $\mathrm{~N}_{2}$ \\
\hline Combustion zone & 0.26 & 0.62 & 0.01 & 0.10 & 0 & 0.01 \\
\hline Gasification zone & 0.43 & 0.46 & 0.03 & 0.05 & 0.02 & 0.01 \\
\hline
\end{tabular}

Table 5.2. Membrane reactor characteristics

\begin{tabular}{|l|l|}
\hline $\mathrm{H}_{2} / \mathrm{CO}_{2}$ selectivity & 1000 \\
\hline $\mathrm{H}_{2}$ permeance, $\mathrm{mol} /\left(\mathrm{s} \cdot \mathrm{m}^{2} \cdot\right.$ atm $)$ & 0.20 \\
\hline Membrane area used, $\mathrm{m}^{2}$ & 6800 \\
\hline
\end{tabular}

Table 5.3. IGCC-MR nominal conditions

\begin{tabular}{|l|l|}
\hline Gas turbine efficiency, \% & 89.8 \\
\hline Gas turbine exhaust temperature, K & 835 \\
\hline Steam turbine (HP and LP) efficiencies, \% & 70.0 \\
\hline Net power generation, MW & 700 \\
\hline
\end{tabular}


Table 5.3 (Continued). IGCC-MR nominal conditions

\begin{tabular}{|l|l|}
\hline Plant efficiency (HHV), \% & 37.9 \\
\hline Hydrogen purity in the permeate & 0.593 \\
\hline Temperature of cooled syngas stream, K & 665 \\
\hline Temperature of cooled permeate stream, K & 490 \\
\hline
\end{tabular}

Table 5.4. Initial IGCC-MR simulation conditions

\begin{tabular}{|l|l|l|l|l|l|l|l|}
\hline Stream & $\begin{array}{l}\text { Slurry in } \\
\text { combustion } \\
\text { zone }\end{array}$ & $\begin{array}{l}\text { Slurry in } \\
\text { gasification } \\
\text { zone }\end{array}$ & $\begin{array}{l}\mathrm{O}_{2} \\
\text { rich }\end{array}$ & $\begin{array}{l}\mathrm{GT} \\
\text { air }\end{array}$ & Sweep & $\begin{array}{l}\text { Syngas } \\
\text { cooler }\end{array}$ & $\begin{array}{l}\text { Exhaust } \\
\text { cooler }\end{array}$ \\
\hline $\begin{array}{l}\text { Flowrate, } \\
\mathrm{kg} / \mathrm{s}\end{array}$ & 63.11 & 17.80 & 40.85 & 391.3 & 28.30 & 43.18 & 24.44 \\
\hline $\begin{array}{l}\text { Temperature, } \\
\mathrm{K}\end{array}$ & 400 & 400 & 300 & 288 & 633 & 298 & 298 \\
\hline
\end{tabular}

\subsection{MEA-based Carbon Capture Process}

The MEA-based carbon capture process addressed here is part of an SCPC power plant. Two different carbon capture configurations are considered: the conventional configuration and a lean vapor compression (LVC) configuration.

\subsubsection{Conventional Carbon Capture Process}

The conventional MEA post-combustion $\mathrm{CO}_{2}$ capture system is shown in Figure 5.3 (Zhang et al., 2016). Flue gas blowers are used to provide the motive force to move the $\mathrm{CO}_{2}$ through the parallel absorption units. Flue gas first passes through a direct contact cooler (DCC) to lower the temperature of the gas feed using circulating water. Flue gas then passes counter-currently with the $30 \mathrm{wt} \%$ MEA solution in the absorber where the $\mathrm{CO}_{2}$ reacts with MEA. The cleaned flue gas then enters the MEA washing section to minimize solvent loss by recovering MEA, which is recycled back to the absorber and the MEA washing section. At the bottom of the absorber, the rich solvent is pumped into 
the top of the stripper via a heat exchanger in which the rich solvent is preheated to a temperature close to the stripper operating temperature and the lean solvent is subsequently cooled. $\mathrm{CO}_{2}$ and $\mathrm{MEA}$ are recovered within the stripper at an elevated temperature and pressure. The energy penalty for $\mathrm{CO}_{2}$ removal is significant because thermal energy must be provided to regenerate the solvent in the stripper reboiler. This thermal energy is supplied by the extracted, low-pressure steam. The overhead stream from the stripper contains mainly water and $\mathrm{CO}_{2}$. High purity $\mathrm{CO}_{2}$ may be stored or used for other purposes and may be pressurized (in 6 stages of inter-cooling and compression) and dehydrated to a suitable pressure and moisture content for transportation in a pipeline and subsequent sequestration. Lean solvent from the bottom of the stripper is pumped back to the absorber via the rich/lean solvent heat exchanger and a cooler. Lean solvent finally enters the absorber at a temperature close to the absorber operating condition. Both the absorber and stripper are packed bed columns, which are used due to their higher contact area and lower pressure drop compared to tray columns. From the simulation results for a $550 \mathrm{MWe}$ supercritical pulverized coalfired power plant with $\mathrm{CO}_{2}$ capture, a total of $564 \mathrm{~m}^{3} / \mathrm{s}$ of flue gas with a $\mathrm{CO}_{2}$ mole fraction of $13.53 \%$ at around 1 atm and $57^{\circ} \mathrm{C}$ needs to be treated. By equally splitting the overall flue gas into six streams/trains, each absorber has a design capacity of 94 $\mathrm{m}^{3} / \mathrm{s}$ of flue gas. 


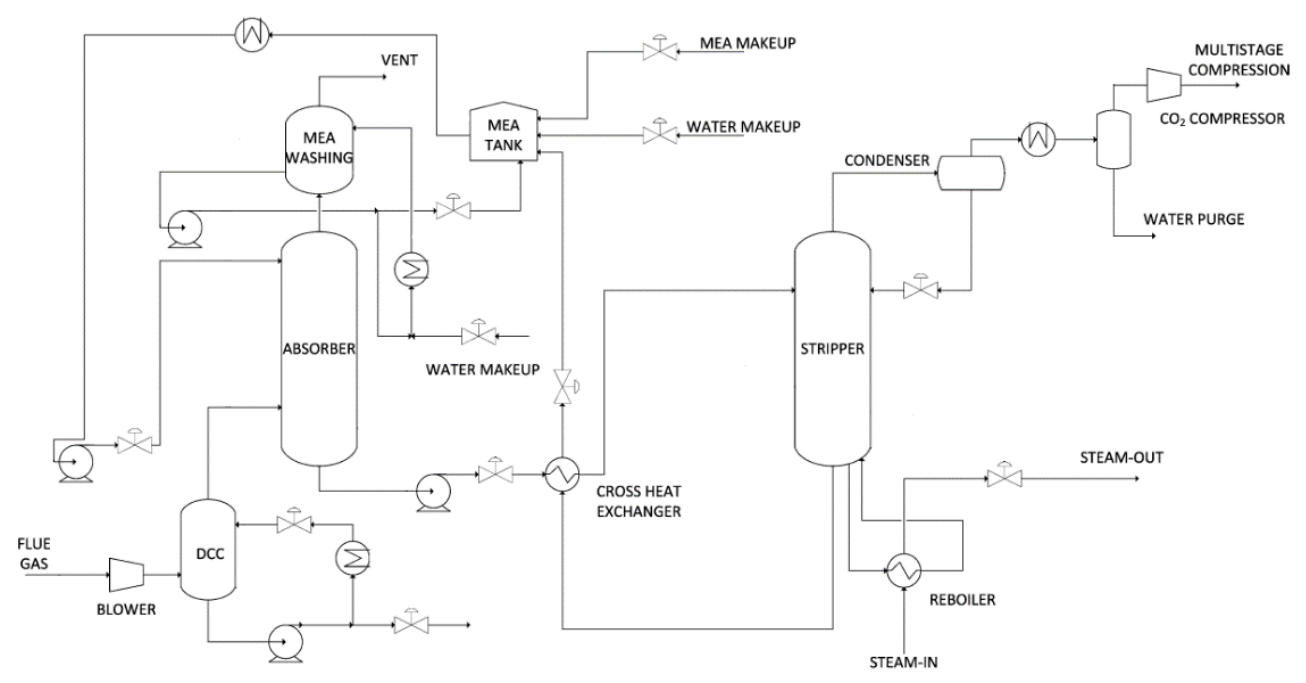

Figure 5.3. Simplified flowsheet of the conventional $\mathrm{CO}_{2}$ capture system (adapted from Zhang et al., 2016)

\subsubsection{LVC Carbon Capture Process}

The advanced LVC configuration is shown in Figure 5.4. The main difference between the LVC and the conventional configuration is that the lean solvent from the bottom of the stripper is flashed, and the resulting vapor is compressed and returned to the stripper. This modified arrangement allows for partially recovering the sensible heat of the hot lean stream in the form of latent heat, and it is anticipated to reduce energy demand without greatly increasing process complexity.

It is assumed that the LVC is retrofitted to a standard MEA plant without any modifications in the existing equipment. In this scenario, the reboiler duty decreases due to the extra stripping vapor coming from the LVC flash vessel, while additional electricity is needed to drive the LVC compressor. An energy analysis is performed in terms of an equivalent work calculation. The total equivalent work for each simulation is calculated as in Equation (5.1):

$$
W_{e q}=\alpha Q_{r e b}+W_{\text {pump }}+W_{\text {comp }}
$$

in which, $Q_{\text {reb }}$ is the estimated reboiler duty, $W_{\text {pump }}$ is the estimated work for pumps and $W_{\text {comp }}$ is the estimated work for the LVC compressor. The term $\alpha$ accounts for the loss 
of turbine power due to steam extraction for the reboiler. This factor depends on the steam quality. Since steam quality is assumed unchanged in this analysis, a constant value for $\alpha$ of 0.23 has been assumed based on literature values (Fernandez et al., 2012). For the calculation of pump work, a pump efficiency of $85 \%$ has been used (including mechanical efficiency). For the compressor, an efficiency of $77 \%$ has been used. For the reference case, $94 \mathrm{~m}^{3} / \mathrm{s}$ of flue gas containing $13.53 \mathrm{~mol}_{\mathrm{CO}} \mathrm{CO}_{2}$ is processed with $90 \% \mathrm{CO}_{2}$ capture in the standard MEA plant (Zhang et al., 2016). This stream corresponds to one of the six split streams of the flue gas generated by a 550 MWe supercritical coal-fired power plant.

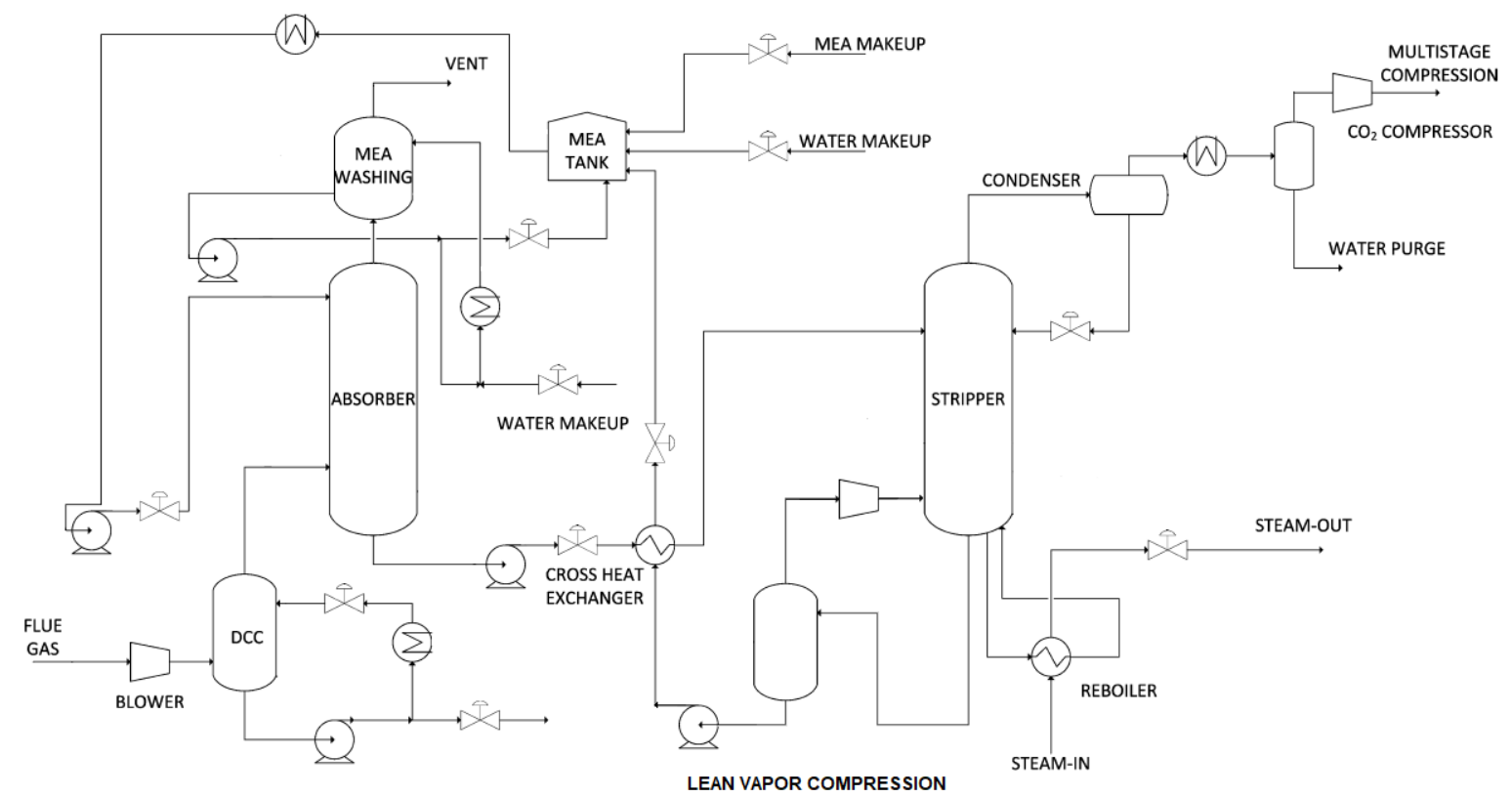

Figure 5.4 Simplified flowsheet of LVC $\mathrm{CO}_{2}$ capture system (adapted from Karimi et al., 2012)

Several simulations are conducted initially with varying LVC flash pressures for sensitivity analysis of the process. Table 5.5 shows a summary of the equipment duties when considering different flash pressures for the LVC. Specifically, the reboiler duty decreases with decreasing flash pressures, while the pump and compressor work increase. Based on the sensitivity analysis of the flash pressure and equivalent work, 
the optimal pressure in the flash vessel is selected as 1.3 bar for the control studies below.

Table 5.5. Equipment duties and equivalent work for LVC (bold represents the optimal)

\begin{tabular}{|l|l|l|l|l|}
\hline $\begin{array}{l}\text { Flash Pressure } \\
(\text { bar })\end{array}$ & $\begin{array}{l}\text { Reboiler(M } \\
\text { Wth) }\end{array}$ & $\begin{array}{l}\text { Pump } \\
(\mathrm{KWe})\end{array}$ & $\begin{array}{l}\text { Compressor(M } \\
\text { We })\end{array}$ & $\begin{array}{l}\text { Equivalent Work } \\
(\mathrm{MWe})\end{array}$ \\
\hline 2.1 & 61.61 & 0 & 0 & 14.17 \\
\hline 1.7 & 60.69 & 10.92 & 0.06 & 14.03 \\
\hline 1.6 & 60.12 & 13.63 & 0.12 & 13.96 \\
\hline 1.5 & 59.42 & 16.33 & 0.21 & 13.89 \\
\hline 1.4 & 58.68 & 19.02 & 0.33 & 13.85 \\
\hline 1.3 & 57.86 & 21.69 & $\mathbf{0 . 5 0}$ & 13.83 \\
\hline 1.2 & 56.98 & 24.36 & 0.71 & 13.84 \\
\hline 1.1 & 56.02 & 27.01 & 0.98 & 13.89 \\
\hline 1.0 & 54.86 & 29.66 & 1.34 & 13.99 \\
\hline
\end{tabular}

\subsection{Entire SCPC-MEA Process}

The entire SCPC-MEA process is the combination of a $550 \mathrm{MWe}$ supercritical pulverized coal-fired (SCPC) power plant and the associated conventional MEA postcombustion $\mathrm{CO}_{2}$ capture subsystem introduced above. The simplified flowsheet of the SCPC-MEA process is shown in Figure 5.5.

In the SCPC plant, the pulverized coal boiler consists of a coal burner, air preheater, superheater, reheater, and economizer. The boiler is operated at a slightly negative pressure so that there is no air leakage from the boiler. Flue gas exits the boiler at $169^{\circ} \mathrm{C}$ and passes through the fabric filter (baghouse) for ash removal. An induced draft fan (ID-fan) provides the motive force for the flue gas to pass through a flue gas 
desulfurization (FGD) unit and the flue gas temperature is increased to $181^{\circ} \mathrm{C}$ after the ID-fan. The FGD unit is used to remove $\mathrm{SO}_{2}$ as it can react with MEA and reduce the solvent loading capacity.

In the steam cycle, superheated steam $\left(24.1 \mathrm{MPa}\right.$ and $\left.593^{\circ} \mathrm{C}\right)$ passes through high-, intermediate-, and low-pressure steam turbines arranged sequentially to produce electricity. The steam from the outlet of the high-pressure turbines is reheated to $593^{\circ} \mathrm{C}$. The boiler feed water is heated by several heat exchangers in series by using steam at appropriate temperatures before returning to the boiler. A portion of the steam (at 0.51 $\mathrm{MPa}$ and $290^{\circ} \mathrm{C}$ ) is extracted between the intermediate-pressure steam turbine outlets and the low-pressure steam turbine inlets to supply the thermal energy in the stripper reboiler for solvent regeneration. This extracted steam and the corresponding reduction in power production from the low-pressure steam turbines is the major cause of the energy penalty associated with carbon capture.

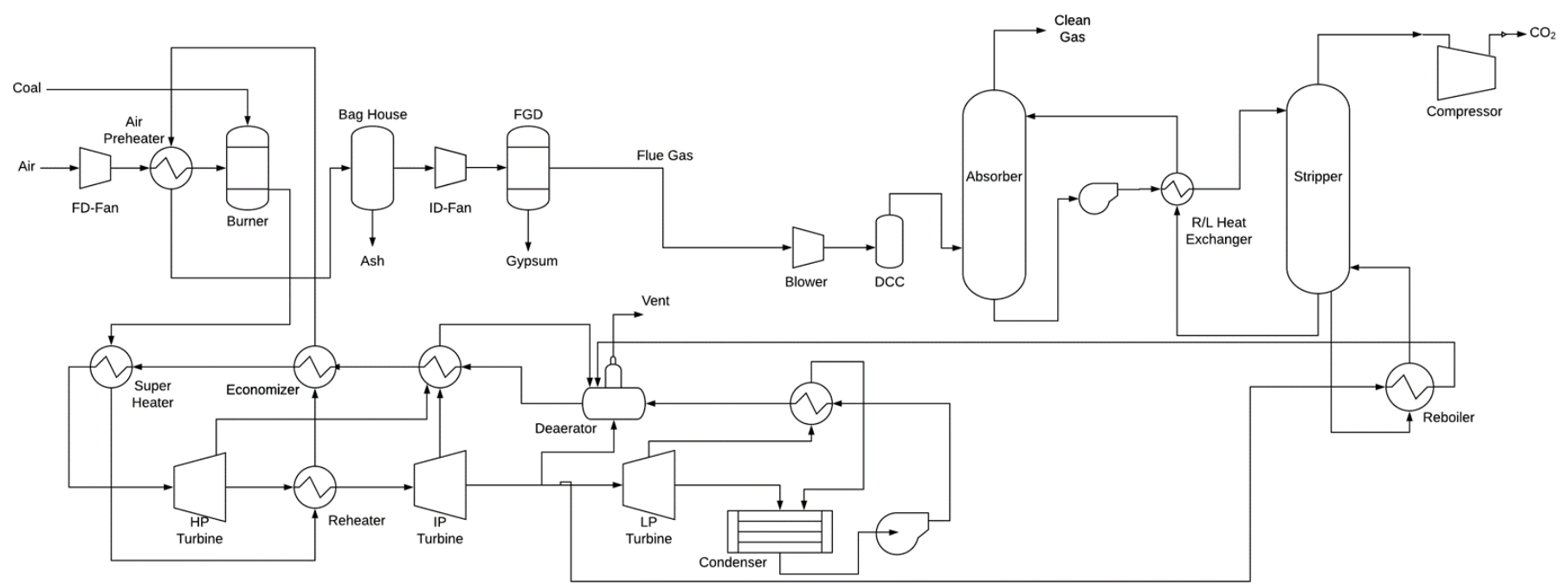

Figure 5.5. Simplified flowsheet of the SCPC-MEA process

For the nominal plant operating point, the compositions of the SCPC plant flue gas stream after the FGD unit are given in Table 5.6. The energy performance of the SCPC plant and the power losses of the carbon capture subsystem at the nominal point are presented in Tables 5.7 and 5.8, respectively. The column sizing and packing parameters are shown in Tables 5.9 and 5.10, respectively. 
Table 5.6. SCPC-MEA power plant flue gas molar composition

\begin{tabular}{|l|l|l|l|l|}
\hline $\mathrm{N}_{2}$ & $\mathrm{H}_{2} \mathrm{O}$ & $\mathrm{CO}_{2}$ & $\mathrm{O}_{2}$ & $\mathrm{Ar}$ \\
\hline 68.08 & 15.17 & 13.53 & 2.40 & 0.82 \\
\hline
\end{tabular}

Table 5.7. SCPC-MEA operating conditions at the nominal point

\begin{tabular}{|l|l|}
\hline Net power without carbon capture, MW & 550 \\
\hline Net plant efficiency without carbon capture (HHV) & $39.30 \%$ \\
\hline Flue gas temperature, K & 310 \\
\hline Lean solvent temperature, K & 308 \\
\hline Lean solvent loading, \% & 28.6 \\
\hline Absorber pressure, bar & 1 \\
\hline Stripper pressure, bar & 2.1 \\
\hline
\end{tabular}

Table 5.8. SCPC-MEA carbon capture power losses at the nominal point

\begin{tabular}{|l|l|}
\hline Flue gas blower, kW & 3,237 \\
\hline $\mathrm{CO}_{2}$ compressor, kW & 33,344 \\
\hline Rich solvent pump, kW & 178 \\
\hline Power loss on reboiler, kW & 92,280 \\
\hline Net power with carbon capture, kW & 420,941 \\
\hline Net plant efficiency with carbon capture (HHV) & $30.08 \%$ \\
\hline Efficiency penalty due to carbon capture & $9.22 \%$ \\
\hline Heat duty per ton of $\mathrm{CO}_{2}$ recovered, GJ/ton & 3.05 \\
\hline
\end{tabular}


Table 5.9. Column sizing parameters

\begin{tabular}{|l|l|}
\hline Absorber height, $m$ & 24.0 \\
\hline Absorber diameter, $\mathrm{m}$ & 5.8 \\
\hline Stripper height, $\mathrm{m}$ & 24.0 \\
\hline Stripper diameter, $\mathrm{m}$ & 5.4 \\
\hline MEA washing column height, $\mathrm{m}$ & 2.4 \\
\hline MEA washing column diameter, $\mathrm{m}$ & 5.8 \\
\hline
\end{tabular}

Table 5.10. Column packing parameters (IMTP 40)

\begin{tabular}{|l|l|}
\hline Surface area $\left(\mathrm{m}^{2} / \mathrm{m}^{3}\right)$ & 151 \\
\hline Void fraction & 0.98 \\
\hline Nominal diameter, $\mathrm{m}$ & 0.038 \\
\hline Hydraulic diameter, $\mathrm{m}$ & 0.026 \\
\hline
\end{tabular}




\section{MPC Applications to Power Plant Cycling}

In this chapter, the results of the case studies associated with the implementation of the MPC strategies on the IGCC-MR, MEA-based carbon capture and SCPC-MEA systems are presented. All states are assumed to be measured for the MPC implementations. Also, all the simulations were carried out on an Intel Xeon E5 3.5 GHz processor.

\subsection{MPC Application to IGCC-MR System}

For the IGCC-MR system, the simplified systems-level first-principles nonlinear model is built in MATLAB (v. 2015b), as described in Chapter 5. The following 7 controlled variables (CVs) are considered in this application: carbon capture rate, power generation, process efficiency, temperature of cooled syngas stream, temperature of cooled permeate stream, steam to CO ratio at WGS-MR inlet and hydrogen purity in the permeate stream. Also, 7 input variables considered as MVs are the following flow rates: water for syngas and permeate cooling, steam injection to syngas to facilitate the WGS reaction, total coal/water slurry and oxygen enriched air to feed the gasifier, sweep gas for the WGS-MR and air to feed the GT. The main objective is to control the power generation according to the specified demands. The IGCC flowsheet stream constraints associated with the MR temperatures and purities are defined as (Lima et al., 2013):

- Temperature of the cooled syngas after steam injection: $473 \mathrm{~K} \leq T_{c, s y n} \leq 673 \mathrm{~K}$

- Steam to CO ratio at the WGS-MR inlet: $y_{\mathrm{H}_{2} \mathrm{O} / \mathrm{CO}} \geq 1.2$

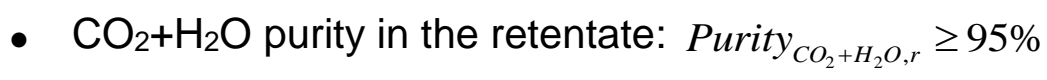

- $\mathrm{H}_{2}$ molar fraction in the retentate: $y_{H_{2}, r} \leq 4 \%$

- $\mathrm{H}_{2}$ purity in the permeate: Purity $_{\mathrm{H}_{2}, p} \geq 44 \%$

For the control studies, the sample time is set to be 15 seconds for the first two scenarios, and 2 minutes for the third scenario based on the available data samples. The prediction horizon and the control horizon are set to be 15 and 10 time steps, respectively. The control horizon is selected to be smaller than the prediction horizon for faster computations and controller internal stability associated with this application. 
The first IGCC-MR scenario (Case 1) considers the setpoint tracking of power generation by simulating a step increase in power demand from the nominal point (steady state of $700 \mathrm{MW}$ ). In particular, a step increase is imposed on the setpoint to $800 \mathrm{MW}$ at time $=60 \mathrm{~s}$. The closed-loop responses obtained for power generation (CV), as well as the slurry and GT air feed (MVs) control moves corresponding to the implementation of the four developed MPC strategies and a classical PID (for comparison purposes) are shown in Figures 6.1, 6.2 and 6.3, respectively. The PID parameters are tuned based on the classical Ziegler- Nichols method: proportional gain $K_{p}=0.26 K_{u}$, integral time $T_{i}=0.5 T_{u}$, and derivative time $T_{d}=0.125 T_{u}$ (in which $K_{u}$ is the ultimate gain and $T_{u}$ is the oscillation period). For example, the $K_{u}$ and $T_{u}$ for the GT air feed flow rate are 0.14 and 27.6, respectively. Note that both the slurry and GT air feed flows are increased for higher power generation. The implementation of the nonlinear MPC approaches can quickly process the demand change in less than 6 time steps. However, the DMC and PID controllers both have sluggish performances with some overshooting. The settling times to process the power demand change requested for the nonlinear MPC approaches are: classical SQP-based MPC (90 seconds), direct transcription-based MPC (60 seconds), and modified SQP-based MPC (90 seconds), which are shorter than DMC (150 seconds) and PID (255 seconds). 


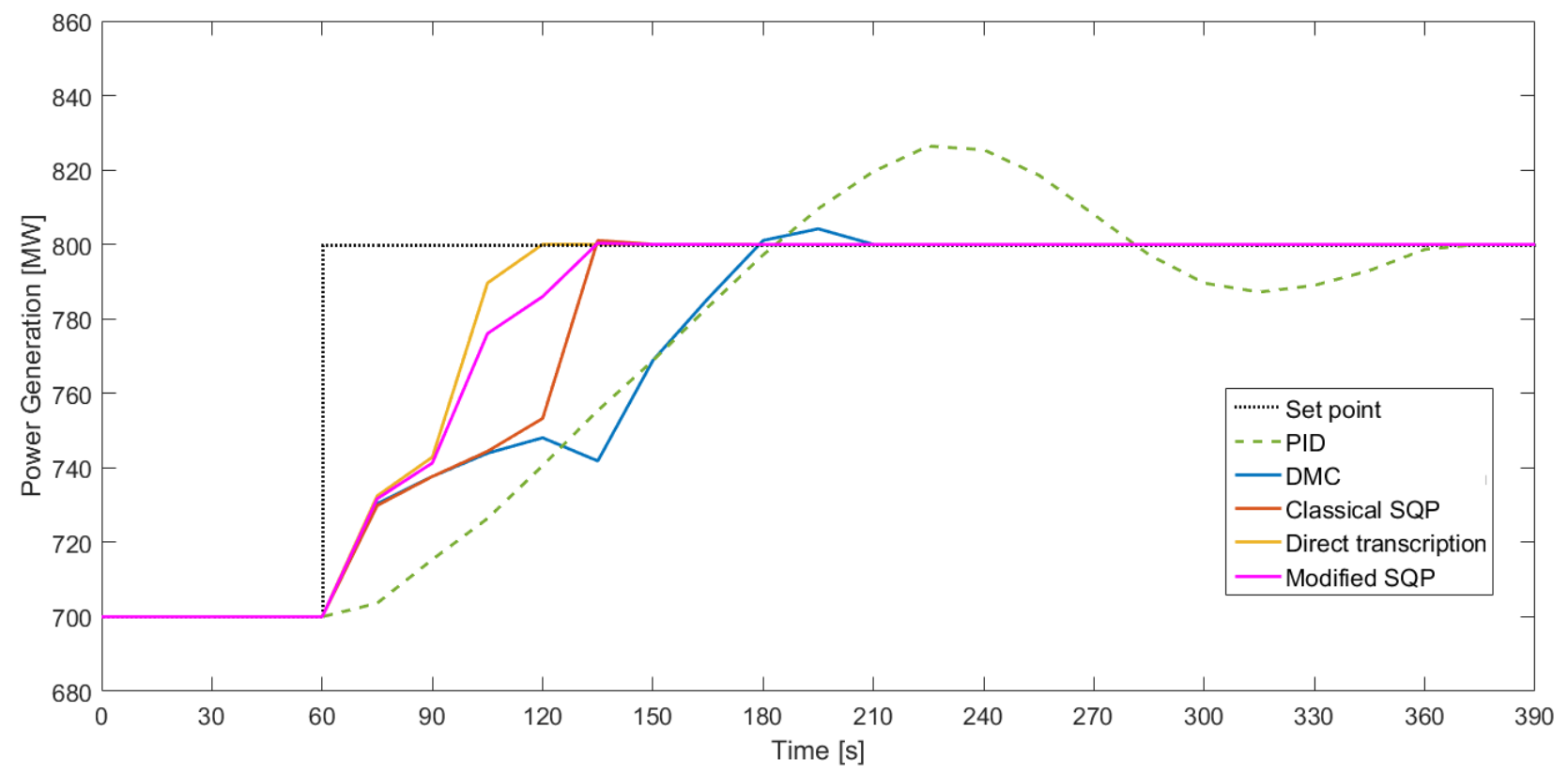

Figure 6.1. IGCC-MR Case 1: closed-loop responses for power generation (CV)

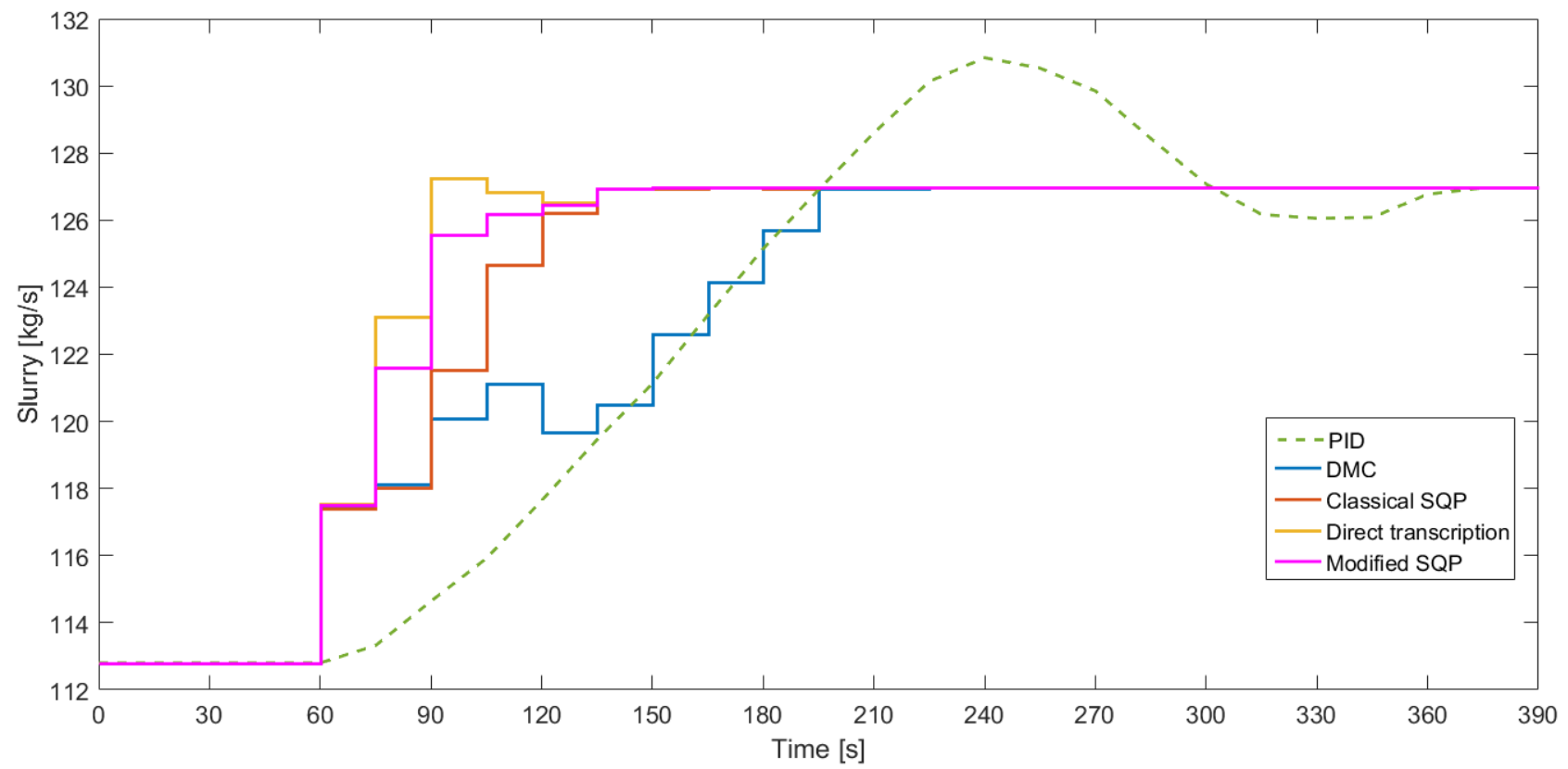

Figure 6.2. IGCC-MR Case 1: closed-loop responses for slurry flow (MV) 


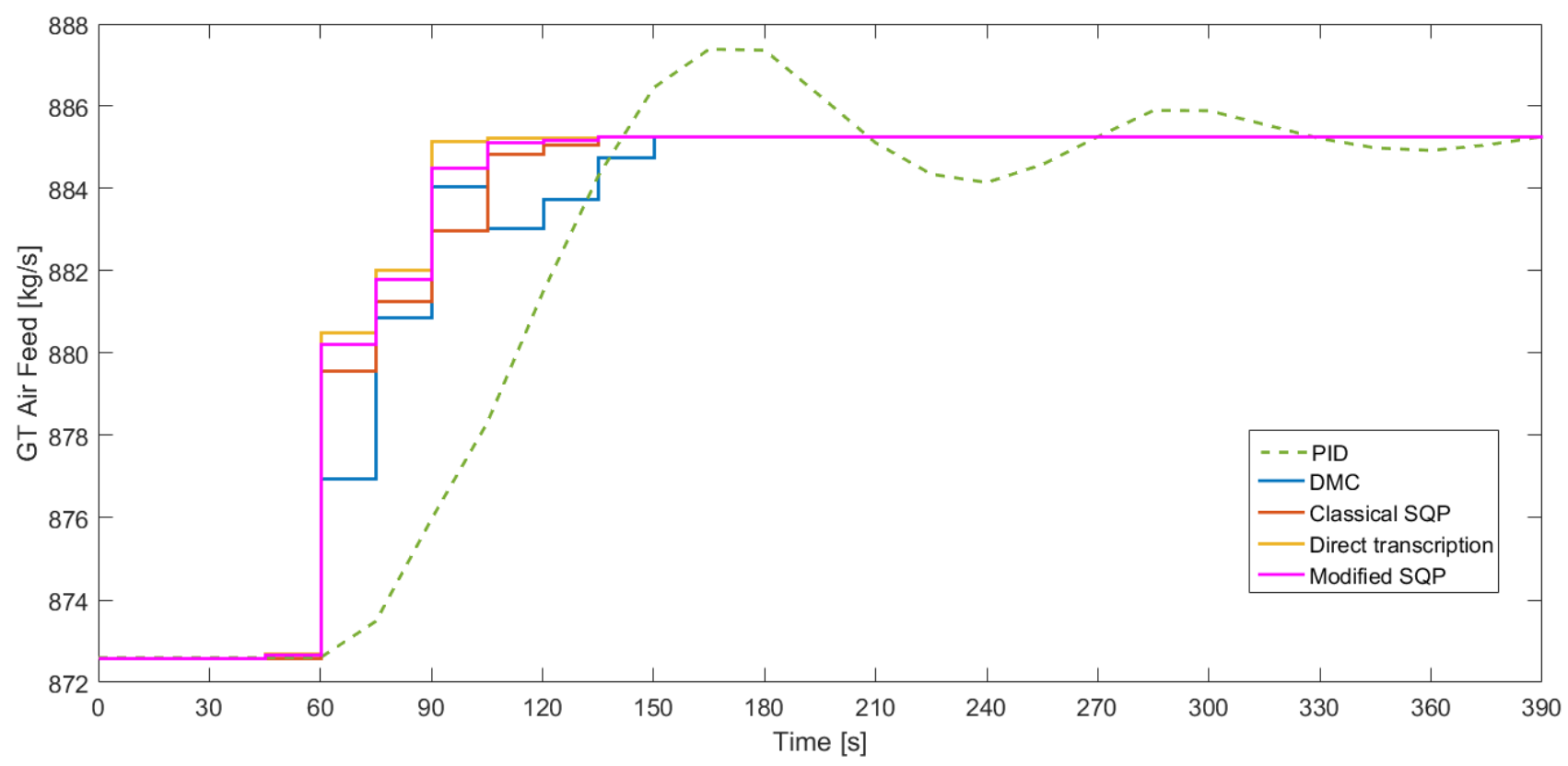

Figure 6.3. IGCC-MR Case 1: closed-loop responses for GT air feed flow (MV)

The second IGCC-MR scenario (Case 2) considers rejecting the disturbance in the coal feed quality coming from an upstream process. In particular, the carbon content in the $\mathrm{coal} / \mathrm{slurry}$ is reduced by $15 \%$ at time $=30 \mathrm{~s}$. Figure 6.4 shows the closed-loop responses for power generation in this scenario for the implemented controllers. Here once again, the nonlinear MPC approaches can quickly bring the power generation back to its original setpoint after the disturbance in less than 5 time steps. The settling times for the nonlinear MPC approaches are: classical SQP-based MPC (75 seconds), direct transcription-based MPC (60 seconds), and modified SQP-based MPC (75 seconds), which are shorter than the DMC (135 seconds) and PID (285 seconds). Extensive PID tuning adjustments had been attempted without significant controller performance improvements. Figures 6.5 and 6.6 show the slurry and steam injection flow (MVs) responses. Note that the controllers increase the slurry flow steady-state value due to the reduction in carbon content. Also, the steam injection flow is decreased due to the higher water ratio in the slurry feed. 


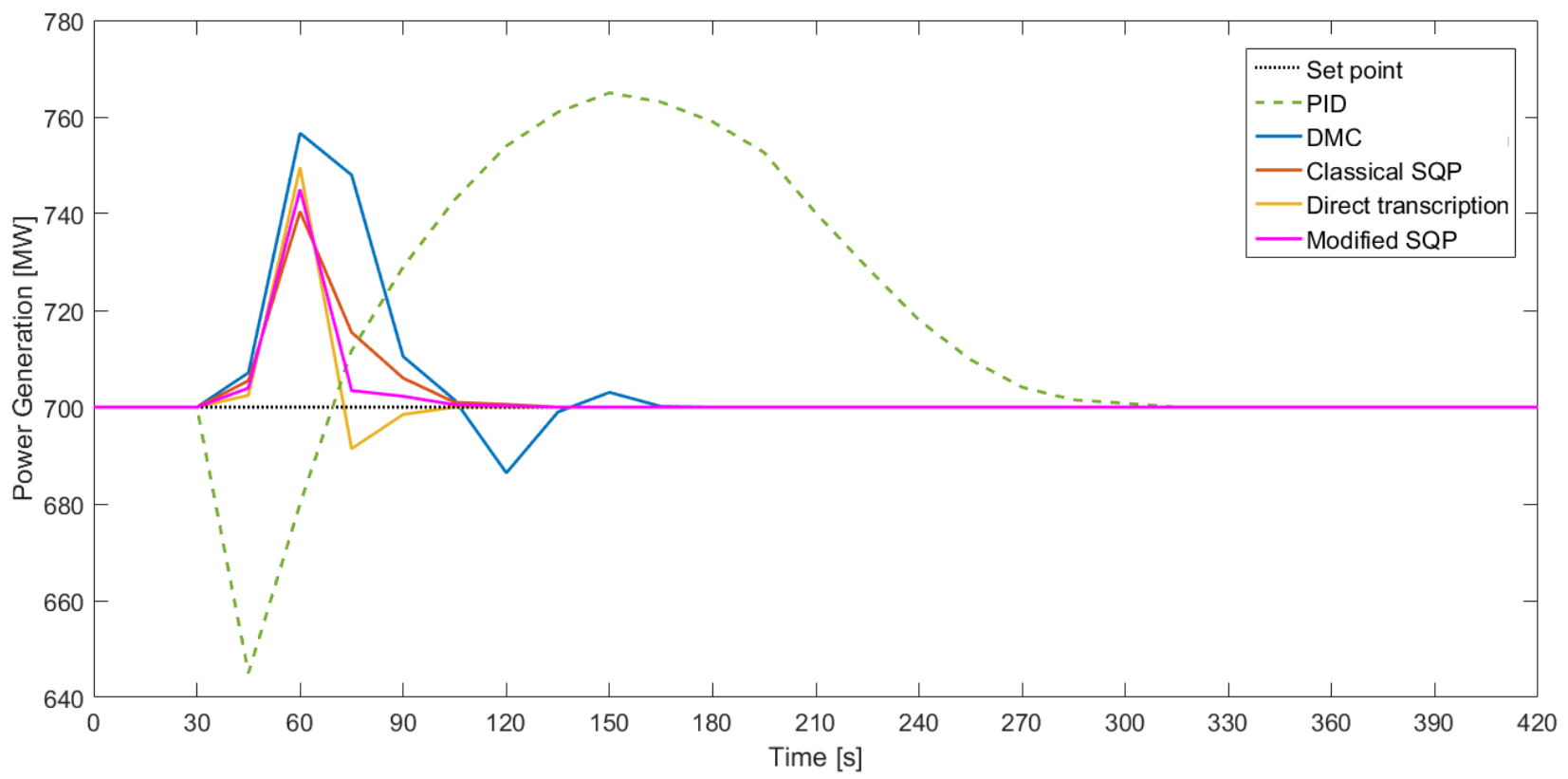

Figure 6.4. IGCC-MR Case 2: closed-loop responses for power generation (CV)

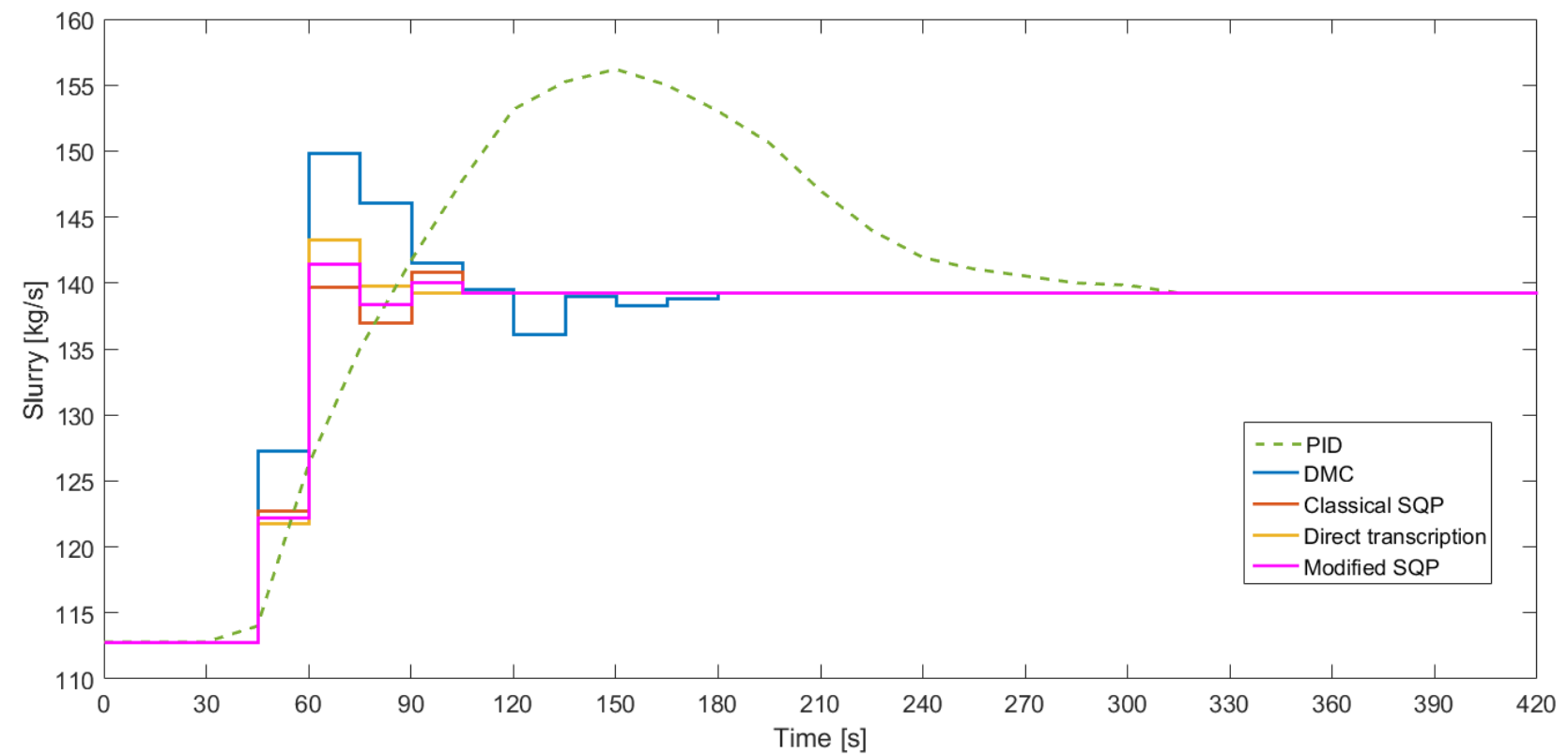

Figure 6.5. IGCC-MR Case 2: closed-loop responses for slurry flow (MV) 


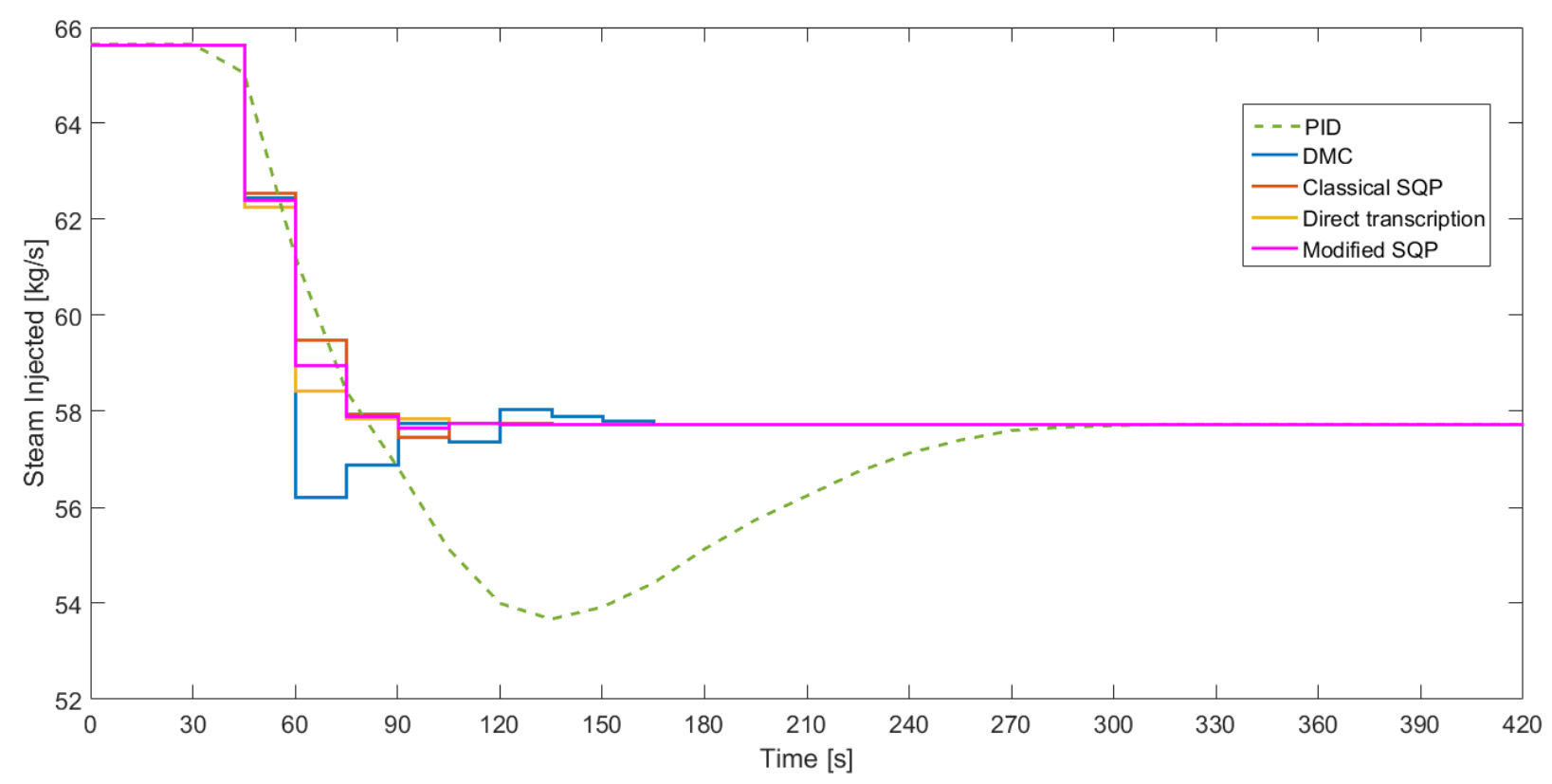

Figure 6.6. IGCC-MR Case 2: closed-loop responses for steam injection flow (MV)

Now that both setpoint tracking and disturbance rejection scenarios have been addressed, the third IGCC-MR scenario (Case 3) considers tracking the power generation cycling trajectory for the IGCC-MR system, simulating the penetration of renewable energy sources into the power grid. As shown in Figure 6.7, the cycling trajectory for the IGCC plant is calculated by deducting the wind power generation amount from the power grid demand. Specifically, the total grid power demand considered is based on the Duke Ohio/Kentucky hourly meter load data between $5 \mathrm{pm}$ and 10 pm on May $7^{\text {th }}, 2016$ (PJM markets \& operations, 2016). Such total demand is divided by 6 to match the nominal power generation of the IGCC-MR system (700MW). Also, the wind power generation trajectory is based on historical real-time data for the same period of time (Sotavento wind farm, 2016). As the sample time from the obtained load data is 6 minutes, the desired cycling trajectory is represented as a third-order polynomial by assuming a 2 minute discretization time, which means the power generation setpoint is changed every 2 minutes. 


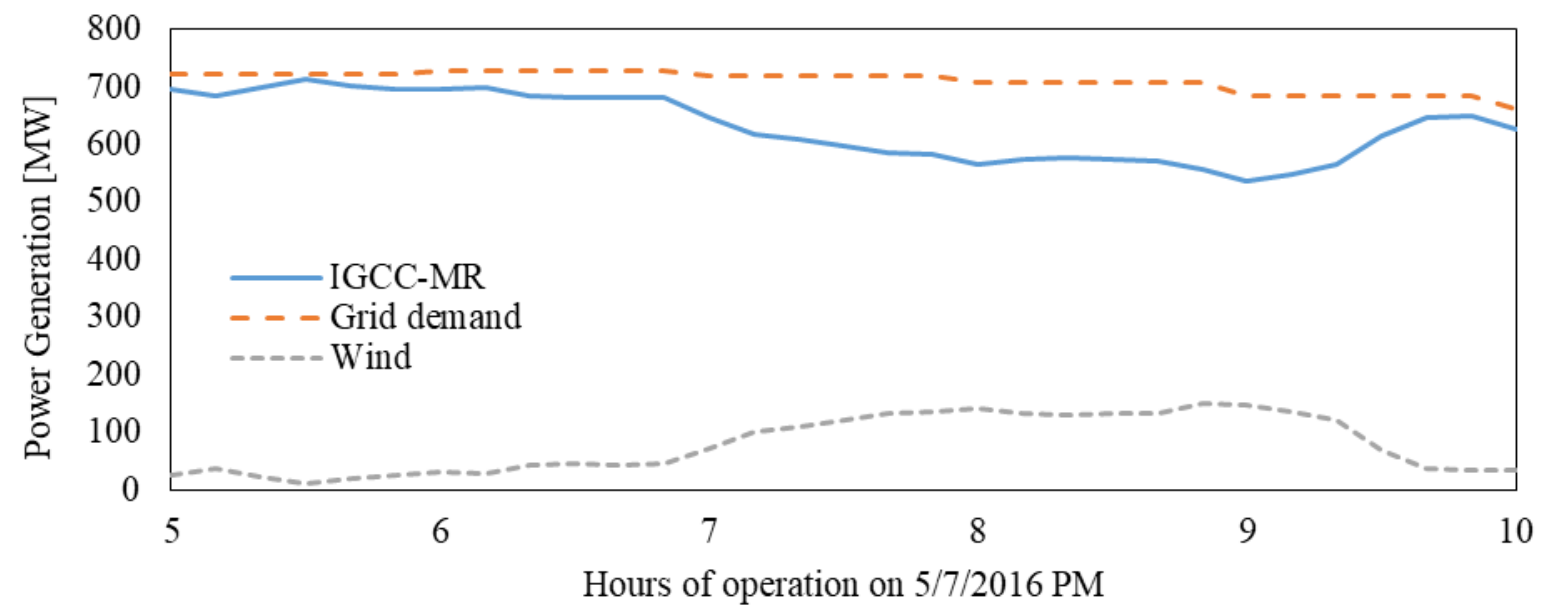

Figure 6.7. IGCC-MR Case 3: IGCC-MR power generation cycling trajectory The results of the MPC applications are shown in Figure 6.8. The implementations of all four MPC algorithms for this trajectory tracking scenario are successful, as all the controllers can follow the power generation cycling profile effectively. Note that the DMC algorithm presents an oscillatory performance with some overshooting (see zoomed version of Figure 6.8). The reason for such performance can be justified by the fact that during cycling, the plant is operating away from the point where the linearized system model for the DMC has been identified. On the other hand, all the nonlinear MPC approaches can follow the desired profile successfully with slightly better tracking performance for the direct transcription-based MPC. The integral squared error (ISE) analysis results for the three different MPC controllers and the PID implemented for Cases 1, 2 and 3 are summarized in Table 6.1. All the three MPC controllers have better performances in terms of ISE when compared to PID and the nonlinear MPC approaches show up to $87.9 \%$ improvement when compared to its linear MPC counterpart (DMC). 

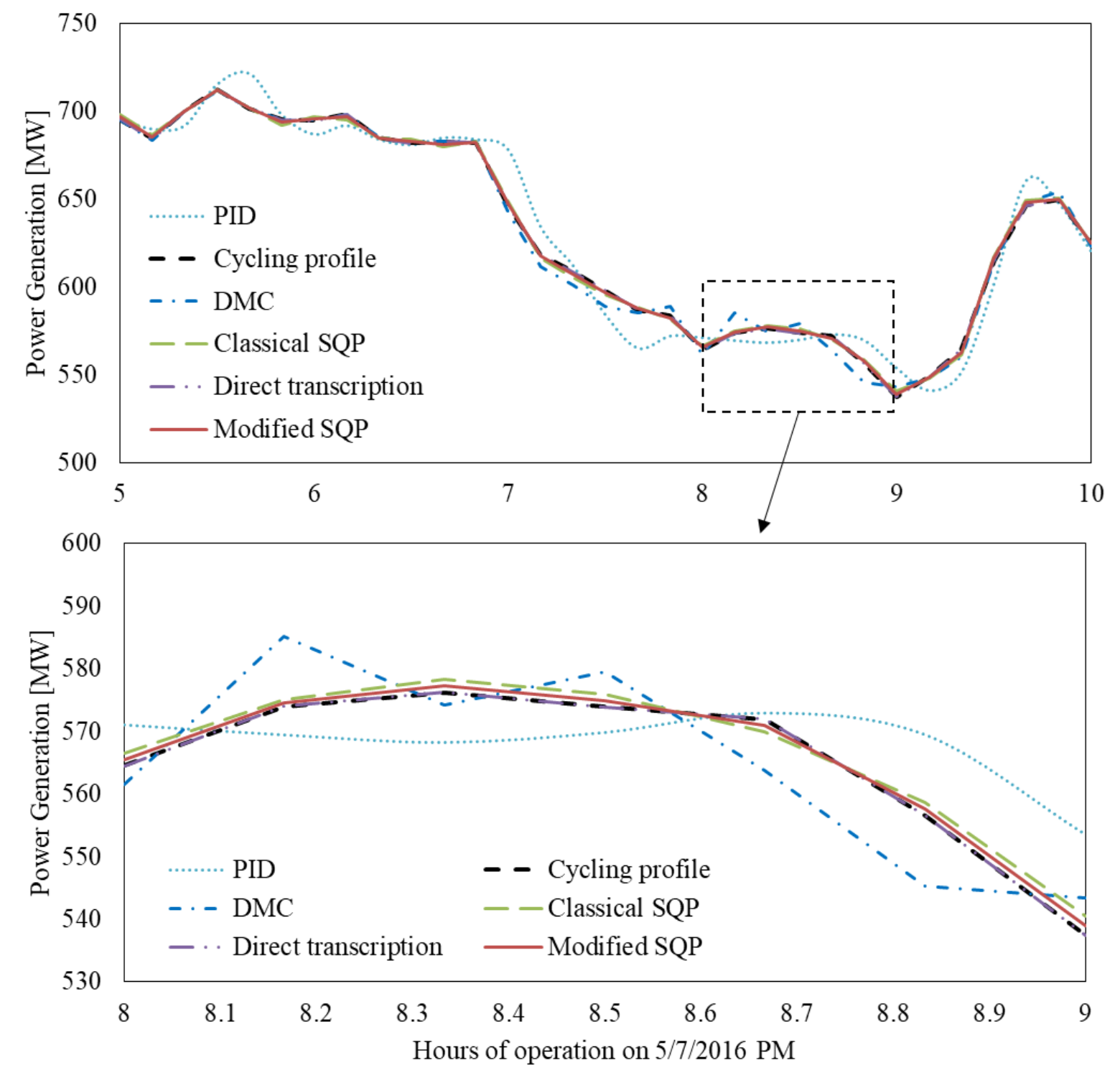

Figure 6.8. IGCC-MR Case 3: closed-loop responses for power generation (CV) The optimizer computational times to solve a single MPC dynamic optimization problem (on average) for the IGCC-MR system were 1.5 CPU seconds for DMC, $13 \mathrm{CPU}$ seconds for proposed modified SQP-based MPC, 16 CPU seconds for classical SQPbased MPC and 18 CPU seconds for direct transcription-based MPC. 
Table 6.1. ISE analysis results for IGCC-MR system

\begin{tabular}{|l|l|l|l|l|l|}
\hline & PID & DMC & Classical SQP & Direct transcription & Modified SQP \\
\hline Case 1 & 0.2365 & 0.1321 & 0.0832 & 0.0513 & 0.0672 \\
\hline Case 2 & 0.3124 & 0.0879 & 0.0508 & 0.0297 & 0.0451 \\
\hline Case 3 & 11.67 & 0.5411 & 0.0872 & 0.0655 & 0.0767 \\
\hline
\end{tabular}

6.2. MPC Application to MEA-based Carbon Capture System

For the MPC application to the MEA-based carbon capture system, the control structure selected for the control studies consists of: flow rates of the flue gas, lean solvent and steam for the reboiler as the input variables, with $\mathrm{CO}_{2}$ capture rate and power consumption as the output variables. Specifically, the power consumption is defined as the sum of power losses from the flue gas blower, $\mathrm{CO}_{2}$ compressor, rich solvent pump and reboiler. The flue gas flow rate, which changes depending on the power plant cycling, is considered as a disturbance variable in this study.

The main control objective is to maintain the carbon capture rate at $90 \%$ while satisfying constraints for the input variables as follows:

$$
\begin{gathered}
2 \leq F_{\text {solvent }}(\mathrm{kmol} / \mathrm{s}) \leq 15 \\
3 \leq F_{\text {steam }}\left(\mathrm{m}^{3} / \mathrm{s}\right) \leq 30
\end{gathered}
$$

in which $F_{\text {solvent }}$ is the flow rate of lean solvent, and $F_{\text {steam }}$ is the flow rate of the reboiler heat steam.

The sampling interval in the Aspen Plus Dynamics models is set to be $0.001 \mathrm{~h}$ to ensure the convergence of the complex ionic, reactive absorption and desorption system. The prediction and control horizons of MPC are set to $0.025 \mathrm{~h}$ and $0.015 \mathrm{~h}$, respectively.

The first scenario (Case 1) considers the conventional $\mathrm{CO}_{2}$ capture configuration, as shown in Figure 5.3. The power plant is simulated in a load-following scenario, in which the power generation is ramped down assuming a $25 \%$ ramp decrease in the flue gas flow rate during the first $0.25 \mathrm{~h}$. The power consumption for this $\mathrm{CO}_{2}$ capture 
configurations is then calculated based on the simulation conditions. The carbon capture rate closed-loop responses for the conventional $\mathrm{CO}_{2}$ capture configuration associated with MPC and PID implementations are shown in Figure 6.9. All the PID and MPC controllers can successfully reject the disturbance in the flue gas flow rate. The nonlinear MPC approaches have similar and improved performance when compared to the linear controllers. The settling times for the nonlinear MPCs are about $1.25 \mathrm{~h}$, which is shorter than the DMC (1.6 h) and PID (2.9 h). As depicted in Table 6.2, the integral square error (ISE) analysis results for nonlinear MPC approaches are also better than the results for DMC and PID. In particular, the proposed modified SQP shows an improvement of approximately $95 \%$ in terms of ISE reduction when compared to the PID controller performance.

Figures 6.10 and 6.11 show the relevant closed-loop control moves for the lean solvent flow rate and reboiler heat flow rate inputs associated with all controllers. The PID controller inputs shows a large overshoot for lean solvent flow rate and sluggish actions for the reboiler steam. The nonlinear MPC controllers reduce the delay and overshoot performance, when compared to the PID and also DMC. 


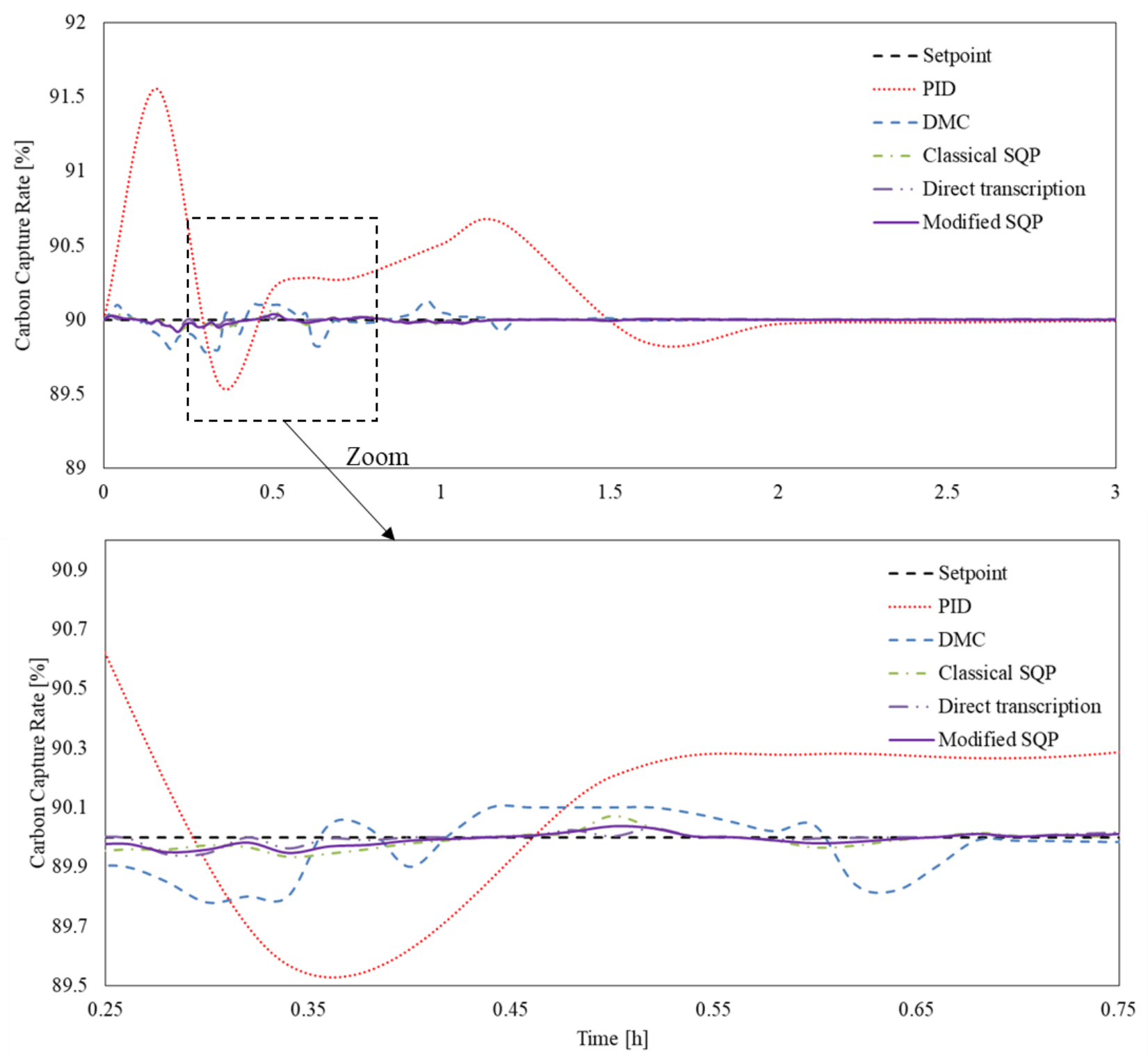

Figure 6.9. Carbon capture system Case 1: closed-loop responses for carbon capture rate (output) 

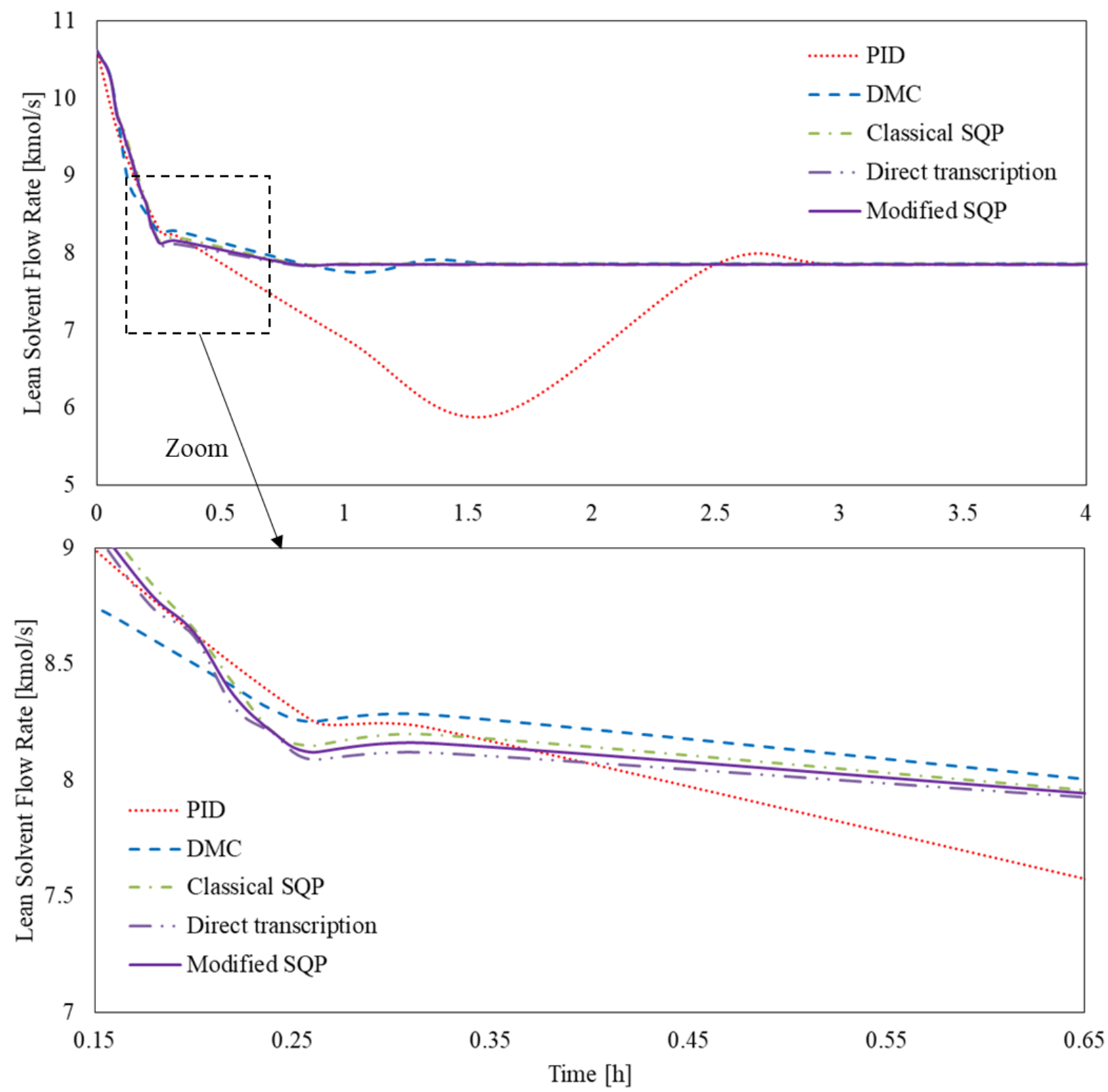

Figure 6.10. Carbon capture system Case 1: closed-loop results for lean solvent flow rate (input) 

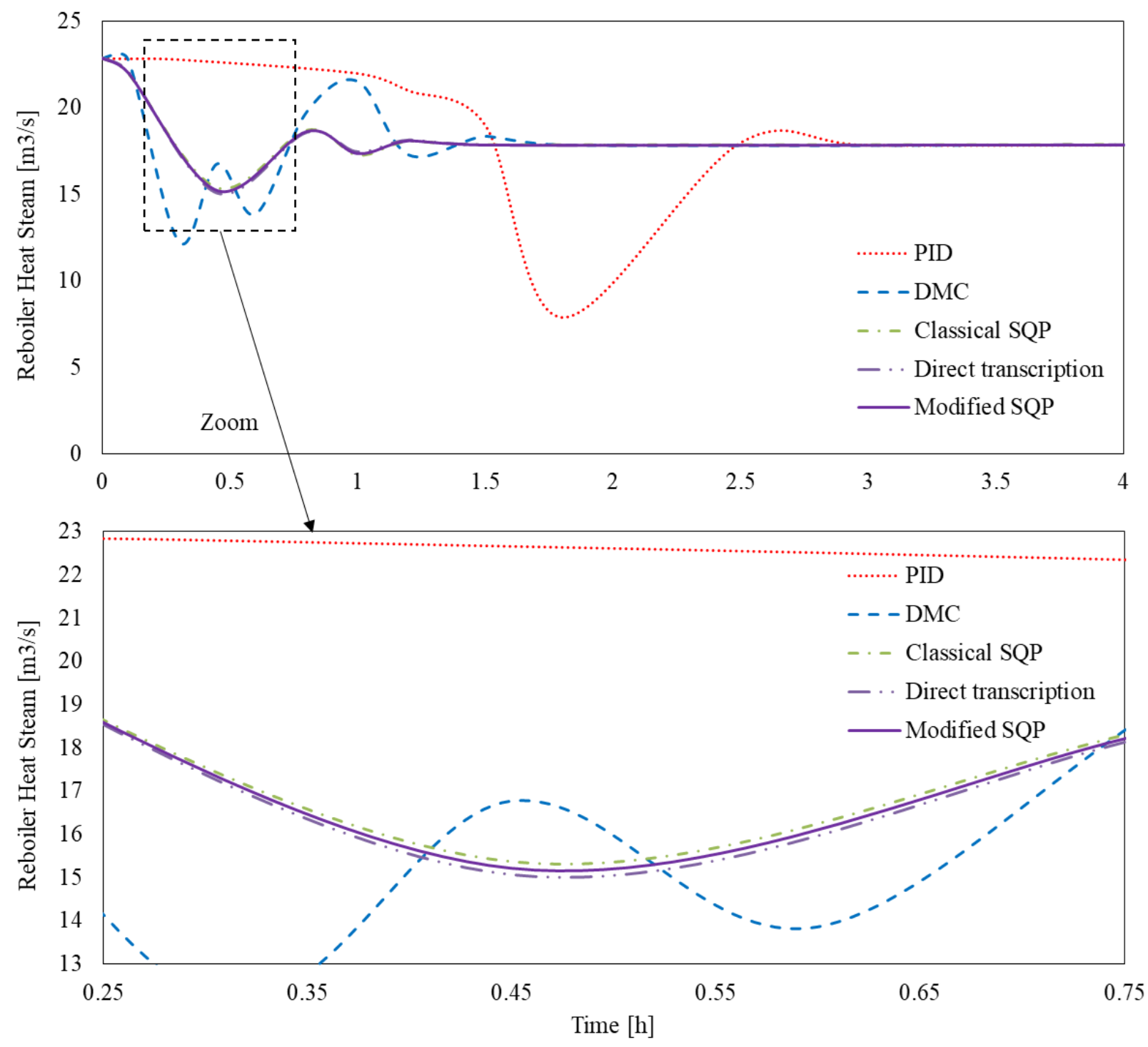

Figure 6.11. Carbon capture system Case 1: closed-loop results for reboiler heat steam flow rate (input)

Table 6.2. ISE analysis results for the conventional configuration

\begin{tabular}{|l|l|l|c|c|c|}
\hline & PID & DMC & Classical SQP & Direct transcription & Modified SQP \\
\hline ISE results & 0.169 & 0.024 & 0.010 & 0.009 & 0.009 \\
\hline
\end{tabular}

The second scenario (Case 2) considers the $\mathrm{LVC} \mathrm{CO}_{2}$ capture configuration, as shown in Chapter 5 (see Figure 5.4). Several simulations are conducted initially with varying LVC flash pressures for sensitivity analysis of the process. Similarly to Case 1, the 
power plant is simulated in a load-following scenario with a $25 \%$ ramp decrease in the flue gas flow rate during the first $0.25 \mathrm{~h}$. The carbon capture rate closed-loop responses for the modified LVC $\mathrm{CO}_{2}$ capture configuration associated with MPC and PID implementations are shown in Figure 6.12. When compared to the conventional configuration responses (shown in Figure 6.9), the closed-loop responses for the LVC case have, in general, larger oscillations and longer settling times. The settling times for the nonlinear MPCs are about $1.45 \mathrm{~h}$, which is shorter than DMC (1.8 h) and PID (3.7 h). The integral square error (ISE) analysis values are also larger than the ones for the conventional configuration, as shown in Table 6.3.

Compared to the conventional configuration, the LVC configuration is a more challenging control problem. In the LVC configuration, the lean solvent from the bottom of the stripper is flashed and the resulting vapor is compressed back to the stripper, which increases the associated stripper and reboiler model nonlinearities. Despite such higher nonlinearity, the LVC configuration is successfully controlled. Figures 6.13 and 6.14 show the relevant closed-loop control moves for the lean solvent flow rate and the reboiler heat flow rate inputs. In general, the inputs show additional oscillations when compared to the conventional configuration. The PID controller inputs still have large overshoot actions for the lean solvent flow rate and sluggish actions for the reboiler heat steam. The nonlinear MPC controllers have once again better performances when compared to the PID and also DMC. 

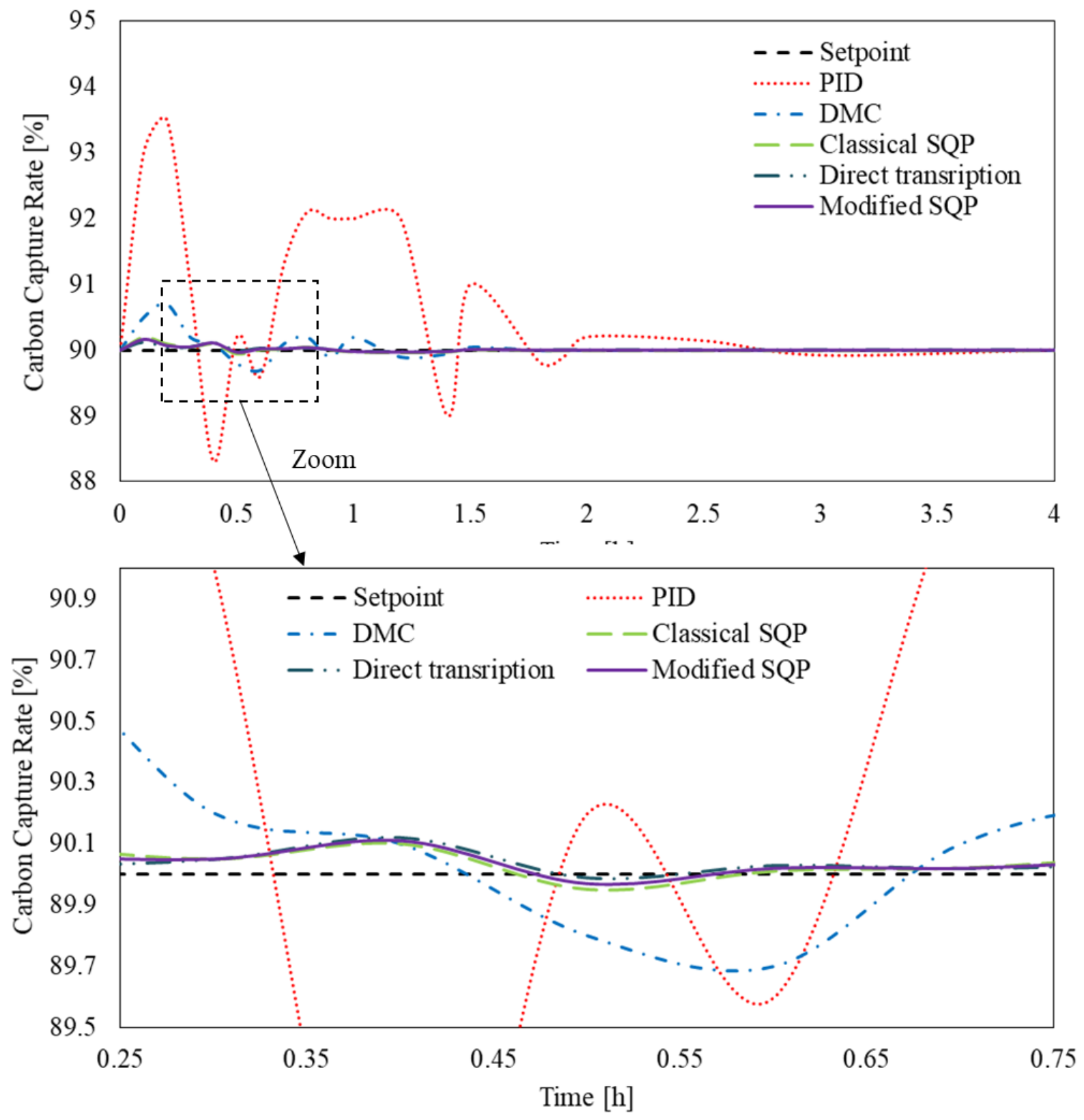

Figure 6.12. Carbon capture system Case 2: closed-loop responses for carbon capture rate (output)

Table 6.3. ISE analysis results for LVC configuration

\begin{tabular}{|l|l|l|c|c|c|}
\hline & PID & DMC & Classical SQP & Direct transcription & Modified SQP \\
\hline ISE results & 0.415 & 0.074 & 0.020 & 0.019 & 0.019 \\
\hline
\end{tabular}




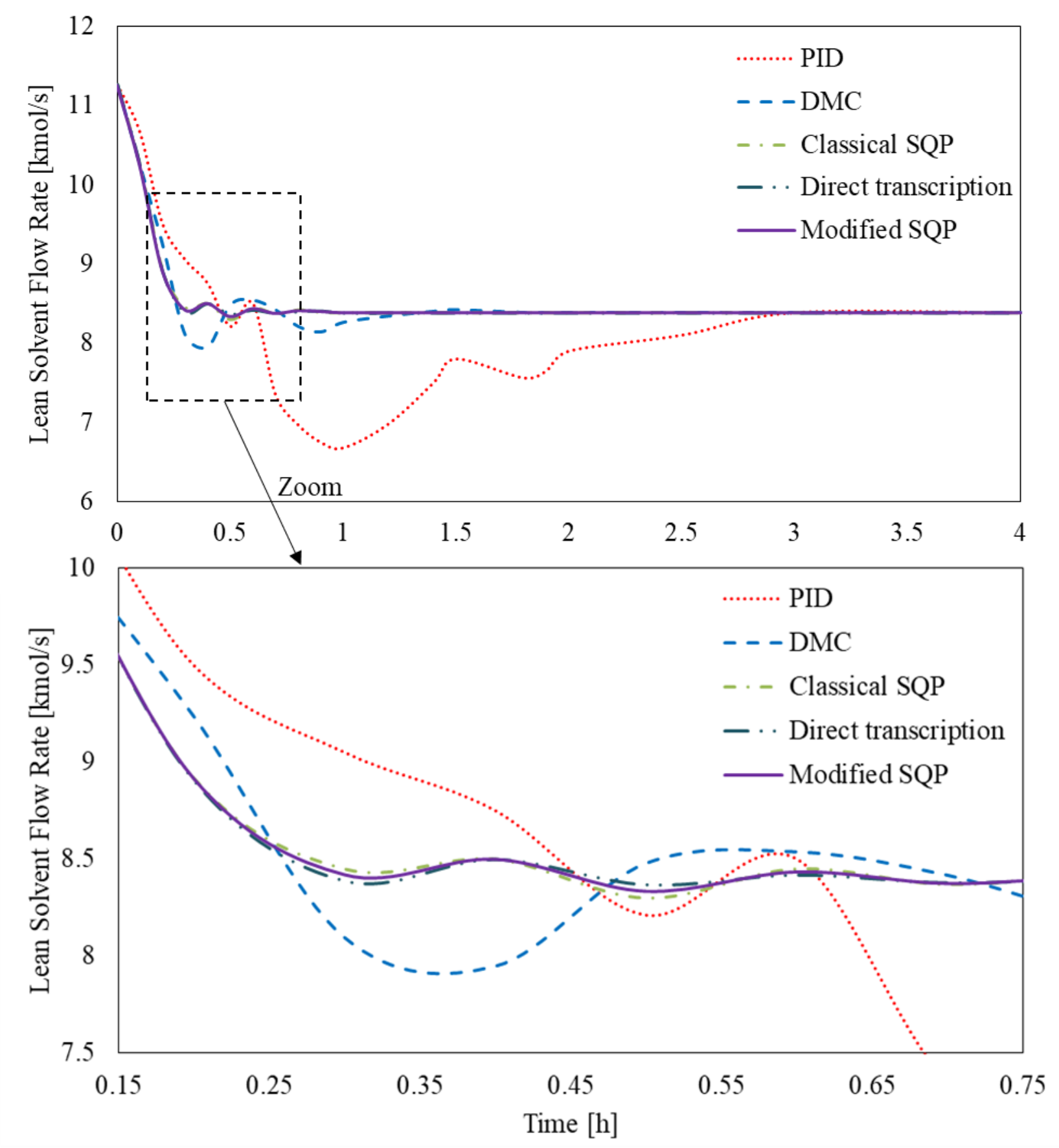

Figure 6.13. Carbon capture system Case 2: closed-loop results for lean solvent flow rate (input) 


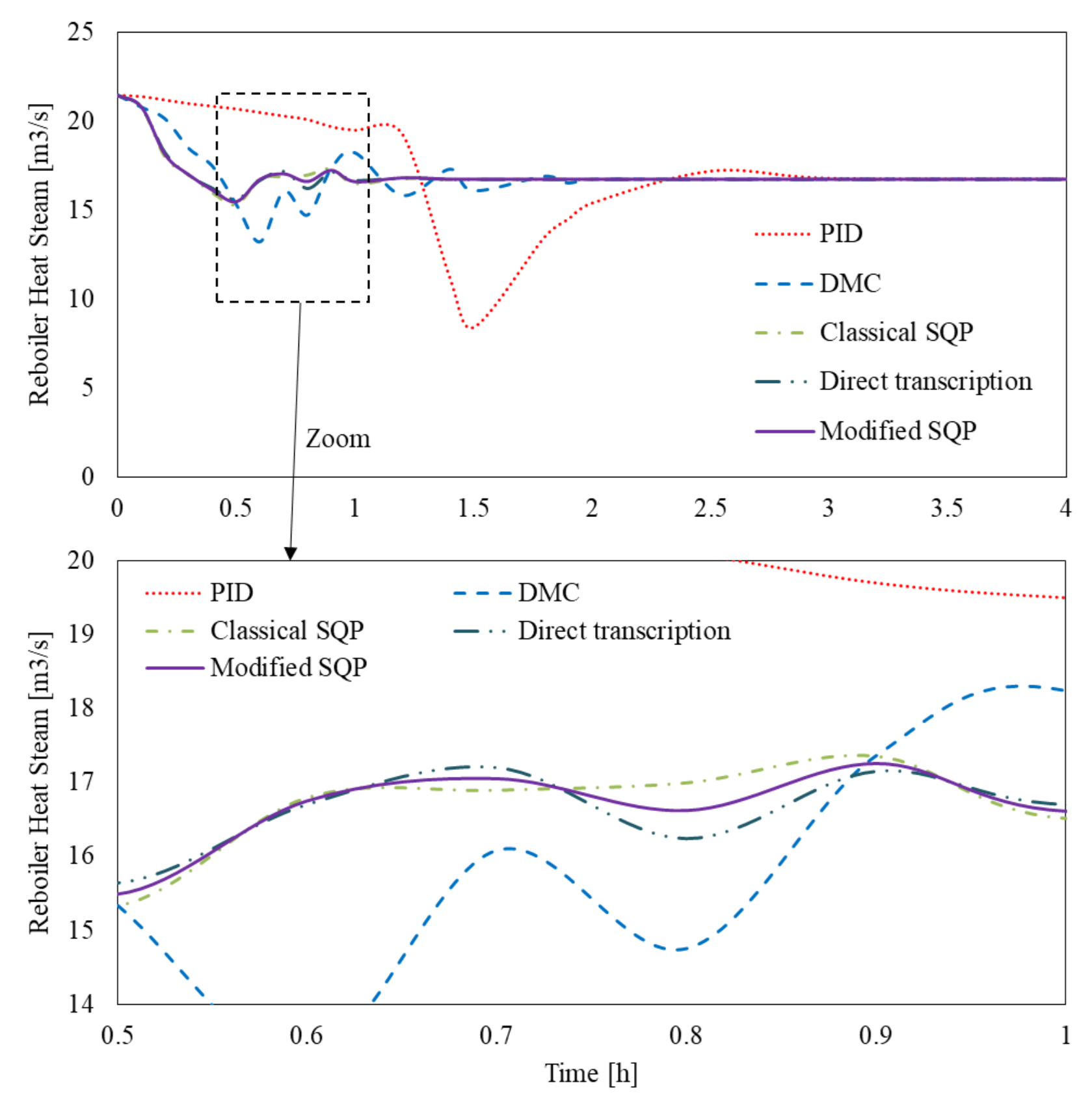

Figure 6.14. Carbon capture system Case 2: closed-loop results for reboiler heat steam flow rate (input)

Since the LVC configuration can potentially reduce the reboiler heat duty, the economic performances of the two configurations are calculated by employing the total equivalent work as mentioned in Chapter 5 (see Equation (5.1)). At new steady states, the total equivalent work for the LVC configuration is $8.23 \mathrm{MWe}$, which is smaller than the 
conventional configuration (8.51 MWe). Additionally, the total equivalent power consumption is calculated by integrating the dynamic equivalent work from time 0 to $4 \mathrm{~h}$ for both cases. As shown in Table 6.4, the $\mathrm{LVC} \mathrm{CO}_{2}$ capture configuration has less equivalent power consumption when compared to the conventional configuration. In particular, the LVC configuration with modified SQP-based MPC implemented has a $5.9 \%$ reduction in terms of total equivalent power consumption when compared to the conventional configuration with PID controllers. These results indicate that the successful implementation of the advanced control strategies for the LVC configuration has potential for performance improvement, ultimately bringing economic benefits.

Table 6.4. Total equivalent power consumption results of two configurations

\begin{tabular}{|c|c|c|c|c|c|}
\hline ConfigurationsiControllers & PID & DMC & $\begin{array}{c}\text { Classical } \\
\text { SQP }\end{array}$ & $\begin{array}{c}\text { Direct } \\
\text { transcription }\end{array}$ & $\begin{array}{c}\text { Modified } \\
\text { SQP }\end{array}$ \\
\hline Conventional (MWh) & 34.12 & 33.45 & 33.04 & 32.98 & 33.01 \\
\hline LVC (MWh) & 33.87 & 33.39 & 32.68 & 32.26 & 32.14 \\
\hline
\end{tabular}

In the third scenario for the MEA-based carbon capture system (Case 3), the conventional configuration is considered in a cycling scenario. Similarly to the third scenario of the IGCC-MR system, the SCPC plant power generation trajectory is calculated by deducting the wind power generation from the grid demand obtained from PJM market. The original total grid demand in this case is divided by 8 to match the SCPC power generation under the designed operating condition (550MW). The objective in this case is to maintain the carbon capture rate at $90 \%$ during the cycling operation. The flue gas flowrate during cycling is considered as a disturbance to the MEA carbon capture subsystem, which is assumed to be proportional to the power generation. The profile for the SCPC power plant cycling trajectory is shown in Figure 6.15. 


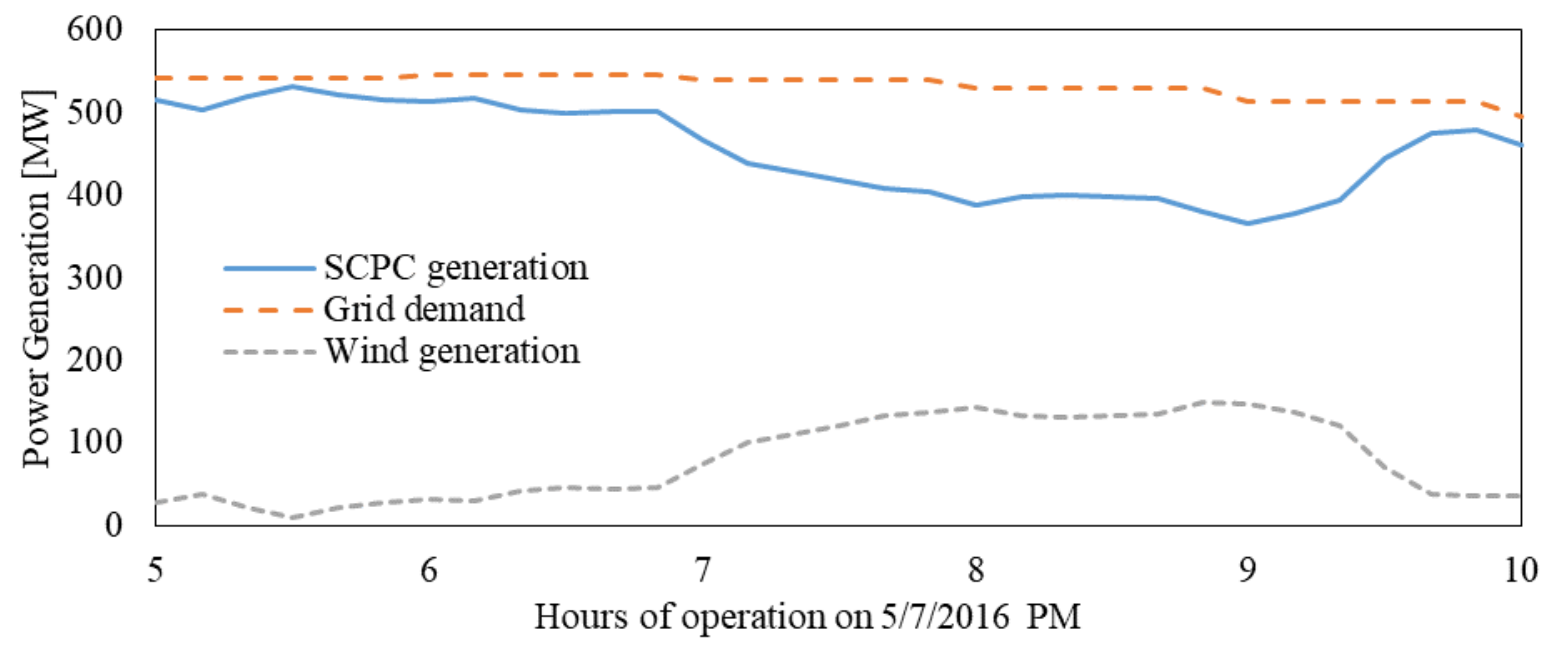

Figure 6.15. Carbon capture system Case 3: SCPC-MEA power generation cycling trajectory

The carbon capture rate closed-loop responses associated with the PID and the four MPC algorithms are shown in Figure 6.16. All linear (DMC) and nonlinear MPC controllers can successfully reject the flue gas flow rate disturbance while keeping the desired carbon capture rate at $90 \%$. Also, the nonlinear MPC controllers show a $73 \%$ improvement in terms of the maximum output deviation when compared to DMC. Comparing to the PID controller, the advantage of the MPC controllers in terms of reducing the oscillations and overshooting in carbon capture rate control is significant, as reflected in the Table 6.5 ISE analysis results for different controllers. 

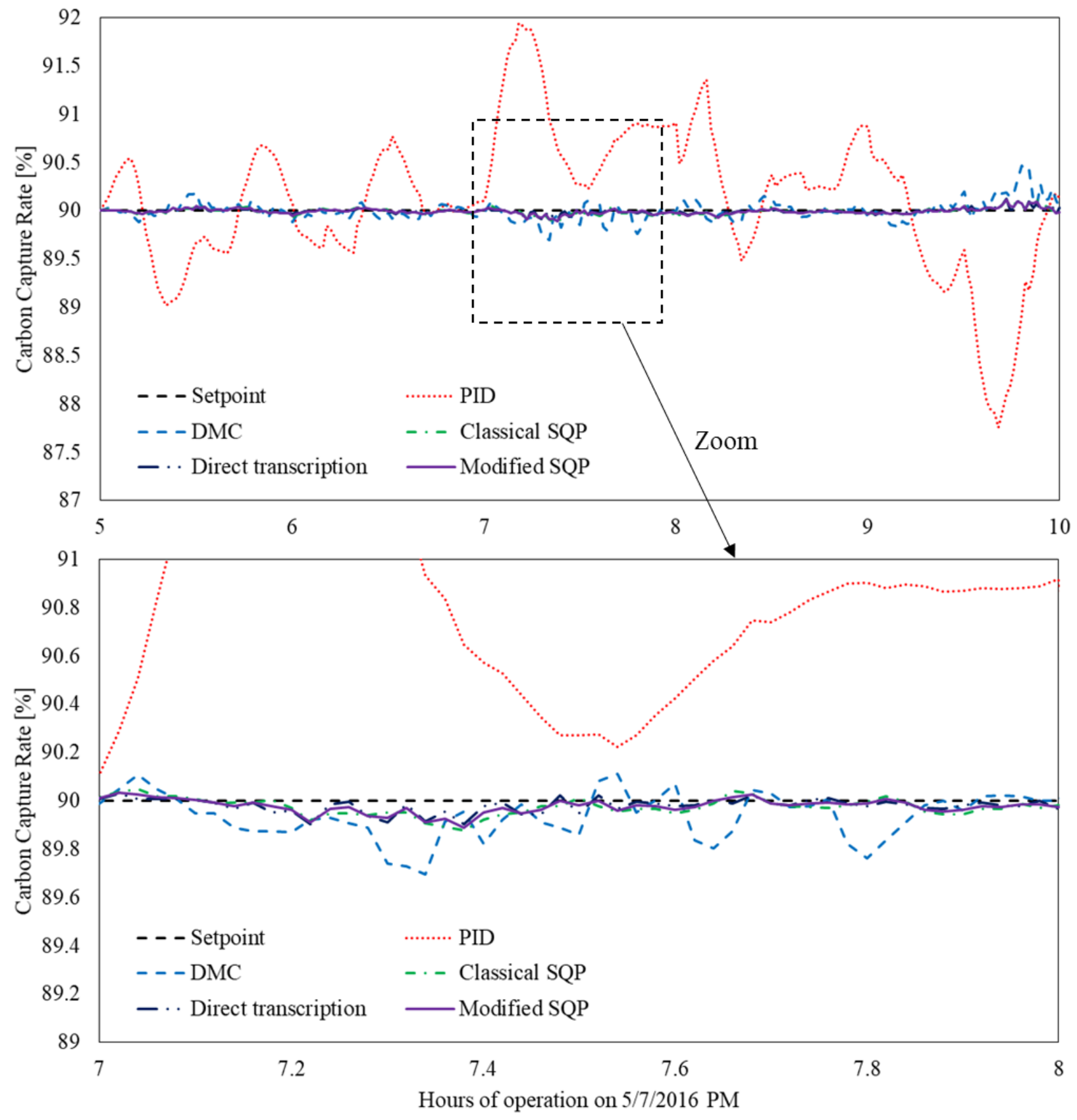

Figure 6.16. Carbon capture system Case 3: closed-loop responses for carbon capture rate $(\mathrm{CV})$

The fourth scenario for the SCPC-MEA carbon capture system (Case 4) considers a combination of disturbance rejection and trajectory tracking. The objective in this case is to maintain the carbon capture rate at $90 \%$ during the first 2 hours (from 5 to $7 \mathrm{pm}$ ) and then change the capture rate to $80 \%$ during the rest of the cycling operation (from 7 to 
$10 \mathrm{pm}$ ). Similarly to Case 3 , the flue gas flowrate during cycling is assumed as a disturbance variable, which is proportional to the power generation. Also, the profile of the SCPC power plant cycling trajectory considered is the same as shown in Figure 6.15 .

The closed-loop results for the PID and MPC approaches for Case 4 are shown in Figure 6.17. The implementations of all developed MPC approaches are successful. The MPC controllers can effectively reject the flue gas flow rate disturbance while following the desired carbon capture rate trajectory from $90 \%$ to $80 \%$. Note that the DMC algorithm presents performance with higher overshooting during the last 3 hours (between 7 to $10 \mathrm{pm}$ ), when compared to the first 2 hours (from 5 to $7 \mathrm{pm}$ ). The DMC performance differences between these two operating setpoints are due to the increased mismatch between the linearized system prediction model used by the controller and the nonlinear system model employed in the plant simulation. In particular, the prediction model becomes less accurate when the desired carbon capture rate is changed from the nominal point $(90 \%$, where the prediction model was identified) to $80 \%$. The ISE analysis results for the PID and all developed MPC controllers are summarized in Table 6.5. The nonlinear MPC approaches show up to $96 \%$ improvement when compared to the linear DMC, in terms of the ISE analysis results. 


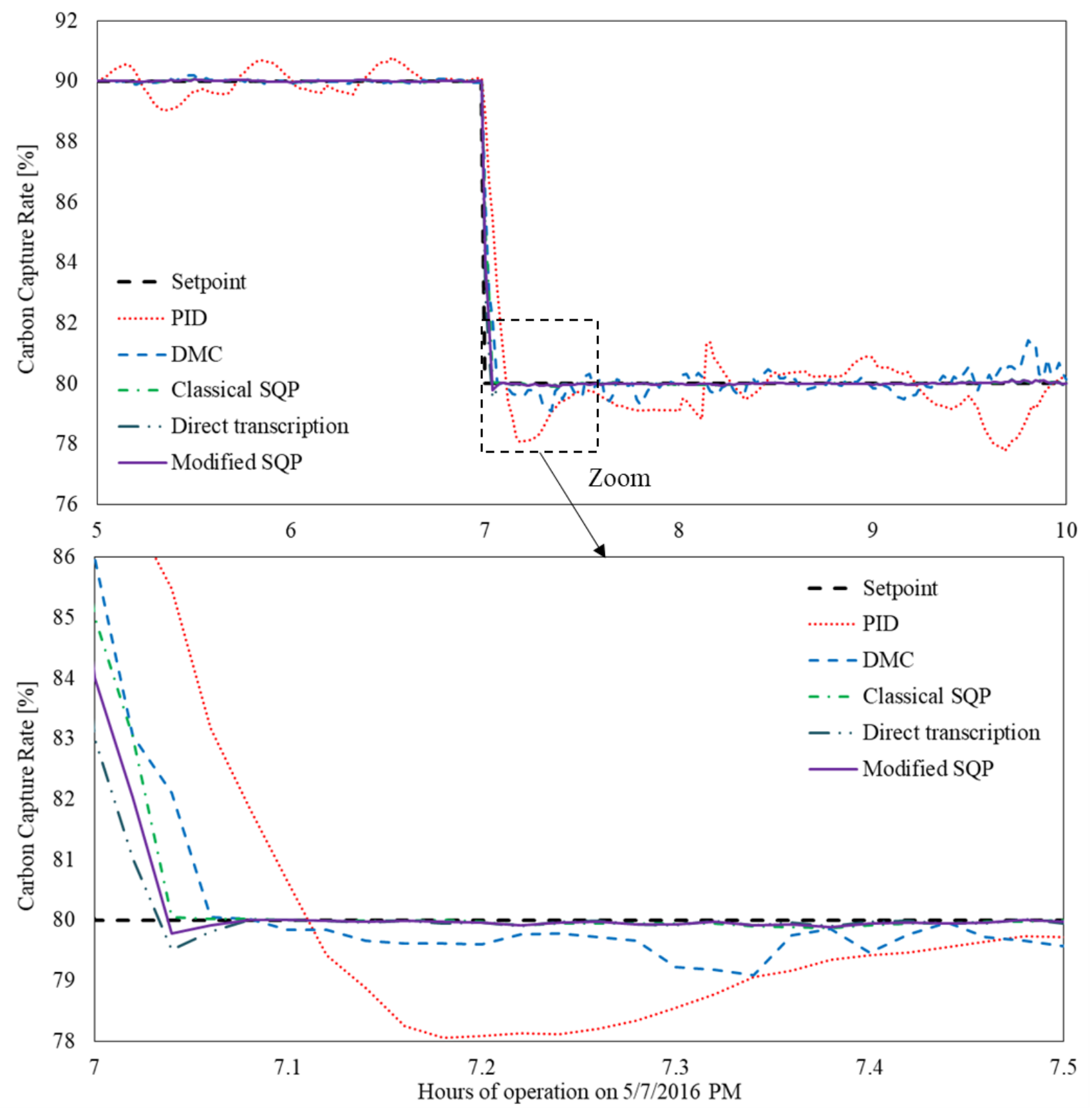

Figure 6.17. Carbon capture system Case 4: closed-loop responses for carbon capture rate $(\mathrm{CV})$

Table 6.5. ISE analysis results for the SCPC-MEA control implementations

\begin{tabular}{|l|c|c|c|c|c|}
\hline & PID & DMC & Classical SQP & Direct transcription & Modified SQP \\
\hline Case 3 & 50.54 & 0.923 & 0.109 & 0.071 & 0.079 \\
\hline Case 4 & 59.08 & 2.325 & 0.133 & 0.094 & 0.102 \\
\hline
\end{tabular}


The computational times (on average) for the MEA-based carbon capture system implementations are: $0.24 \mathrm{CPU}$ seconds for DMC, 1.04 CPU seconds for proposed modified SQP-based MPC, 1.26 CPU seconds for classical SQP-based MPC, and 1.31 CPU seconds for direct transcription-based MPC. The proposed modified SQP-based MPC improves the computational efficiency by $17.4 \%$ when compared to the classical SQP-MPC, and $20.6 \%$ when compared to the direct transcription-based MPC.

\subsection{MPC Application to Entire SCPC-MEA System}

For the MPC application to the entire SCPC-MEA system, the following 9 controlled variables (CVs) are selected:

- electricity power output $\left(W_{n e t}\right)$

- plant efficiency $\left(\eta_{\text {plant }}\right)$

- burner pressure $\left(p_{\text {boiler }}\right)$

- $\mathrm{O}_{2}$ composition in flue gas $\left(C_{O_{2}, \text { flue }}\right)$

- main steam pressure $\left(p_{\text {main }}\right)$

- reheated steam temperature $\left(T_{\text {reheat }}\right)$

- low-pressure turbine efficiency $\left(\eta_{L P}\right)$

- carbon capture rate $\left(\mathrm{C}_{\mathrm{CO}_{2}}\right)$

- lean solvent $\mathrm{CO}_{2}$ loading $\left(\phi_{\text {leanCO }}\right)$

Also, the following 9 input variables are taken as manipulated variables (MVs):

- boiler fuel (coal) feed $\left(F_{\text {coal }}\right)$

- forced draft (FD) fan power $\left(W_{F D}\right)$

- induced draft (ID) fan power $\left(W_{I D}\right)$

- main steam flow rate $\left(F_{\text {main }}\right)$

- high-pressure turbine governor stage position $\left(\alpha_{G O V}\right)$

- condensate pump power $\left(W_{\text {cond }}\right)$

- boiler feed water (FW) pump power $\left(W_{B F W}\right)$ 
- extracted steam flow rate $\left(F_{\text {ext }}\right)$

- lean solvent flow rate $\left(F_{\text {solvent }}\right)$

The steady state for the design operating condition, which is used as the original point for system identification, is denoted as the nominal point. The values of the CVs and MVs at their nominal points are shown in Table 6.6.

Table 6.6. Nominal values of CVs and MVs for SCPC-MEA system

\begin{tabular}{|c|c|c|c|}
\hline CVs & Nominal value & MVs & Nominal value \\
\hline$W_{\text {net }}$ & $550 \mathrm{MWe}$ & $F_{\text {coal }}$ & $4.296 \mathrm{kmol} / \mathrm{s}$ \\
\hline$\eta_{\text {plant }}$ & 0.890 & $W_{F D}$ & $1700 \mathrm{kWe}$ \\
\hline$p_{\text {boiler }}$ & $0.110 \mathrm{MPa}$ & $W_{I D}$ & $6600 \mathrm{kWe}$ \\
\hline$C_{O_{2}, \text { flue }}$ & 0.0325 & $F_{\text {main }}$ & $1663 \mathrm{tonne} / \mathrm{hr}$ \\
\hline$p_{\text {main }}$ & $24.23 \mathrm{MPa}$ & $\alpha_{G O V}$ & 0.5641 \\
\hline$T_{\text {reheat }}$ & $593^{\circ} \mathrm{C}$ & $W_{\text {cond }}$ & $800 \mathrm{kWe}$ \\
\hline$\eta_{L P}$ & 0.407 & $W_{B F W}$ & $4520 \mathrm{kWe}$ \\
\hline$C_{\mathrm{CO}_{2}}$ & 0.900 & $F_{\text {ext }}$ & 0 tonne/hr \\
\hline$\phi_{\text {leanCO }}$ & 0.286 & $F_{\text {solvent }}$ & $10.57 \mathrm{kmol} / \mathrm{s}$ \\
\hline
\end{tabular}

The controllers are set up with a 1 minute sample time. The control and prediction horizons are selected to be 10 and 25 sample times (10 and 25 minutes), respectively. The main objective of the MPC controllers is to track the power generation output according to cycling trajectories. Additionally, the following input and state constraints are considered (positivity constraints are also imposed on other MVs):

- reboiler temperature: $\quad T_{\text {reb }}(K) \leq 403$

- lean solvent flow rate: $2 \leq F_{\text {solvent }}(\mathrm{kmol} / \mathrm{s}) \leq 15$

- extracted steam flowrate: $\quad 10 \leq F_{\text {ext }}(\mathrm{kg} / \mathrm{s}) \leq 100$

Also, the selected MVs have lower limits of 0 (closed value). 
In the first SCPC-MEA scenario (Case 1), the system is simulated to address a wind power penetration case similar to the cycling scenarios in Subsection 6.2. The trajectory profile considered is the same as shown in Figure 6.15.

The power generation closed-loop responses associated with all different MPC controllers are shown in Figure 6.18. Note that all linear and nonlinear MPC controllers can successfully follow the power generation cycling profile. Also, the nonlinear MPC controllers have improved performance when compared to the linear DMC, especially when the system operates away from the nominal point (550 MW) around where the DMC linear model was obtained. The integral squared error (ISE) analysis results for this scenario are shown in Table 6.7. The nonlinear MPC controllers with different solvers have similar performances in terms of ISE results, which are superior to the DMC.

Table 6.7. SCPC-MEA Case 1: ISE analysis results for different MPC solvers

\begin{tabular}{|l|l|l|l|l|}
\hline & DMC & Classical SQP & $\begin{array}{l}\text { Direct } \\
\text { transcription }\end{array}$ & $\begin{array}{l}\text { Modified } \\
\text { SQP }\end{array}$ \\
\hline ISE results & 0.7524 & 0.09721 & 0.09235 & 0.09314 \\
\hline
\end{tabular}




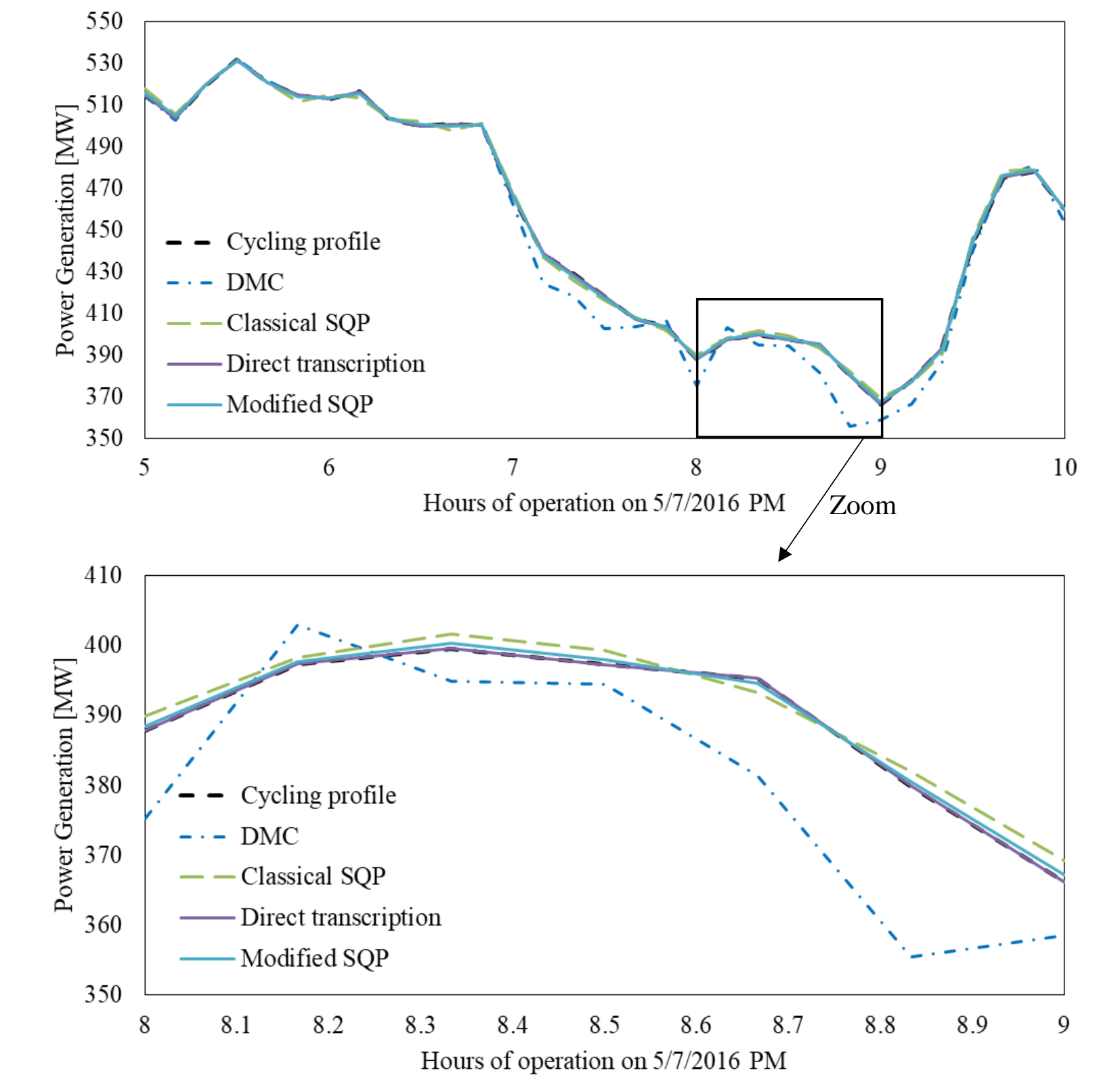

Figure 6.18. SCPC-MEA Case 1: closed-loop response for power generation (CV) The closed-loop simulation for Case 1 included 300 sample time steps. Within each sample time, the different solvers are tested for the MPC tracking optimization problems. Table 6.8 shows the computational performance results of the four developed MPC algorithms in terms of the average computational time. The linear DMC has the best computational efficiency as expected when compared to the nonlinear MPCs, which occurs due to the linear model approximation performed for the DMC formulation. Also, for the nonlinear MPCs, the proposed modified SQP algorithm shows a $24.6 \%$ 
improvement when compared to the classical SQP and a $22.5 \%$ improvement when compared to the direct transcription-based algorithm.

Table 6.8. SCPC-MEA Case 1: computational time results for different MPC solvers

\begin{tabular}{|l|l|l|l|l|}
\hline & DMC & Classical SQP & $\begin{array}{l}\text { Direct } \\
\text { transcription }\end{array}$ & $\begin{array}{l}\text { Modified } \\
\text { SQP }\end{array}$ \\
\hline $\begin{array}{l}\text { Average } \\
\text { computational time } \\
\text { (CPU seconds) }\end{array}$ & 3.94 & 25.40 & 24.72 & 19.15 \\
\hline
\end{tabular}

In the second SCPC-MEA scenario (Case 2), the plant is simulated to reflect solar power penetration. The PVWatts Calculator (NERL, 2019) is used to estimate the daily power generation output of a Duke Energy solar farm in Warsaw, North Carolina. The daily power generation of the solar farm is calculated based on direct and diffusion irradiation data from an Oak Ridge National Lab rotating shadowband radiometer (Maxey and Andreas, 2007) for solar power generation in minute intervals. The calculation estimates that the Duke solar farm in Warsaw has an $88 \mathrm{MWe}$ utility size and a $21.5 \%$ capacity factor. Figure 6.19 shows the simulated solar power generation profile in minute intervals. In this figure, the oscillations occur due to passing clouds, which decrease the direct solar irradiation. As shown in Figure 6.20, the SCPC plant power generation trajectory for this case is calculated by deducting the solar power generation from the grid demand. Similarly to the grid demand profile in Case 1, the total grid power demand considered is based on the Duke Ohio/Kentucky hourly meter load data between 7 am and 11 am on May 7th, 2016 (PJM markets \& operations, 2016). The total grid demand is also divided by 8 to match the $550 \mathrm{MW}$ nominal SCPCMEA power generation. 

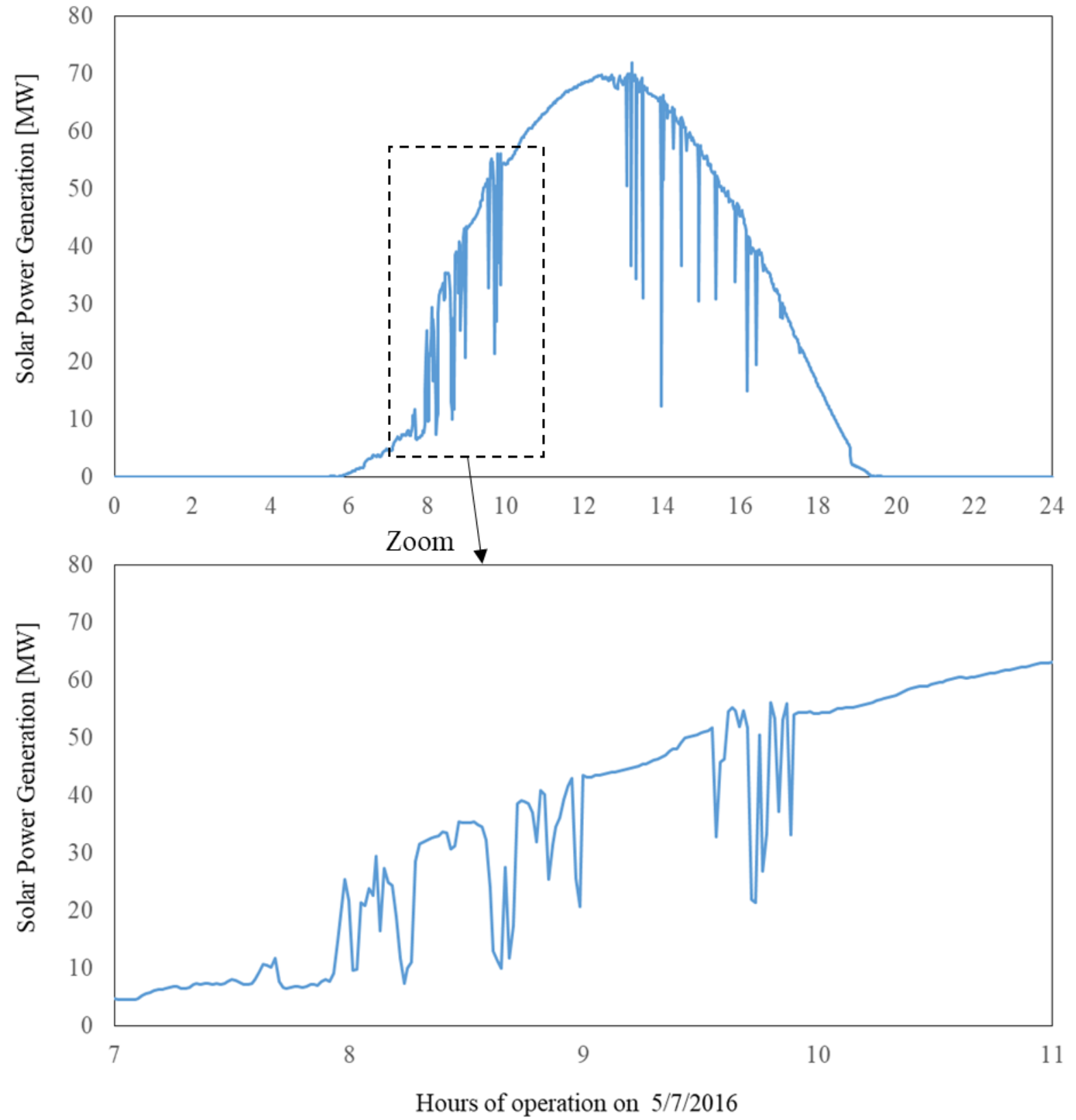

Figure 6.19. SCPC-MEA Case 2: simulated solar power generation profile 


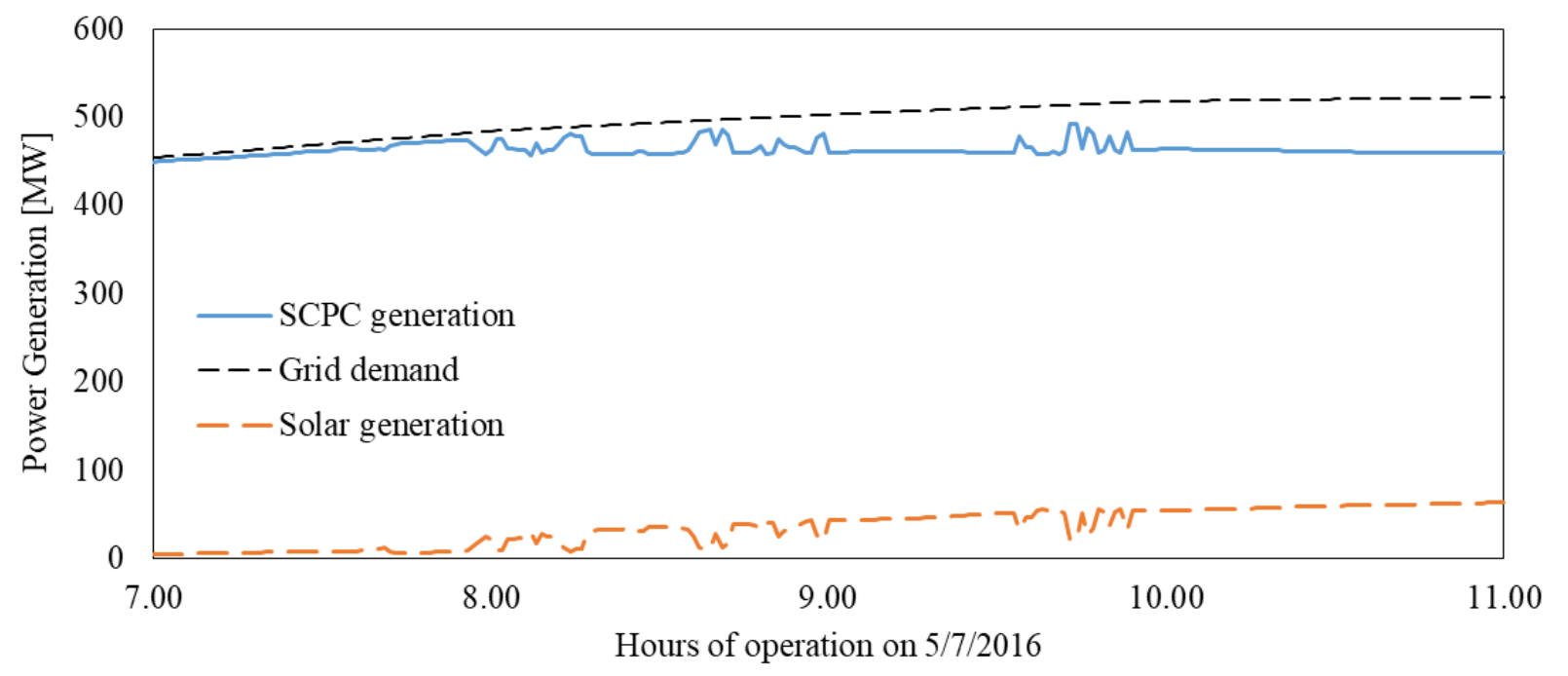

Figure 6.20. SCPC-MEA Case 2: SCPC-MEA power generation cycling trajectory The closed-loop responses of power generation associated with all different MPC controllers for Case 2 are depicted in Figure 6.21. Compared to the linear DMC, the advantage of the nonlinear MPC in terms of reducing the overshooting and oscillations is significant. As reflected in Table 6.9, the nonlinear MPC controllers show over $94 \%$ improvement in terms of ISE analysis results when compared to the linear DMC.

The closed-loop simulation for Case 2 included 240 sample time steps. Table 6.10 shows the computational performance results of the four developed MPC approaches in terms of the average computational time. The proposed modified SQP algorithm shows a $24.4 \%$ improvement when compared to the classical SQP and a $21.7 \%$ improvement when compared to the direct transcription-based algorithm. 


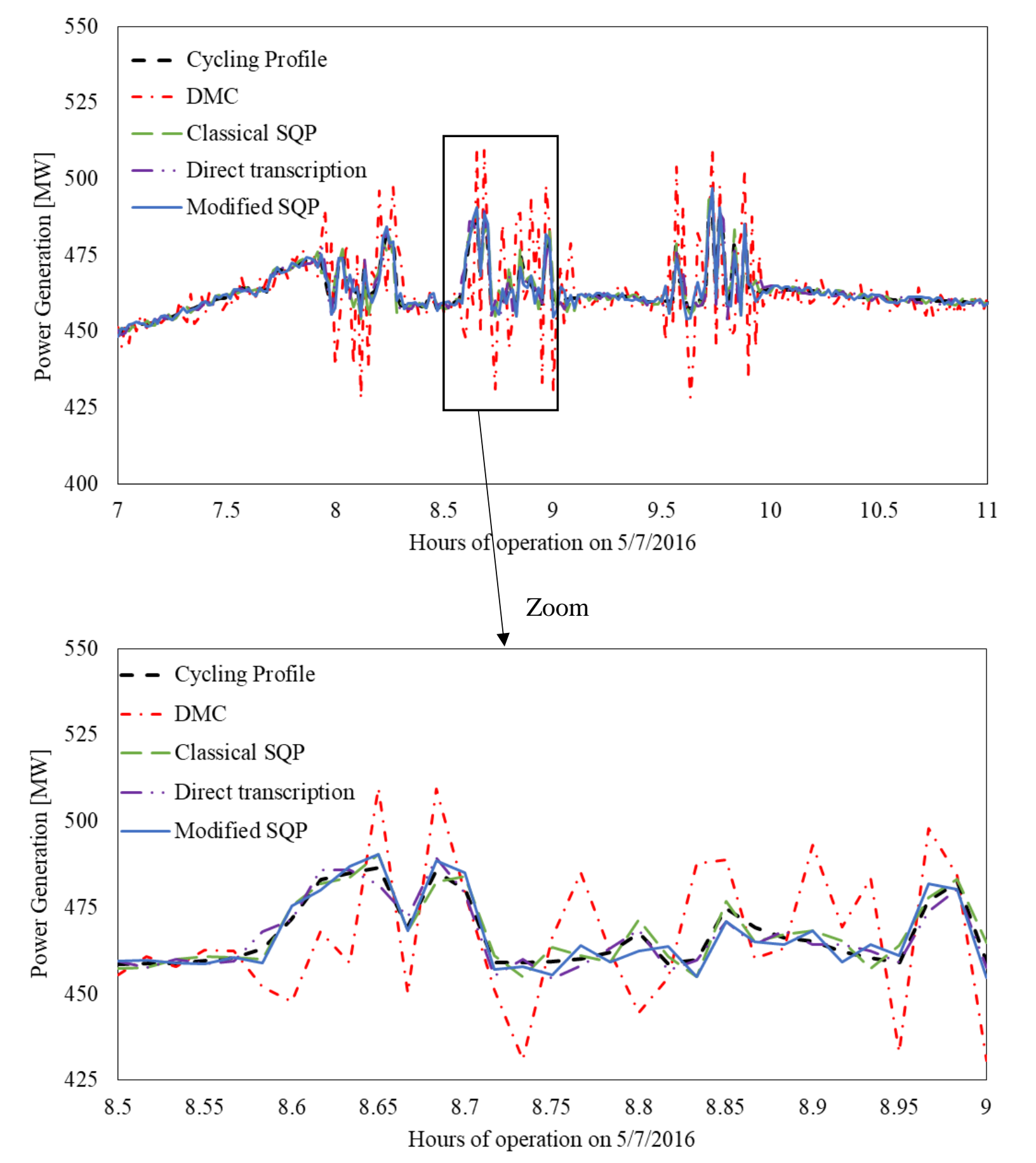

Figure 6.21. SCPC-MEA Case 2: Closed-loop responses for power generation (CV) 
Table 6.9. SCPC-MEA Case 2: ISE analysis results for different MPC solvers

\begin{tabular}{|l|l|l|l|l|}
\hline & DMC & Classical SQP & $\begin{array}{l}\text { Direct } \\
\text { transcription }\end{array}$ & $\begin{array}{l}\text { Modified } \\
\text { SQP }\end{array}$ \\
\hline ISE results & 8.8963 & 0.49634 & 0.50185 & 0.49842 \\
\hline
\end{tabular}

Table 6.10. SCPC-MEA Case 2: computational time results for different MPC solvers

\begin{tabular}{|l|l|l|l|l|}
\hline & DMC & Classical SQP & $\begin{array}{l}\text { Direct } \\
\text { transcription }\end{array}$ & $\begin{array}{l}\text { Modified } \\
\text { SQP }\end{array}$ \\
\hline $\begin{array}{l}\text { Average } \\
\text { computational time } \\
\text { (CPU seconds) }\end{array}$ & 4.24 & 31.48 & 30.37 & 23.79 \\
\hline
\end{tabular}

The third SCPC-MEA scenario (Case 3) considers both trajectory tracking and disturbance rejection (two CVs in objective function). For this scenario, the objective function of MPC has two equally weighted terms to track the desired power generation profile (as in Case 2) and maintain a 90\% carbon capture rate. The closed-loop responses for power generation and carbon capture tracking with all different MPC controllers are depicted in Figures 6.22 and 6.23, respectively. The nonlinear MPCs show good performances in both trajectory tracking and disturbance rejection. Compared to the linear DMC, the advantage of the nonlinear MPCs in terms of reducing the overshoots and oscillations is once again significant. As reflected in Table 6.11, all the nonlinear controllers show over $90 \%$ improvement when compared to the linear DMC in terms of ISE analysis results. 

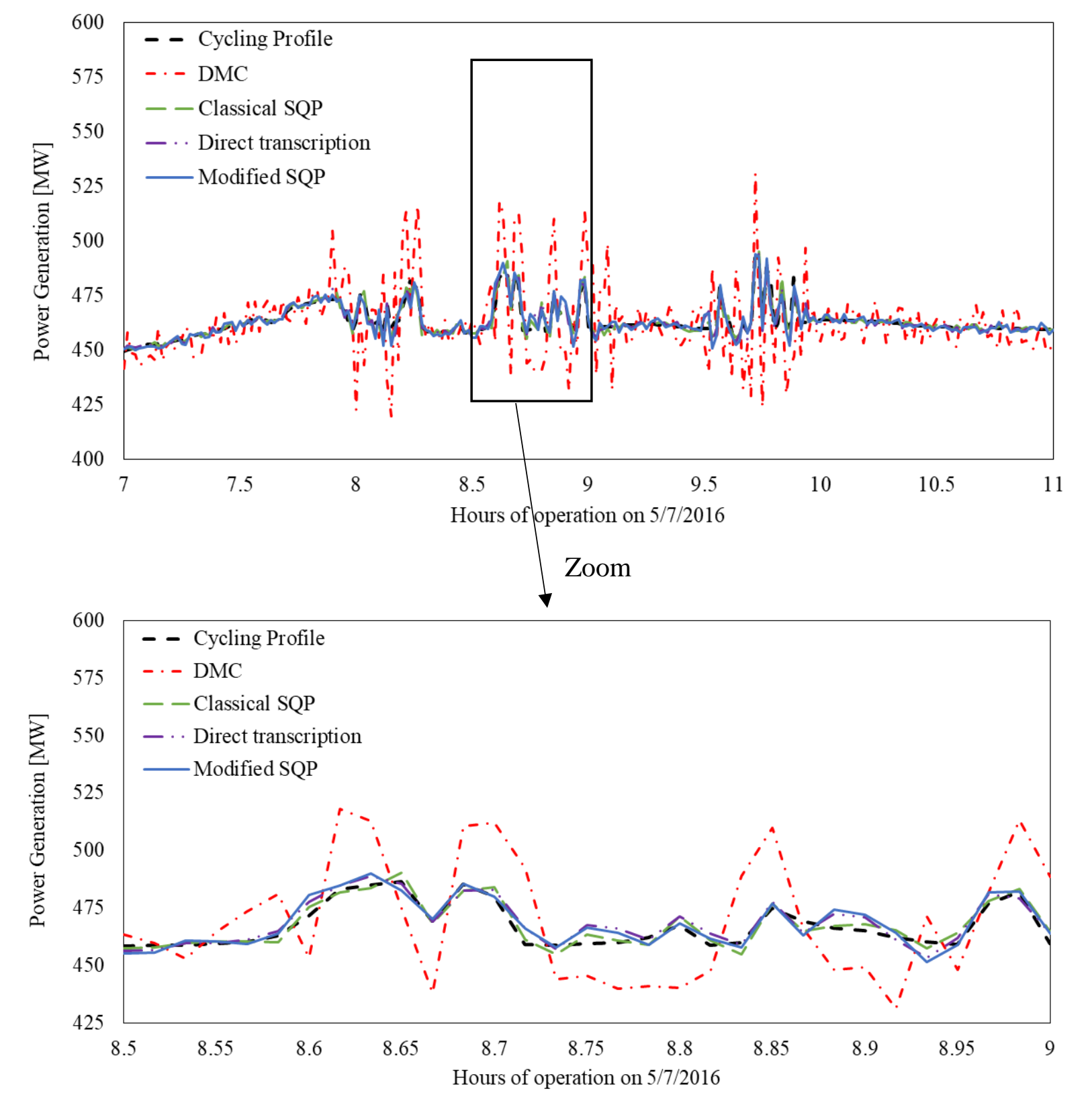

Figure 6.22. SCPC-MEA Case 3: Closed-loop responses for power generation 

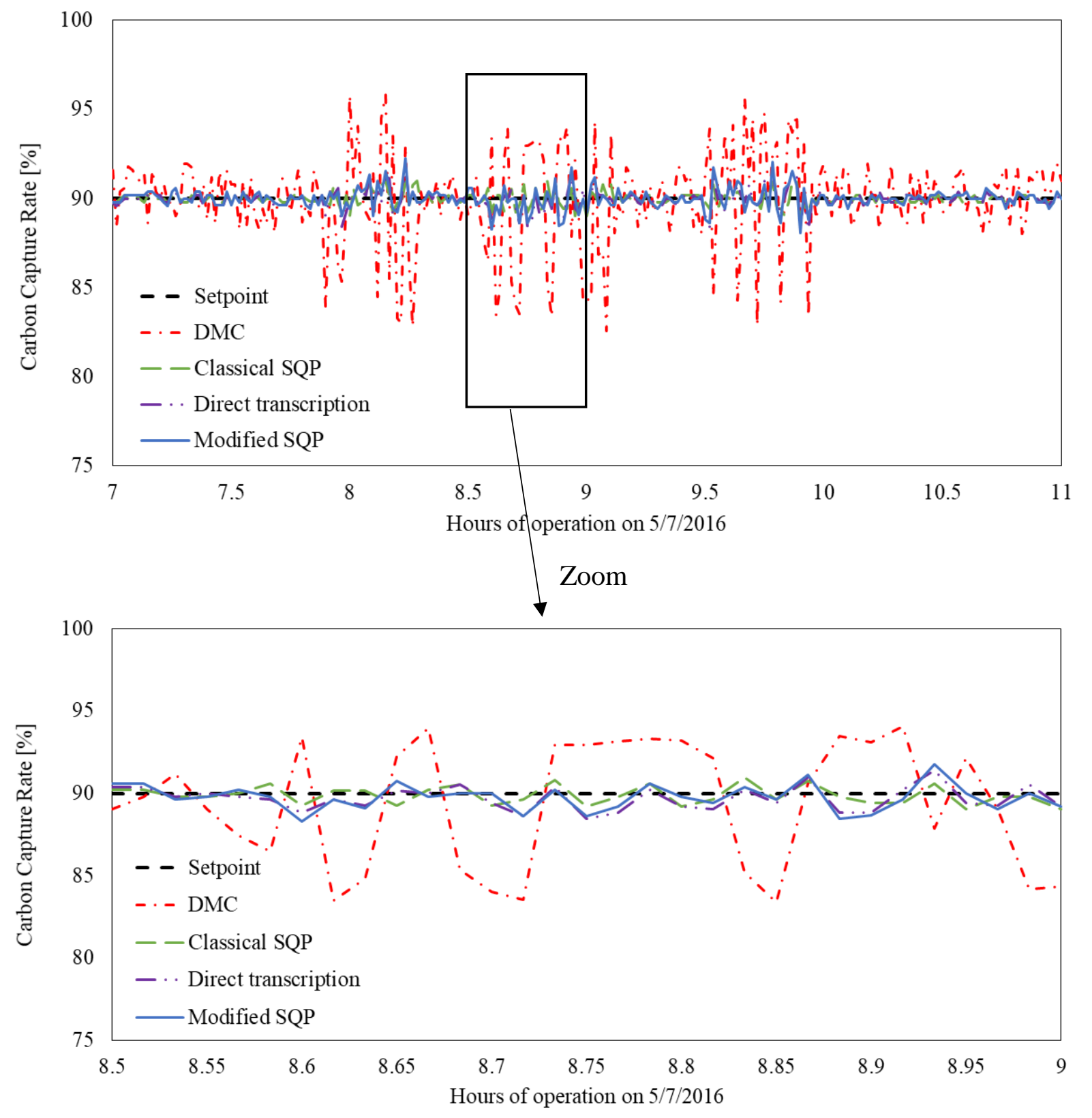

Figure 6.23. SCPC-MEA Case 3: Closed-loop responses for carbon capture rate Similarly to Case 2, the closed-loop simulation for Case 3 included 240 sample time steps. Table 6.12 shows the computational performance results of the four developed solvers for MPC in terms of the average computational time. The proposed modified SQP algorithm shows a $24.9 \%$ improvement when compared to the classical SQP and a $22.1 \%$ improvement when compared to the direct transcription-based algorithm. Note that the average computational times of the classical SQP-based and direct 
transcription-based nonlinear MPCs are larger than $30 \mathrm{CPU}$ seconds, which means only the proposed modified SQP-based nonlinear MPC would have the potential for a sample time reduction from $1 \mathrm{~min}$ to $0.5 \mathrm{~min}$. The computational times of the nonlinear MPCs for all the 240 sample time steps are shown in Figure 6.24.

Table 6.11. SCPC-MEA Case 3: ISE analysis results for MPCs employing different solvers

\begin{tabular}{|l|l|l|l|l|}
\hline & DMC & Classical SQP & $\begin{array}{l}\text { Direct } \\
\text { transcription }\end{array}$ & $\begin{array}{l}\text { Modified } \\
\text { SQP }\end{array}$ \\
\hline ISE values & 11.2461 & 0.6589 & 0.6418 & 0.6482 \\
\hline
\end{tabular}

Table 6.12. SCPC-MEA Case 3: Computational time results for MPCs employing different solvers

\begin{tabular}{|l|l|l|l|l|}
\hline & DMC & Classical SQP & $\begin{array}{l}\text { Direct } \\
\text { transcription }\end{array}$ & $\begin{array}{l}\text { Modified } \\
\text { SQP }\end{array}$ \\
\hline $\begin{array}{l}\text { Average } \\
\text { computational time } \\
\text { (CPU seconds) }\end{array}$ & 4.31 & 32.13 & 30.97 & 24.12 \\
\hline
\end{tabular}

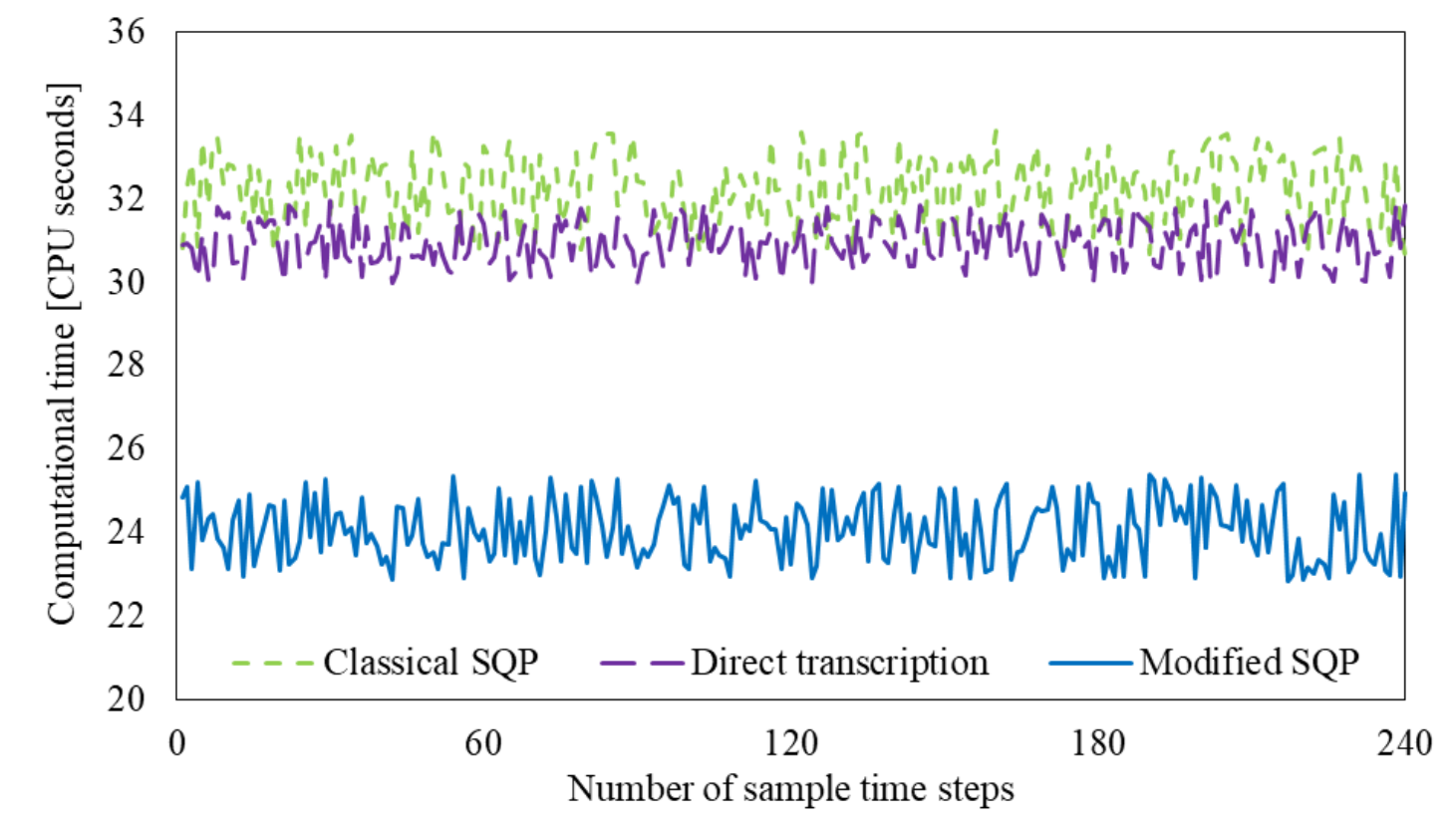

Figure 6.24. Computational times for nonlinear MPCs employing different solvers 


\section{Conclusions}

In this thesis, MPC strategies were designed and implemented for improved power plant cycling. To enhance the nonlinear MPC computational efficiency, a novel modified SQPbased algorithm was developed for faster solving the MPC NLP. The proposed modified SQP algorithm is based on the backtracking line search framework, which employs a group of relaxed step acceptance conditions for faster convergence. The numerical results for motivating examples, which were selected from literature problem sets, served as proof of concept to verify that the proposed modified SQP has the potential for better acceptance of long steps and faster convergence, when compared to a classical SQP method available in the literature.

The MPC strategies developed correspond to a DMC-based linear MPC, a classical SQP-based nonlinear MPC, a direct transcription-based nonlinear MPC and the proposed modified SQP-based nonlinear MPC. An MPC implementation framework with Aspen Plus Dynamics and MATLAB components was also built, in which MATLAB Simulink was used for interfacing the MPC codes programmed in MATLAB and the dynamic model in Aspen Plus Dynamics that represents the addressed plant.

To illustrate the tracking performance and computational efficiency of the developed MPC strategies, three processes of different dimensionalities were addressed. The first process was an IGCC-MR system, which corresponds to a first-principles and simplified systems-level nonlinear model in MATLAB. A setpoint tracking scenario simulating a step increase in power demand, a disturbance rejection scenario simulating a coal feed quality change, and a trajectory tracking scenario simulating a wind power penetration into the power grid were presented. The second process was an MEA-based carbon capture process as part of an SCPC power plant, whose model was built in Aspen Plus Dynamics. Two different carbon capture system configurations were considered: the conventional configuration and the LVC configuration. A disturbance rejection scenario assuming a ramp decrease in the flue gas flow rate, a disturbance rejection scenario simulating wind power penetration, and a scenario considering a combination of wind power penetration and carbon capture rate setpoint tracking were addressed. The third process was the entire SCPC-MEA plant, whose model was also built in Aspen Plus 
Dynamics. Power output trajectory tracking and carbon capture rate setpoint tracking scenarios associated with wind and solar power penetrations were studied.

The MPC implementations on the three processes for the different scenarios addressed were successful. The closed-loop results showed that the proposed modified SQPbased nonlinear MPC enhances the tracking performance by up to $96 \%$ when compared to the DMC-based linear MPC in terms of integral squared error results. The novel approach also improves the computational efficiency for solving the MPC NLP by $20 \%$ when compared to classical SQP-based and direct transcription-based nonlinear MPCs. 


\section{Future Recommendations}

\subsection{MPC Toolbox}

The linear and nonlinear MPC approaches developed in this thesis could be extended to a software package. The package could be incorporated as a toolbox in MATLAB. This toolbox would be helpful for linear and nonlinear MPC applications associated with power plant cycling or other complex chemical processes. This toolbox development has been initiated and it will be completed in the near future.

\subsection{Incorporation of Optimal Profile from DRTO}

The power plant cycling scenarios analyzed in this thesis were based on power plant generation output profiles for tracking and maintaining a $90 \%$ carbon capture rate. However, such profiles available in the literature may not be the optimal for economic performances. Employing optimized profiles based on Dynamic Real-time Optimization (DRTO) results with an economic objective will be helpful to improve the power plant economic performance during cycling operations.

\subsection{Economic-MPC Development}

In this thesis, the MPC role in the hierarchical planning and operations framework discussed in Chapter 2 was to track the optimal trajectory based on literature data or calculated results by an RTO layer. However, there is a large difference between the time scales of RTO (typically in hours) and the trajectory tracking MPC (typically in minutes). Besides, the optimal trajectory from RTO (typically calculated employing steady-state models) might be infeasible for the tracking MPC to follow. An economicMPC framework should be able to combine the RTO and MPC layers, although the computational efficiency challenge will need to be addressed.

\subsection{Multi-stage MPC development}

In this thesis, a single centralized MPC was used for plantwide control. If the dimensionality of the process system increases, for example for a very detailed firstprinciples model with partial differential equations, the optimization problem for the nonlinear MPC might need to be solved using a multi-stage MPC control structure. In 
such structure, the whole plant system could be divided into several islands and each island would be controlled by a local MPC. A supervisory level MPC would be implemented on top of the local MPCs for centralized plantwide control. Additionally, the supervisory level MPC could be an economic-MPC to include the RTO layer. 


\section{References}

Abela, M., Bonavita, N., Martini, R., editors., 2007. Advanced process control at an integrated gasification combined cycle plant. ERTC Asset Maximisation Conference.

Amrit, R., Rawlings, J.B. and Biegler, L.T., 2013. Optimizing process economics online using model predictive control. Computers \& Chemical Engineering 58: 334-343.

Lima, F.V., Amrit, R., Tsapatsis, M., \& Daoutidis, P., 2013. Nonlinear model predictive control of IGCC plants with membrane reactors for carbon capture. In American Control Conference (ACC), IEEE, 3747-3752.

Aurora, C., Diehl, M., Kuehl, P., Magni, L. and Scattolini, R., 2005. Nonlinear model predictive control of combined cycle power plants. In Proceedings of 16th IFAC World Congress, Prague, Czech Republic.

Bartusiak, R., 2007. NLMPC: A platform for optimal control of feed or product flexible manufacturing, in R. Findeisen, F. Allgower and L. Biegler, eds, 'Assessment and Future Directions of Nonlinear Model Predictive Control', Springer, 1-16.

Bentek Energy LLC, 2010. How less became more.... Wind power, and unintended consequences in the Colorado energy market.

https://www.westernenergyalliance.org/wpcontent/uploads/BENTEKEnergy_IPAMS_Wind_Study.pdf (accessed 01.30.2019).

Bielschowsky, R.H. and. Gomes, F.A.M., 2008. Dynamic control of infeasibility inequality constrained optimization. SIAM J. Optim. 19:1299-1325.

Birgin, E.G., Castillo, R., and Mart'ınez, J.M., 2005. Numerical comparison of augmented Lagrangian algorithms for nonconvex problems, Comput. Optim. Appl., 31:31-55.

Boggs, P.T. and Tolle, J.W., 1995. Sequential quadratic programming, Acta Numer., 4:1-51. 
Conn, A.R., Gould, N.I.M. and Toint, Ph.L., 1991. A globally convergent augmented Lagrangian algorithm for optimization with general constraints and simple bounds, SIAM J. Numer. Anal., 28: 545-572.

Curtis, F.E., Schenk, O. and Wachter, A., 2010. An interior-point algorithm for largescale nonlinear optimization with inexact step computations, SIAM J. Sci. Comput., 32: 3447-3475.

Curtis, F.E., Jiang, H. and Robinson, D.P., 2015. An adaptive augmented Lagrangian method for large-scale constrained optimization, Math. Program, 151:201-245.

Cutler, C. and Perry, R, 1983. Real-time optimization with multivariable control is required to maximize profits, Comp. Chem. Eng. 7:663-667.

Decardi-Nelson, B., Liu, S., and Liu, J., 2018. A Comparison of Economic and Tracking Model Predictive Control in a Post Combustion CO 2 Capture Process. In 2018 Annual American Control Conference (ACC), IEEE, 3921-3926.

EPA, 2015. Carbon pollution emission guidelines for existing stationary sources: electric utility generating units. https://www.gpo.gov/fdsys/pkg/FR-2015-10-23/pdf/201522842.pdf (accessed 01.30.2019).

EIA, 2017. Annual Energy Outlook 2017: With Projections to 2050, https://www.eia.gov/outlooks/aeo/pdf/0383(2017).pdf (accessed 01.30.2019).

Ferrari-Trecate, G., Gallestey, E., Letizia, P., Spedicato, M., Morari, M., \& Antoine, M., 2004. Modeling and control of co-generation power plants: a hybrid system approach. IEEE Transactions on Control Systems Technology, 12(5):694-705.

Findeisen, R. and Allgower, F, 2004. Computational delay in nonlinear model predictive control, in 'Proc. Int. Symp. Adv. Control of Chemical Processes', HongKong.

Fletcher, R. and Leyffer, S., 2002. Nonlinear programming without a penalty function, Math. Program., 91:239-269.

Garcia, C. and Morshedi, A., 1986. Quadratic programming solution of dynamic matrix control (QDMC), Chemical Engineering Communication 46: 73-87. 
Georgis, D., Lima, F.V., Almansoori, A., Daoutidis, P., 2014. Thermal management of a water-gas-shift membrane reactor for high-purity hydrogen production and carbon capture. Industrial \& Engineering Chemistry Research. 53(18):7461-7469.

Gould, N.I.M. and Robinson, D.P., 2012. A second derivative SQP method with a "trustregionfree" predictor step, IMA J. Numer. Anal., 32:580-601.

Gould, N.I.M., Loh, Y., and Robinson, D.P., 2015. A nonmonotone filter SQP method: local convergence and numerical results, SIAM J. Optim., 25: 1885-1911.

Han. S.P., 1977. A globally convergent method for nonlinear programming. J. Optim. Theory Appl. 22: 297-309.

Huang, R., Biegler, L. T., \& Patwardhan, S. C., 2010. Fast offset-free nonlinear model predictive control based on moving horizon estimation. Industrial \& Engineering Chemistry Research, 49(17), 7882-7890.

Lima, F.V., Daoutidis, P., Tsapatsis, M., Marano, J.J., 2012. Modeling and optimization of membrane reactors for carbon capture in integrated gasification combined cycle units. Industrial \& Engineering Chemistry Research. 51(15):5480-9.

Lima, F.V., Daoutidis, P., and Tsapatsis, M., 2016. Modeling, optimization, and cost analysis of an IGCC plant with a membrane reactor for carbon capture. AIChE Journal, 62(5):1568-1580.

Lima, F.V., He, X., Amrit, R. and Daoutidis, P., 2017. Advanced control strategies for IGCC plants with membrane reactors for $\mathrm{CO} 2$ capture. In Process systems and materials for $\mathrm{CO} 2$ capture: modelling, design, control and integration, A.I. Papadopoulos and P. Seferlis (eds.), Wiley.

Liu, X.W. and Yuan, Y.X.. 2011 A sequential quadratic programming method without a penalty or a filter for nonlinear equality constrained optimization. SIAM J. Optim. 21: $545-571$

He, X., Wang, Y., Bhattacharyya, D., Lima, F.V. and Turton, R., 2018. Dynamic modeling and advanced control of post-combustion $\mathrm{CO} 2$ capture plants. Chemical Engineering Research and Design, 131:430-439. 
Hock, W. and Schittkowski, K. 1981. Test Examples for Nonlinear Programming Codes, Lecture Notes in Economics and Mathematics System, vol.187, Springer-Verlag, Berlin.

Jillson, K.R., Chapalamadugu, V., Ydstie, B.E., 2009. Inventory and flow control of the IGCC process with CO2 recycles. Journal of Process Control. 19(9):1470-85.

Karimi, M., Hillestad, M. and Svendsen, H. F., 2012. Investigation of the dynamic behavior of different stripper configurations for post-combustion $\mathrm{CO} 2$ capture. International journal of greenhouse gas control 7: 230-239.

Maratos, N. 1978. Exact penalty function algorithms for finite dimensional and control optimization problems. Ph.D. thesis from University of London

Marlin, T., 1995. Process Control, McGraw-Hill, New York.

Martinsen, F., Biegler, L.T. and Foss, B.A., 2002. Application of optimization algorithms to nonlinear MPC. IFAC Proceedings 35(1): 369-374.

Mohamed, O., Wang, J. and AI-Duri, B. 2011. Study of a multivariable coordinate control for a supercritical power plant process. In The 17th International Conference on Automation and Computing, IEEE, 69-74.

Mohamed, O., Wang, J. and Al-Duri, B, Lu, J. Gao, Q., Xue, Y. and Liu, X., 2012. Predictive control of coal mills for improving supercritical power generation process dynamic responses. In 2012 IEEE 51st IEEE Conference on Decision and Control (CDC), IEEE, 1709-1714.

Morari, M. and Lee, J., 1999. Model predictive control: past, present and future, Computer \& Chemical Engineering 23: 667-682.

Maxey, C. and Andreas, A., 2007. Oak Ridge National Laboratory (ORNL); Rotating Shadowband Radiometer (RSR); Oak Ridge, Tennessee (Data); NREL Report No. DA-5500-56512. http://dx.doi.org/10.5439/1052553

NREL, 2019. PVWatts Calculator, from https://pvwatts.nrel.gov/index.php 
Omell, B.P., and Chmielewski, D.J., 2013. IGCC power plant dispatch using infinitehorizon economic model predictive control. Industrial \& Engineering Chemistry Research. 52(9):3151-64.

PJM markets \& operations, 2016. Duke Ohio/Kentucky hourly metered load data. http://www.pjm.com/markets-and-operations/ops-analysis/historical-load-data (accessed 01.30.2019).

Qin, S. and Badgwell, T., 2003, A survey of industrial model predictive control technology, Control Engineering Practice 11:733-764.

Rossiter, J.A., Neal, P.W. and Yao, L., 2002. Applying predictive control to a fossil-fired power station. Transactions of the Institute of Measurement and Control 24(3): 177-194.

Santos, L., Afonso, P., Castro, J., Oliveira, N. and Biegler, L.T., 2001, ‘On-line implementation of nonlinear mpc: An experimental case study', Control Engineering Practice 9, 847-857.

Sotavento wind farm, 2016. Historical real time data. http://www.sotaventogalicia.com/en/real- time-data/historical (accessed 01.30.2019).

Ulbrich, M., Ulbrich, S. and Vicente, L. N., 2004. A globally convergent primal-dual interior-point filter method for nonlinear programming. Math. Program, 100: 379410.

Wachter, A., Biegler, L.T., Lang, Y.D. and Raghunathan, A., 2002. IPOPT: An Interior Point Algorithm for Large-Scale Nonlinear Optimization, http://www.coin-or.org.

Wachter, A. and Biegler, L.T., 2005. Line search filter methods for nonlinear programming: motivation and global convergence. SIAM J. Optim, 16:1-31.

Wachter, A. and Biegler, L.T, 2006. On the implementation of an interior-point filter linesearch algorithm for large-scale nonlinear programming, Math. Program., 106: $25-57$. 
Waltz, R., Morales, J., Nocedal, J. and Orban, D., 2006. An interior algorithm for nonlinear optimization that combines line search and trust region steps, Math. Program., 107: 391-408.

Wang, G., Yan, W. Chen, S. Zhang, X. and Shao, H., 2014. Multi-model predictive control of ultra-supercritical coal-fired power unit. Chinese Journal of Chemical Engineering 22(7): 782-787.

Zhang, Q., Turton, R. and Bhattacharyya, D., 2016. Development of model and model predictive control of an MEA-based postcombustion $\mathrm{CO} 2$ capture process. Industrial \& Engineering Chemistry Research 55(5): 1292-1308.

Zhang, Q., Richard T., and Debangsu B., 2018. Nonlinear model predictive control and $\mathrm{H} \infty$ robust control for a post-combustion $\mathrm{CO} 2$ capture process. International Journal of Greenhouse Gas Control 70: 105-116. 